\title{
DESIGN AND ANALYSIS OF A LIFT ASSIST WALKER
}

\author{
A Thesis \\ presented to \\ the Faculty of California Polytechnic State University, \\ San Luis Obispo
}

In Partial Fulfillment

of the Requirements for the Degree

Master of Science in Mechanical Engineering

by

Deep Pradipkumar Sobhagchand Shah

March 2016 
(C) 2016

Deep Pradipkumar Sobhagchand Shah

ALL RIGHTS RESERVED 


\section{COMMITTEE MEMBERSHIP}

TITLE:

AUTHOR:

DATE SUBMITTED:

COMMITTEE CHAIR:

COMMITTEE MEMBER:

COMMITTEE MEMBER:

COMMITTEE MEMBER:
Design And Analysis Of A Lift Assist Walker

Deep Pradipkumar Sobhagchand Shah

March 2016

Thomas J. Mackin, Ph.D.

Professor of Mechanical Engineering

John Ridgely, Ph.D.

Professor of Mechanical Engineering

Xi (Julia) Wu, Ph.D.

Associate Professor of Mechanical Engineering

Kourosh Bagheri,

Sponsor 


\section{ABSTRACT \\ Design and Analysis of a Lift Assist Walker \\ Deep Pradipkumar Sobhagchand Shah}

Walkers provided stability to the elderly but cannot assist a person from sitting to standing. The objective of this project is to present the design and analysis of a lift assist walker. This report discusses the design and analysis of a collapsible lift assist walker capable of lifting a patient up to $250 \mathrm{lbs}$. from seated to standing in under 10 seconds. The designed walker utilized a two stage scissor mechanism with a gas spring assisted embedded linear actuator.

Keywords: Walker, Lift-assist walker, powered walker, advance mobility aide, smart walker, modular walker. 


\section{ACKNOWLEDGMENTS}

First I would like to thank my parents and family for their unconditional love and support throughout.

I would like to thank Dr. Thomas Mackin for introducing me to this project, and for his guidance and support in the completion of this thesis. A thank you to my committee Dr. Ridgely and Dr. $\mathrm{Wu}$ for their advice in this project. I would also like to thank Dr. Mello, who let me use the composites lab to store and test the benchmark prototype.

I would like to thank Corinne Warnock and the Eichemuellers (Mike and Rosalie) for valuable insights for brainstorming ideas. I would like to thank Kelsey Engel for instigating harmless pranks to liven up the ME grad lab. Also I would like to thank the rest of the ME grad students (including Jim Stefani) that had valuable suggestions. 


\section{TABLE OF CONTENTS}

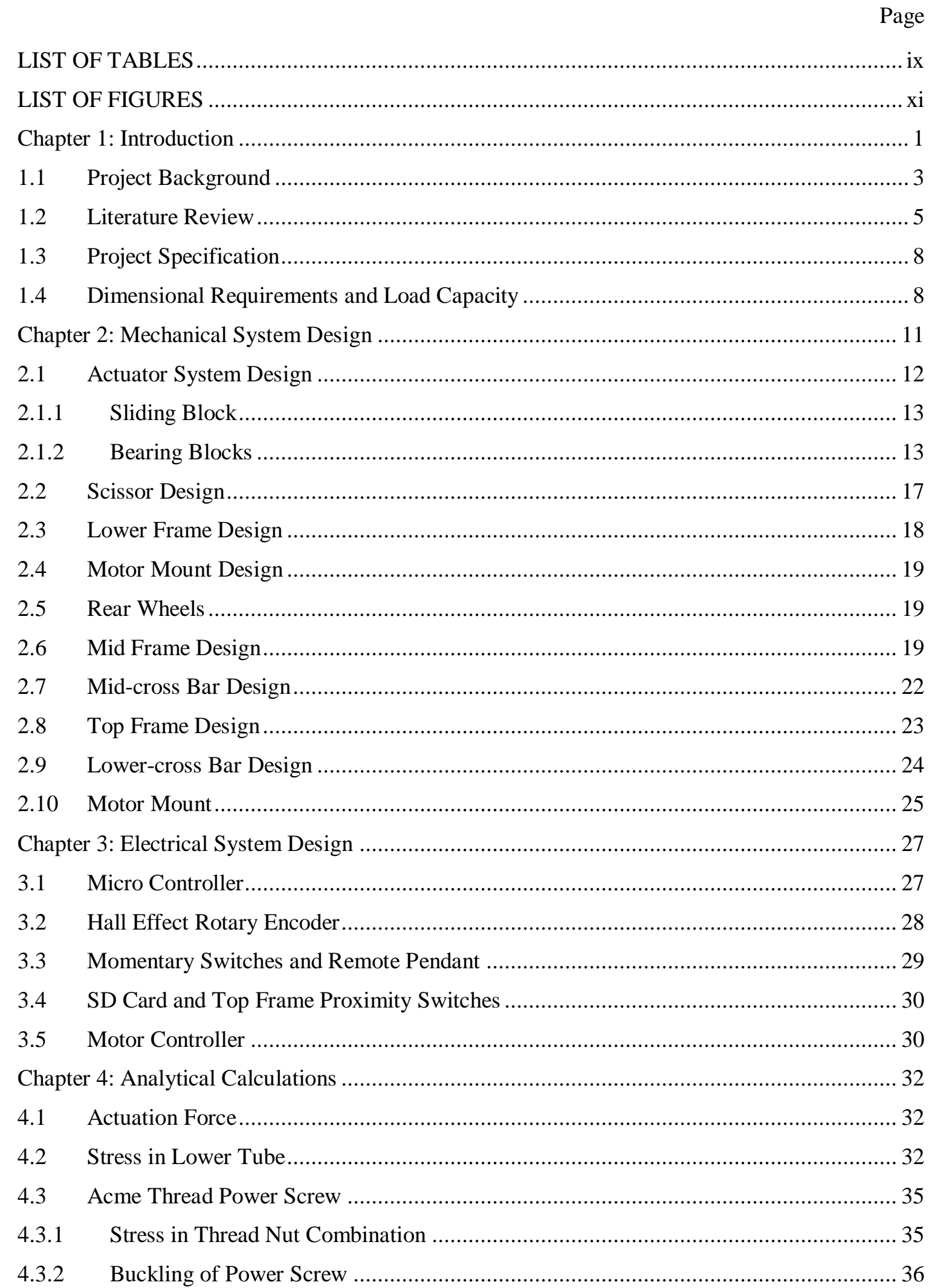


4.3.3 Self-Locking Feature of Acme Thread Screw .......................................................... 37

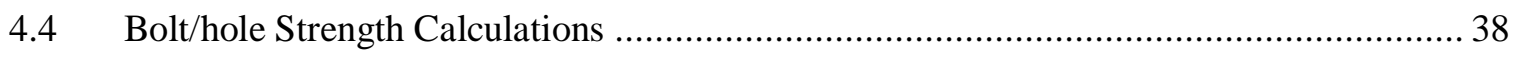

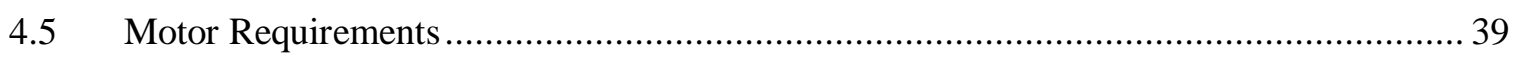

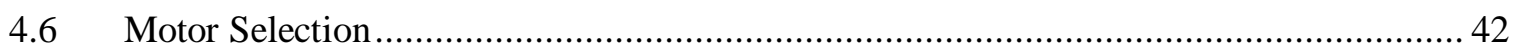

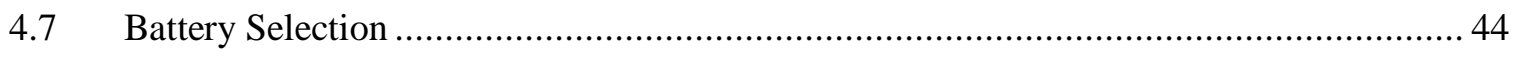

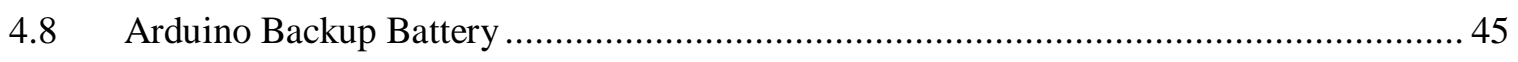

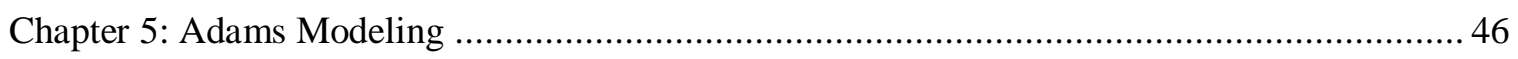

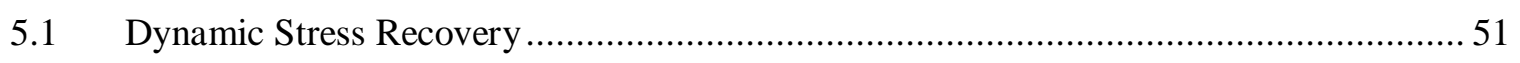

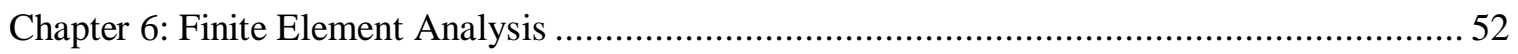

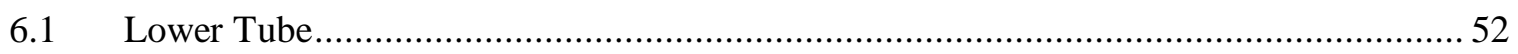

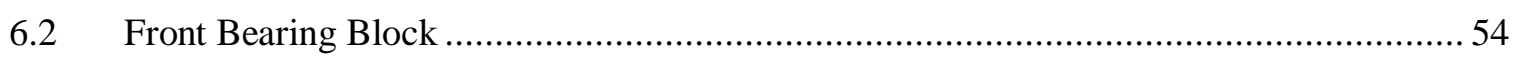

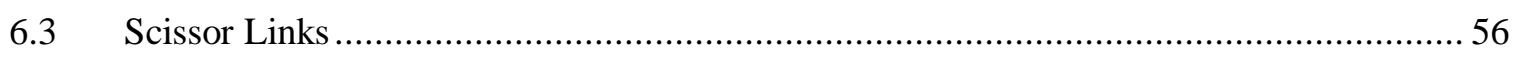

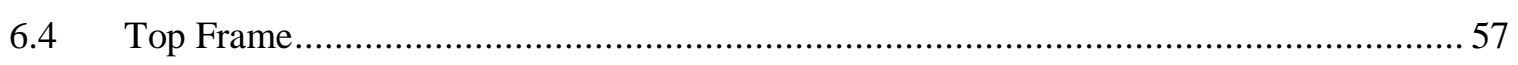

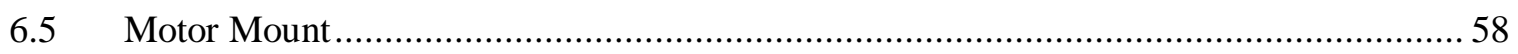

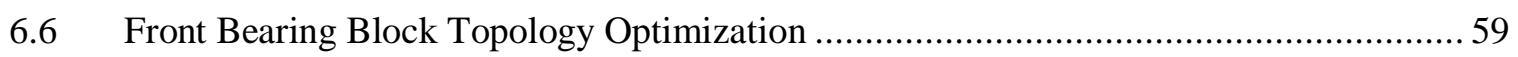

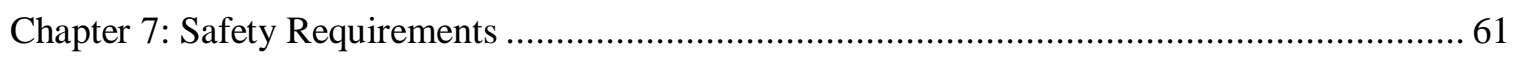

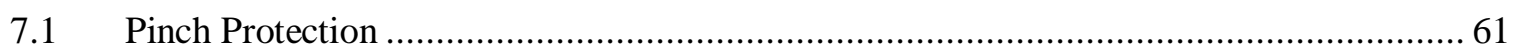

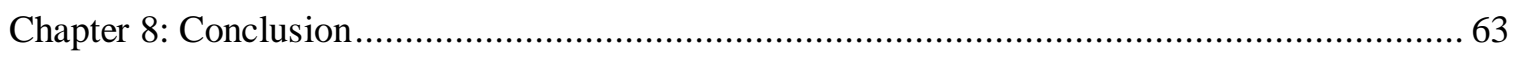

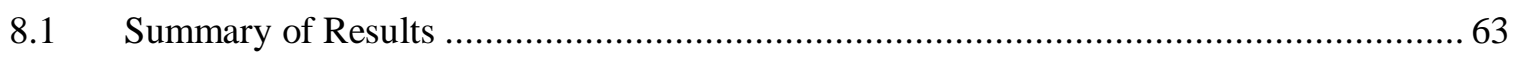

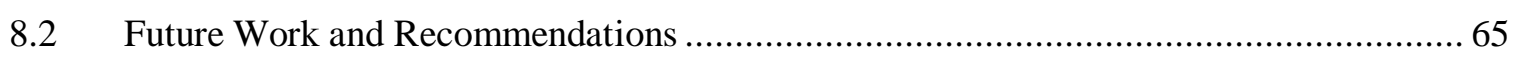

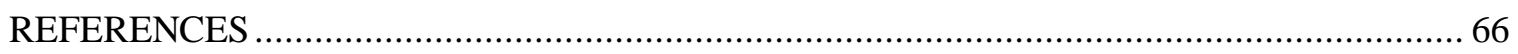

APPENDICES

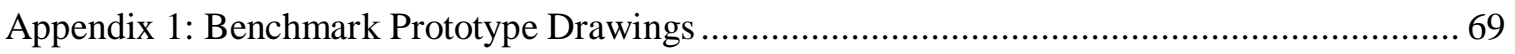

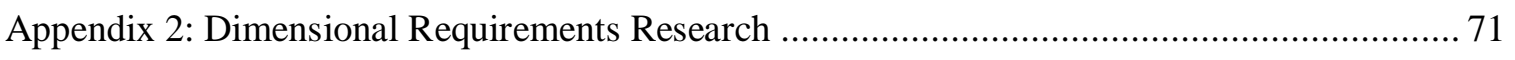

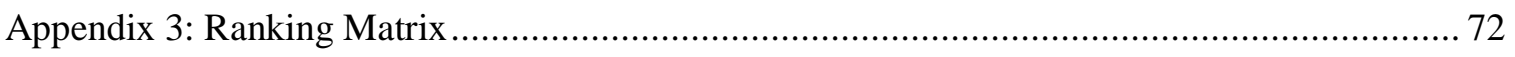

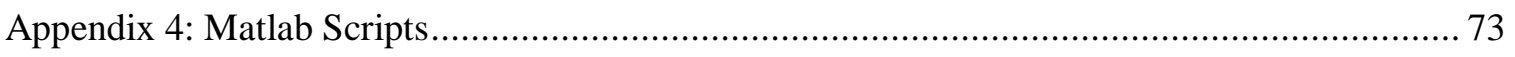

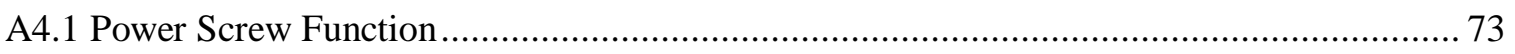

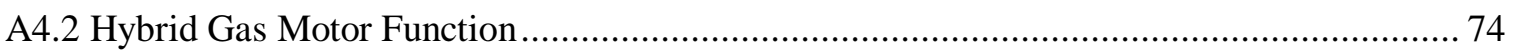

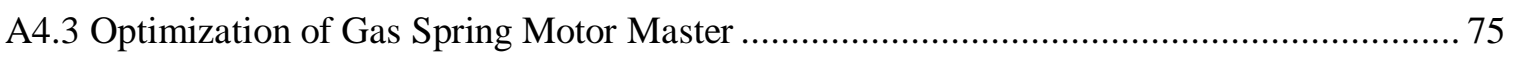

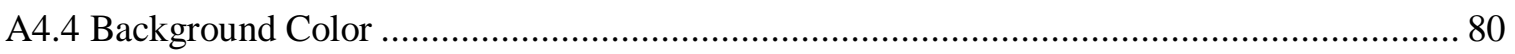

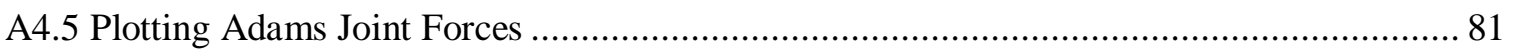

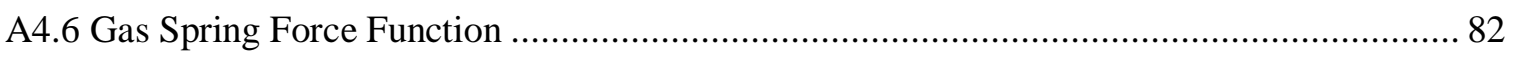

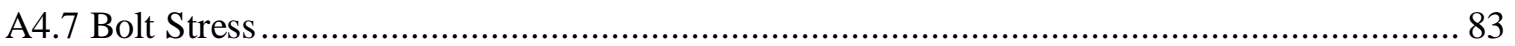

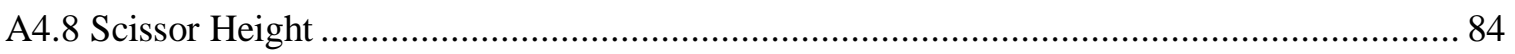

Appendix 5: Material Properties used for Simulations and Finite Element Analysis ................... 87 


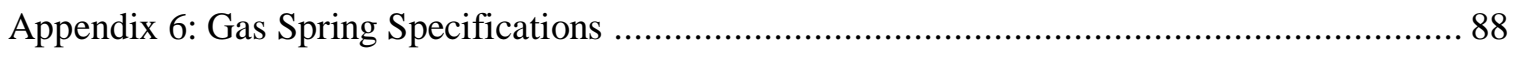

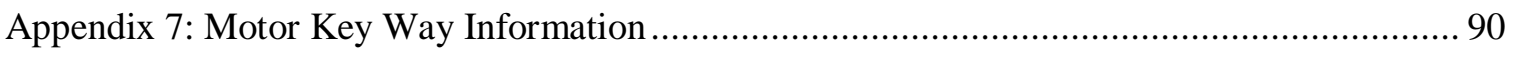

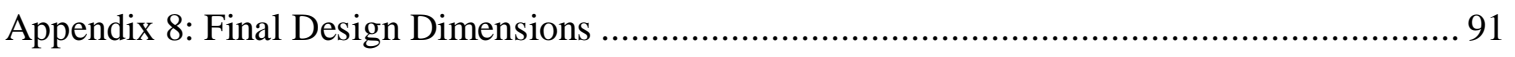

Appendix 9: Joint Loads for Typical Conditions (Functioning Gas Spring)............................. 92

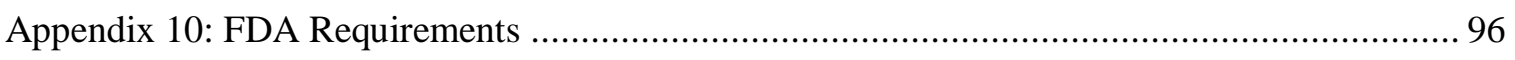

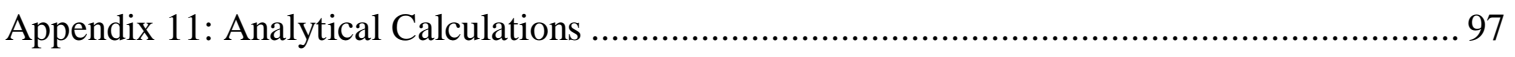

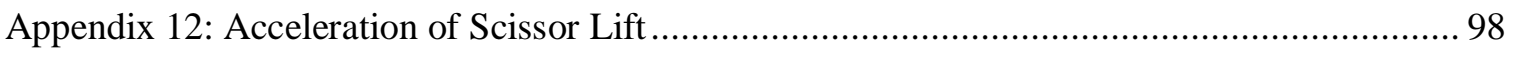

Appendix 13: Scissor Link Bolt Strength Selection ............................................................ 99

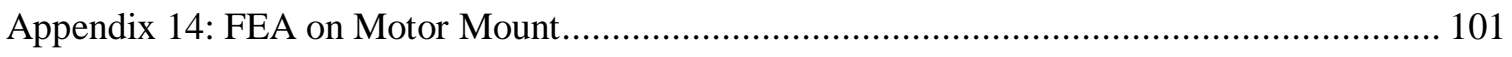

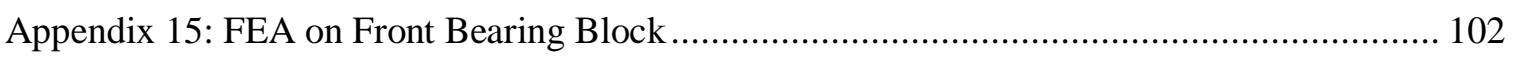

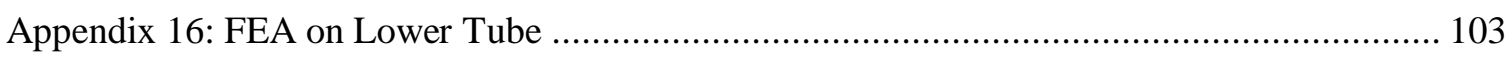

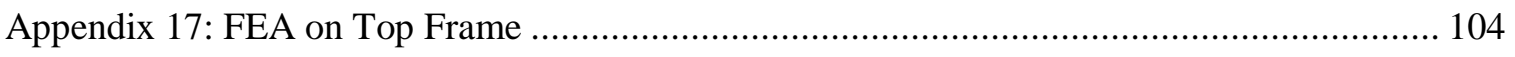

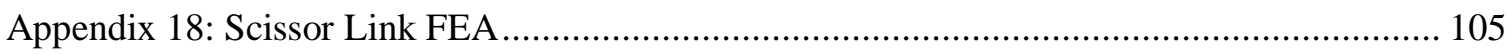

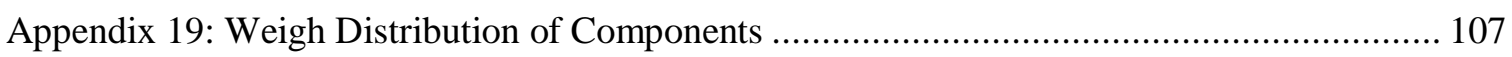

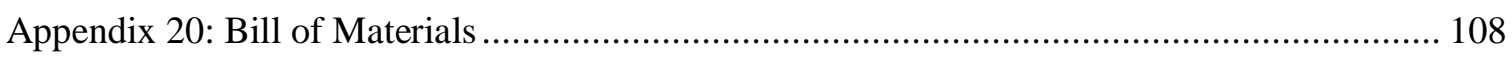




\section{LIST OF TABLES}

Table

Table 1: Cost and weight capacity of lift hoists of some commercially available products

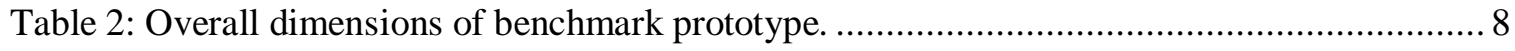

Table 3: Summary of overall dimensional requirements. ....................................................... 9

Table 4: Pin requirement list for the proposed components.................................................... 27

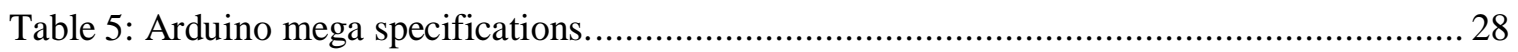

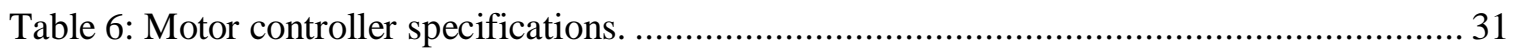

Table 7: Summary of the analytical calculations for the stresses. The yield of Al 6061-T6 is

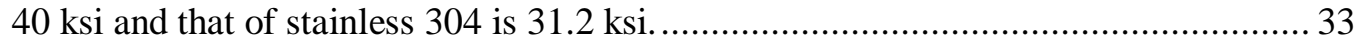

Table 8: Parameters used to determine the power screw is self locking. ................................... 38

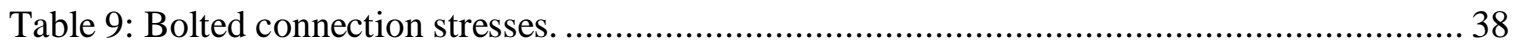

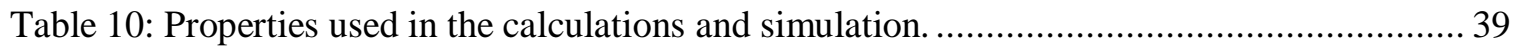

Table 11: Lift times for various motor speeds for a 0.1 in pitch power screw. ............................ 40

Table 12: Summary of gas spring and motor torque requirements from optimization. …............ 42

Table 13: Rated specifications of selected DC gear motor from Bodine Electric. ....................... 43

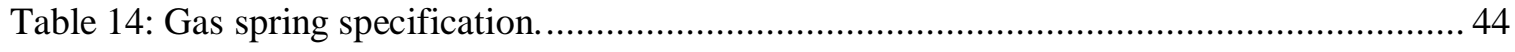

Table 15: Lift cycles for various battery capacities. .......................................................... 45

Table 16: Battery Specifications from manufacturer's website .............................................. 45

Table 17: Material assignment properties used in the ADAMS model...................................... 46

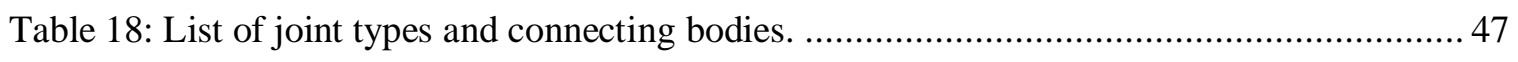

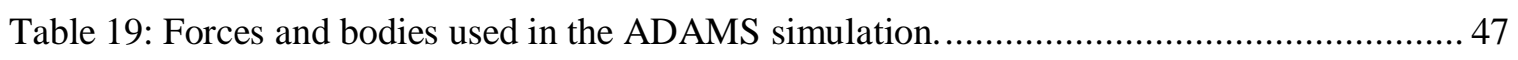

Table 20: Summary of joint forces for the case with and without a gas spring.......................... 49

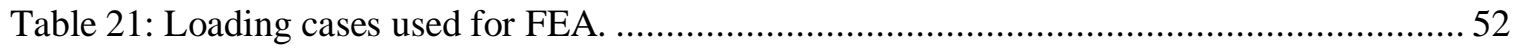

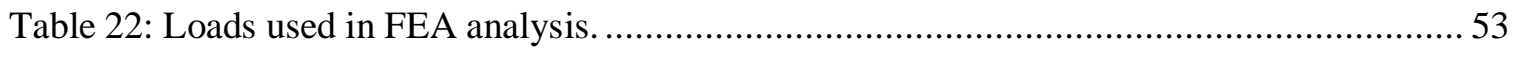

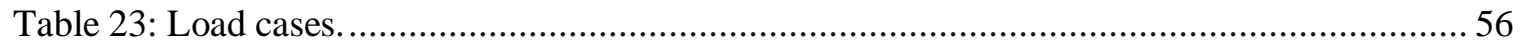

Table 24: Surface traction loads and vectors applied to the top frame. .................................... 57

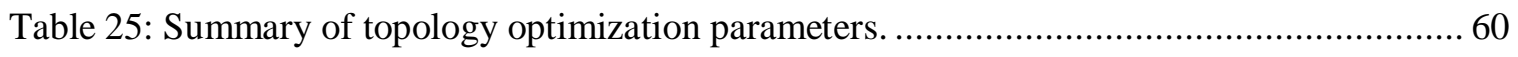

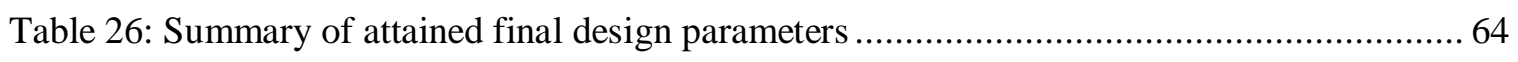

Table 27: Ranking matrix comparing a pneumatic vs electric actuation design......................... 72

Table 28: Description of the score and weight used in the ranking matrix............................... 72

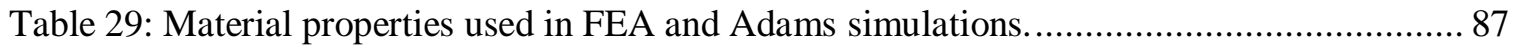




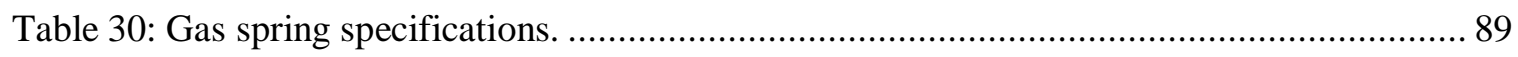

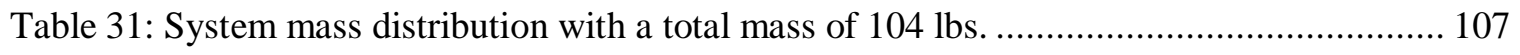




\section{LIST OF FIGURES}

Figure

Figure 1: Use of a pickup walker during ambulation from reference 1. The image in the center shows the moment when there is no support to the user. ................................ 2

Figure 2: Merry Walker that functions as a rollator................................................................ 3

Figure 3: Patented scissor lift walker by Bagheri. ............................................................... 4

Figure 4: Isometric view of the benchmark prototype before modifying the scissors for

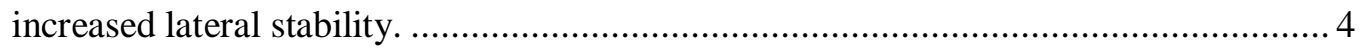

Figure 5: Pneumatic lift walker patented by Knutz, US 6,503,176 .................................... 5

Figure 6: Patented walker designed by students at Stony Brook University. .............................. 6

Figure 7: An example of a hoist device that is used to lift and then transfer a patient. This device is typically operated by a trained assistant............................................... 7

Figure 8: Annotation of key dimensions for both the benchmark prototype and completed design.

Figure 9: The angle theta referred to in this document is the angle the scissor makes with the horizontal [9]

Figure 10: Actuator force requirements for a two parallel scissor mechanisms lifting a 250lbs load.

Figure 11: Sliding block design, the scissor yokes on the left and right are bolted on after the sliding block inserted in the lower tube. The Teflon shells provide a smooth sliding surface.

Figure 12: Mid bearing block assembly. From left to right: ACME threaded-bore clamp on collar, thrust washer, thrust bearing roller cage, thrust washer, sleeve bearing, bearing block.....

Figure 13: Front bearing block shown with caster. This assembly is similar to the mid bearing block

Figure 14: Schematic showing the drive system components assembly and how they are connected.

Figure 15: Screenshot of the drive system components, the shaft (cyan) transmits power from the gear motor (black) to the acme threaded rod (red).

Figure 16: The overall design of the scissor assembly, both scissor assemblies are identical with the same components for manufacturing ease.

Figure 17: The Inner scissor has a cross member in the center that is a hollow tube to increase lateral stability.

Figure 18: The outer scissor is wider than the inner scissor for them to be able stack/collapse.... 17

Figure 19: Scissor assembly showing gas spring attached between the stages of the scissor. ...... 18 
Figure 20: Lower tube showing all machined features.

Figure 21: Overview of mid- frame, showing the fixed clevis on the left, and the sliding clevis on the right.

Figure 22: Exploded view of sliding clevis. From top to bottom: square lock nuts, Teflon sliding block, Teflon gasket, aluminum clevis, and hex head bolts.

Figure 23: Screenshot of the clevis in the sliding tube, the sliding block (cyan) is made of Teflon.

Figure 24: The rear fixed clevis will be bolted on to the mid frame.

Figure 25: The mid bar is designed to be secured using a quick release pin or bolt to secure it in place for the prototype. 22

Figure 26: The middle bar is designed to be pinned or bolted in place.

Figure 27: With a 9inch tall top frame, the walker will cater to the $95^{\text {th }}$ percentile of the elderly population.

Figure 28: Schematic of the top frame showing the five harness attachment points. 24

Figure 29: Lower-cross bar will be constructed out of aluminum with lots of holes drilled to lower mass. 25

Figure 30: Motor assembly with aesthetic looking shroud. 26

Figure 31: Proposed setup configuration and typical output signal for a gear tooth speed sensor.

Figure 32: Revolutions vs total height of the walker. A cubic fit was used to extrapolate an equation that related rotations to the height of the walker.

Figure 33: Example of proposed spring pin contacts to be embedded in the top frame for electrical connections and proximity sensing.

Figure 34: The maximum flexure occurs at the fully upright position, this max bending stress is $5.7 \mathrm{ksi}$ for square tube of thickness 0.125 inches with a side of 2 inches. The yield of $\mathrm{Al} 6061 \mathrm{~T} 6$ is $40 \mathrm{ksi}$.

Figure 35: Maximum axial stress occurs at the fully lowered position when lifting a person. The maximum axial stress for a 0.125 inch Aluminum tube is $2.97 \mathrm{ksi}$.

Figure 36: Analytical calculation of von Mises stress.

Figure 37: The von Mises stress of three power screws with half the patient load applied.

The stresses for all the screws are below yield for steel (36 ksi).

Figure 38: The compressive load on the power screw is below the critical buckling load for a 0.5 inch diameter power screw.

Figure 39: Torque requirements for raising a 250 pound patient.

Figure 40: Optimized motor torque requirements for $200 \mathrm{lbs}$ patient from lifted from 20.6, 22.5 and 24.4 inches. The solidlines represent lifting, and dashed represent lowering. 
Figure 41: Optimized motor torque requirements for $250 \mathrm{lbs}$ patient from lifted from 20.6, 22.5 and 24.4 inches. Solidlines represent lifting, and dashed represent lowering. ...... 42

Figure 42: Scatter plot of DC gear motors available from Bodine Electric, the red point shows the selected motor.

Figure 43: The half walker model showing the components connected. The icons show the forces and joints.

Figure 44: The joint reaction forces in the vertical direction stay within a range of $+/-125$ lbs. This is consistent with the applied load, weight of $250 \mathrm{lbs}$, with failed gas springs.

Figure 45: The Joint forces in the $\mathrm{z}$ direction, the maximum force is experienced is by Joint 3. This is for a patient weight of $250 \mathrm{lbs}$, with failed gas springs.

Figure 46: The top tube vertical velocity (y-direction) matched the analytical calculation validating the rigid body simulation.

Figure 47: The von Mises stress is around $10 \mathrm{ksi}$ and is concentrated around joint 3 in the model.

Figure 48: Loads and Boundary conditions for the lower tube. .52

Figure 49: Analysis of a 2 inch Extruded Aluminum tube of wall thickness 0.120 inches. The stress around the holes is at yield.

Figure 50: Close up of stress distribution around the holes, there are some areas that are at yield which is expected with a stress concentration.

Figure 51: The von Mises Stress distribution in the lower tube, the stress of the lower tube is reduced with an increase in wall thickness from 0.120 to 0.188 inches

Figure 52: The boundary conditions applied to the bearing block. A pressure load with total force of $1557 \mathrm{lbs}$. applied to region 1, with a ground reaction force of 200lbs applied to region 3. A fixed boundary condition was applied to the holes in region 2 .

Figure 53: The von Mises stress distribution, it is significantly below yield of Al 6061-T6 which has a yield of $40 \mathrm{ksi}$.

Figure 54: Annotation for prescribed loads and boundary conditions for the scissor link........... 56

Figure 55: The von Mises stress for load case 1. The maximum stress is less than $10 \mathrm{ksi}$. .57

Figure 56: Top frame region annotations, the applied surface tractions are listed in Table 24. Encaster boundary conditions were applied to the attachment point of the top frame to the middle frame.

Figure 57: Stress contour plot of the top frame, there are some hot spots, but these will be eliminated during manufacturing by rounding any edges. The von Mises stress of

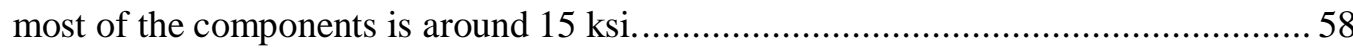

Figure 58: Load and boundary condition annotation on the motor mount...............................59

Figure 59: The von Mises stress on the motor mount for the worse loading case ...................... 59

Figure 60: Optimized bearing block geometry using topology optimization. 
Figure 61: The proposed bellowing would encompass all moving parts

Figure 62: Top view of walker showing bellowing and a modified top frame. The bellowing encompasses the scissor links as seen. ....

Figure 63: The design allows the walker to be disassembled in to 5 pieces for transportation.

The heaviest component is the scissor assembly with a weight of $35 \mathrm{lbs}$.

Figure 64: Collapsed height of benchmark prototype walker was 9.4 inches. ............................ 69

Figure 65: Extended height of benchmark prototype was 43.75 inches.

Figure 66: Dimension of the u-shaped frame for the benchmark prototype, the max length was 39.9 inches with a width of 22.9 inches.

Figure 67: Anthropometric data for the elderly population. The maximum 65 year + weight is 218 with a max elbow height of 45 inches.

Figure 68: The force ratio is the slope of the gas spring is P2/P1 for the case of an extension gas spring. This typically ranges from 1.1 to 1.4 for standard gas springs [19].

Figure 69: Sections of the motor showing the keyway dimensions as well as shaft diameter for the selected DC gear motor model no 5060 from Bodine electric.

Figure 70: The overall dimensions of the final design are within the maximum specified requirements as listed in Table 3 .

Figure 71: The collapsed height is 14.73 inches.

Figure 72: The force in the $\mathrm{x}$ is close to zero for Joints 1-8 indicates that simulation was successful, and that there is no lateral force. Case with failed gas spring.

Figure 73: Joint force Fx with functioning gas spring. 93

Figure 74: Joint Force Fy with functioning gas spring. 94

Figure 75: Joint force $\mathrm{Fz}$ with functioning gas spring. 95

Figure 76: The acceleration vs angle during lifting. The acceleration well below $1 \mathrm{~g}$ (386 $\mathrm{in} / \mathrm{s} / \mathrm{s})$.

Figure 77: Bolt shear stress for various diameter bolts. A bolt over 0.25 inches will be strong enough.

Figure 78: P-value calculator for a bushing, the dotted line shows a super oilite bronze bushing max pressure rating.

Figure 79: Displacement contour plot of the motor mount. 101

Figure 80: The stress at the attachment holes converges with increasing elements

Figure 81: Displacement contour plot of front bearing block. The displacement is negligible as expected.

Figure 82: The stress at a in the middle of the bearing block converges with increasing elements. 102

Figure 83: Displacement of Lower Tube, the maximum displacement is 0.12 inches. 103 
Figure 84: The stress at the attachment holes where the middle bearing block attaches is converging with a fine mesh.

Figure 85: Displacement contour plot for the top frame, the maximum displacement is 0.2 inches. 104

Figure 86: The stress converges with increasing elements. 104

Figure 87: Displacement contour plot for a steel scissor, the displacement at the end is 0.022inches. 105

Figure 88: Displacement contour plot for an aluminum scissor, the displacement at the end is 0.056 inches. 105

Figure 89: The stress around the center hole converges to $10.8 \mathrm{ksi}$ with increasing elements.... 106 


\section{Chapter 1: Introduction}

The desire to create a lift assist increased stability walker is crucial in preventing injuries as well as improving the mobility of the elderly. Ambulatory devices such as canes and walkers have been used to improve stability and mobility of the elderly by providing additional support during gait. These devices not only provide additional stability but can increase confidence and feeling of safety which increases their mobility and independence [1-3].

Of these two devices walkers generally provide users with superior balance; however, use of walkers come at increased metabolic cost to the user. There is a $217 \%$ increase in metabolic cost per distance travelled with a pick up walker [4]. There is a reduction in this metabolic cost with the use of wheeled walkers but the use of a wheel walker is still $55 \%$ energetically more expensive than unassisted gait but less than that of a pickup walker.

The need to use a walker arises as some of the elderly are generally too weak to generate stabilizing forces due to postural perturbation naturally or the reaction times are slower. A typical way for a healthy person to regain balance is to alter the base of support by stepping rapidly or grabbing a hand rail which increase a person's base of support preventing a fall [5].

Walkers aid in balance, as they provide a mobile support to the user. For a pick up walker, the user picks up the walker places it in front of them and then steps forward, at this moment there is no lateral support in the event of a lateral fall as shown in Figure 1. 

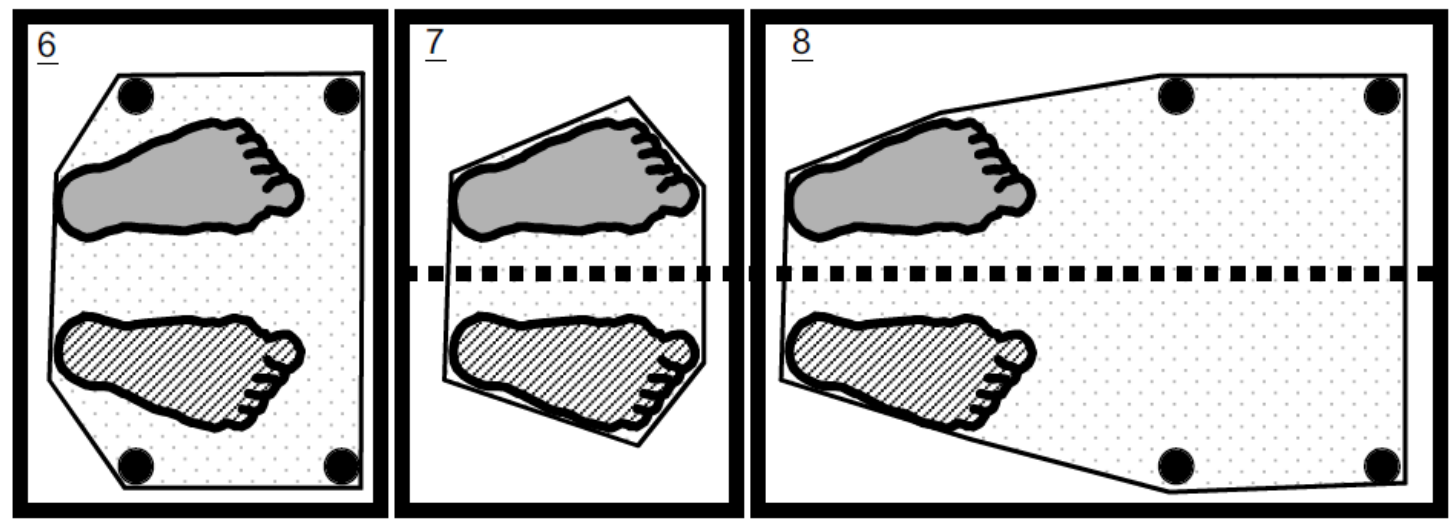

Figure 1: Use of a pickup walker during ambulation from reference 1. The image in the center shows the moment when there is no support to the user.

Another study revealed that in the average adult, compensators stepping and grasping are much more rapid than volitional movements and are effective in decelerating motion due to sudden perturbations [6]. Older adults are more reliant on grasping but less able to execute these motions quickly, hence it is important to create a walker that keeps the users hands in contact throughout ambulation.

Typical widely used walkers are light weight and adjustable to about waist height and either rolling, sliding or pick up. A variety of improved devices such as the Merry Walker have been created that claim to provide tip resistance from features such as bottom weighting and a wider bottom base[7]. This device, seen in Figure 2 is constructed of tubular steel and isn't appealing to use.

Some other alternative devices are available on the market that are primarily classified as hoists, they are used to transfer a patient from one location to another (e.g. from a bed to a chair). These devices provide an easy way to lift a patient however they are typically operated by a trained assistant and don't provide independence. 
This project focuses on the design of a lift assist walker for prototype evaluation and proof of concept purposes.
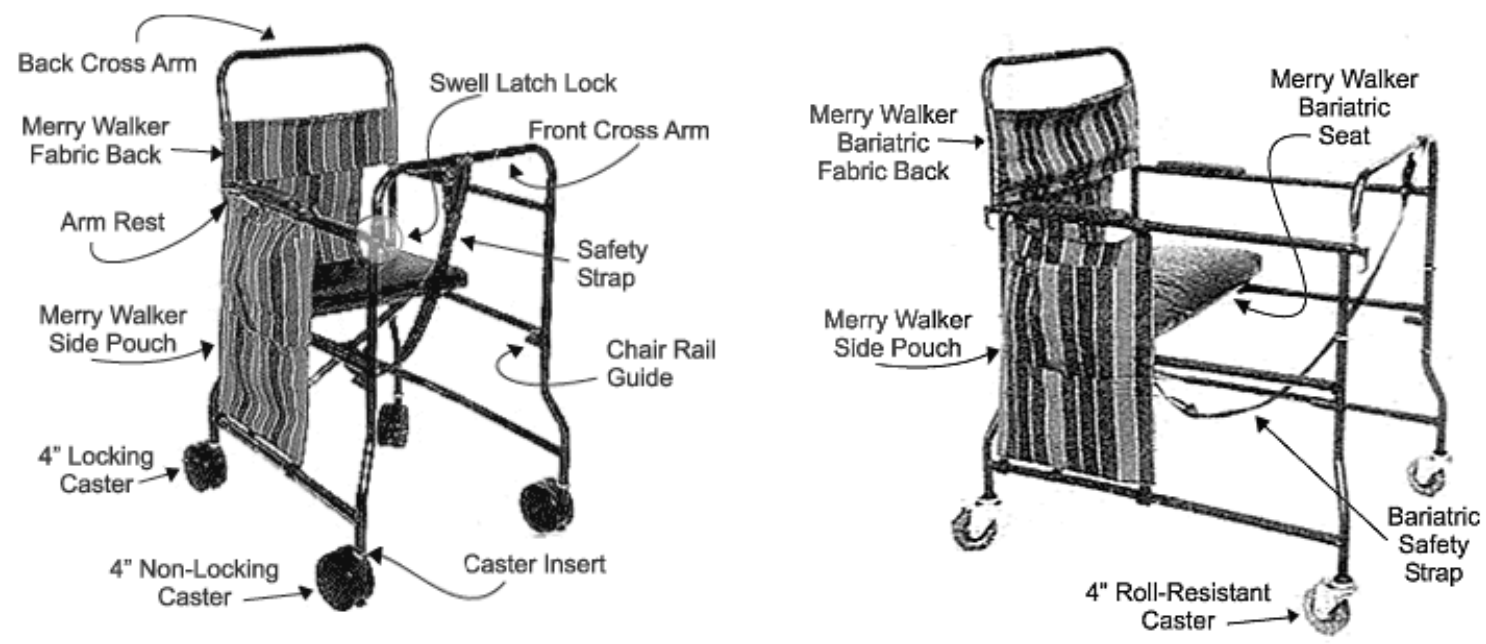

Figure 2: Merry Walker that functions as a rollator.

\subsection{Project Background}

Previous work by Dr. Kourosh Bagheri, included a fabricated prototype that demonstrated the collapsibility of a scissor mechanism walker that was based on his patented design, US8967642 as shown in Figure 3. The claims of his patent to date are for a lifting mechanism based on a multi stage scissor mechanism. This walker is height adjustable and can be stowed but does not provide any lifting mechanism to the user.

This walker is referred to in this thesis as the benchmark prototype, which was modified to improve lateral stability by creating stacking scissor links that allowed for the placement of a gas spring horizontally in between the top and bottom stages of the scissor. 


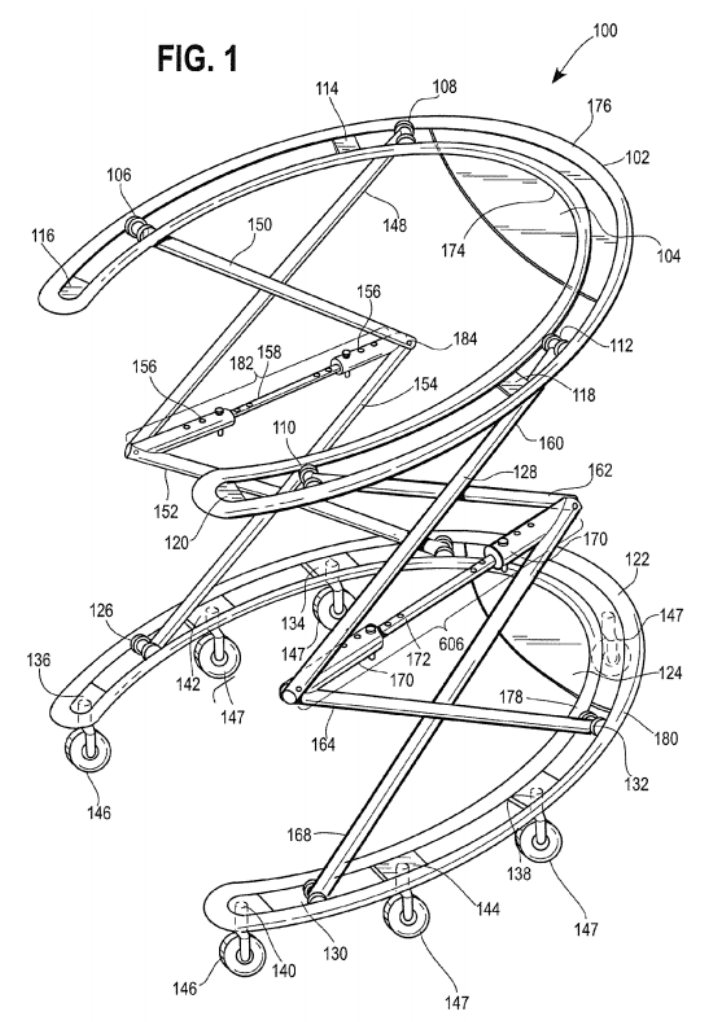

Figure 3: Patented scissor lift walker by Bagheri.

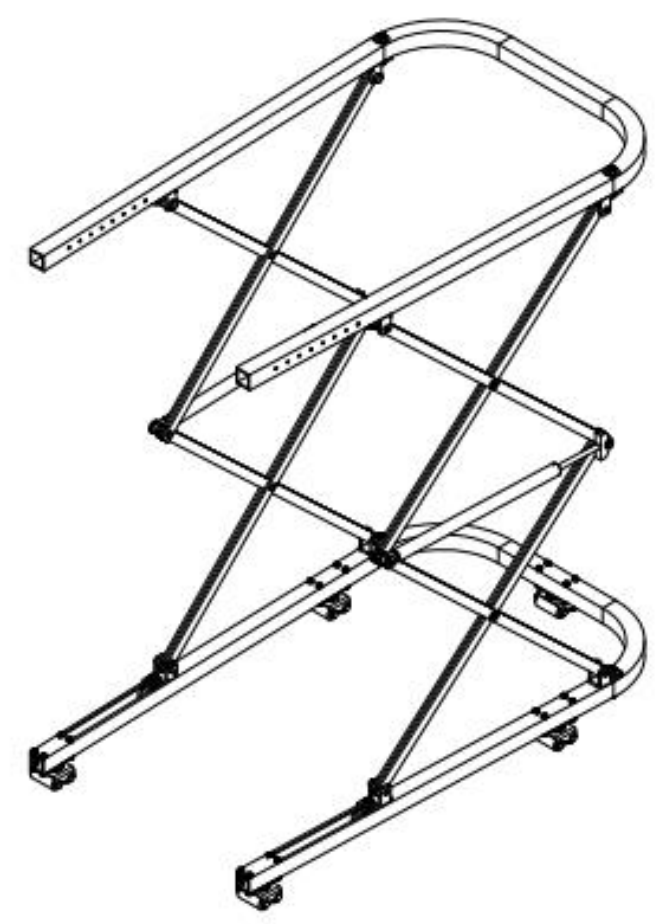

Figure 4: Isometric view of the benchmark prototype before modifying the scissors for increased lateral stability. 


\subsection{Literature Review}

Prior to designing a lifting system a literature review revealed several patents for walkers with lifting features but nothing that was fully collapsible. One such example is a patented pneumatic actuation walker which uses a compressed air reservoir and pneumatic actuators to lift a person.

Figure 5 shows this device which consists of a sliding track as the primary lifting mechanism.

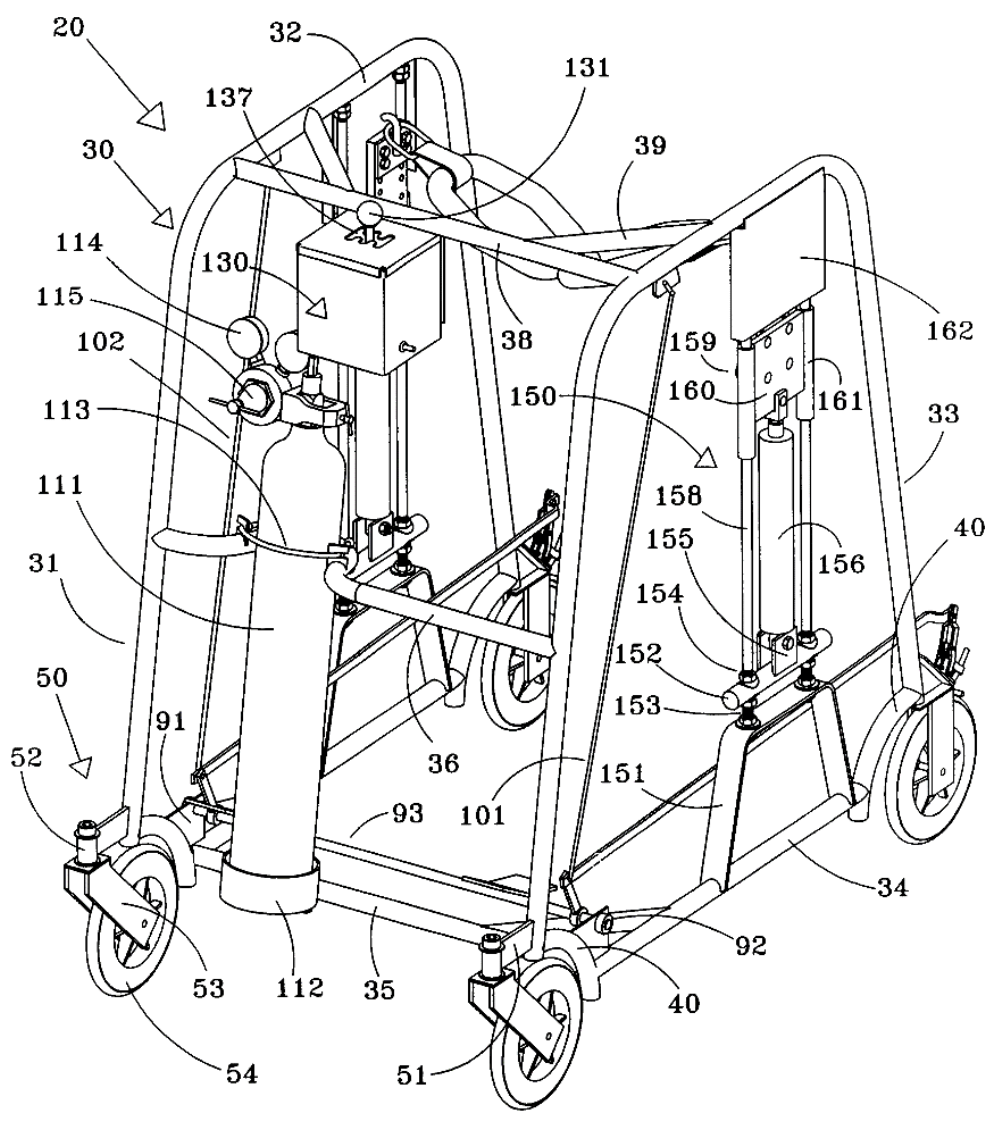

Figure 5: Pneumatic lift walker patented by Knutz, US 6,503,176.

There has not been any commercial version of this walker, and no additional information was available. The closest developed device is a walker designed by a team of engineering students at Stony Brook University in Albany, NY patented as US 8,468,622. The features include an electro-mechanical actuation for lifting a person via a linear actuator and a 6 bar linkage. This 
walker was supposed to be developed by Biodex Medical Systems and commercially available in 2015, but has not yet emerged on the market.

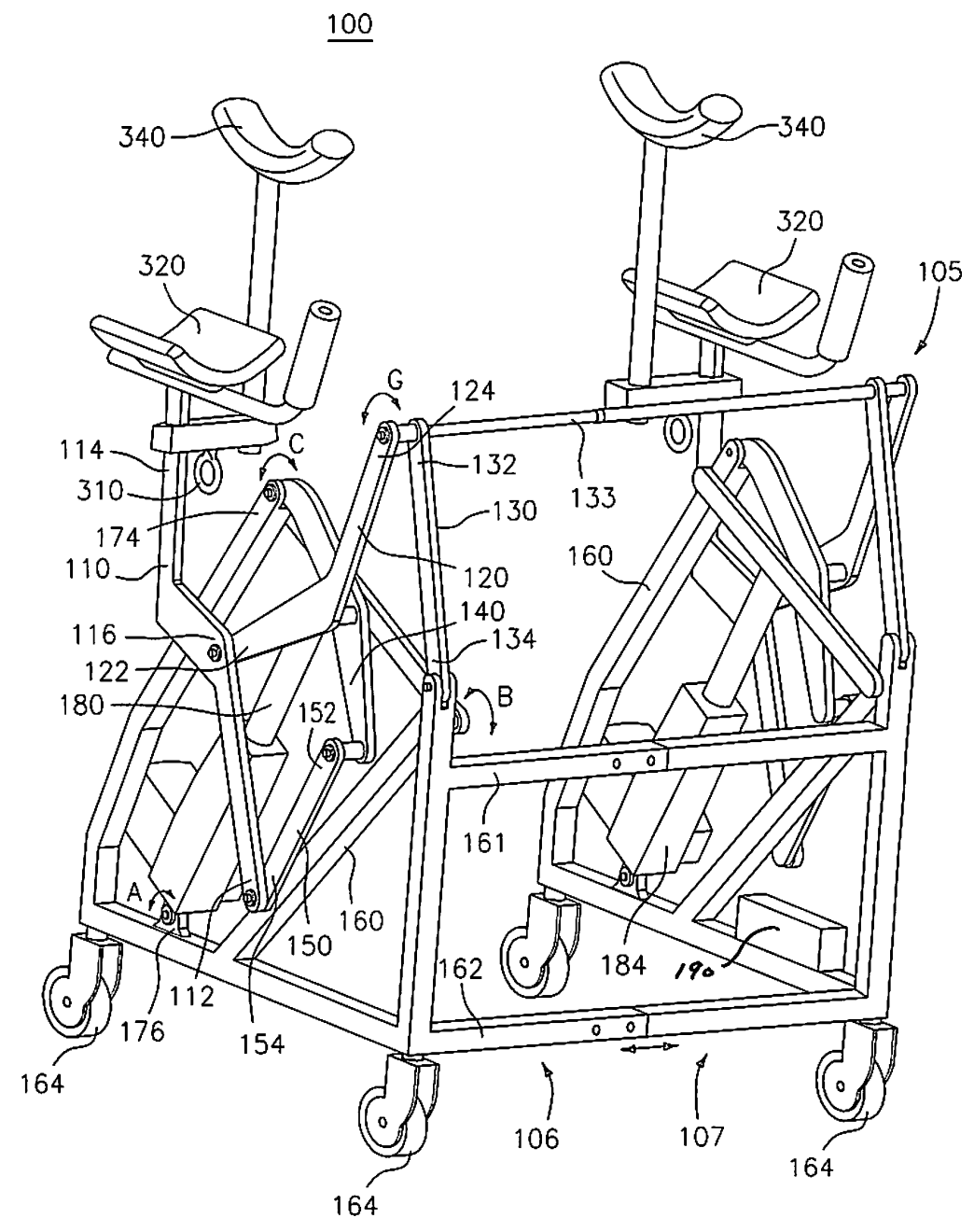

Figure 6: Patented walker designed by students at Stony Brook University.

Some of the other commercially available products are hoist type of devices. These only provide assisted lift features for relocation. These are either electric or hydraulic devices. Table 1 lists some of these devices with their weight capacity. As seen in the list most of these are between 64$116 \mathrm{lbs}$. in weight and are rated to lift heavier patients (350-450 lbs.). Figure 7, shows an 
example of a manually operated hydraulic device where the user is securely strapped in to the device and the device operated by a trained assistant.

Table 1: Cost and weight capacity of lift hoists of some commercially available products.

\begin{tabular}{|c|c|c|c|}
\hline Product & Price [\$] & Weight Capacity [lbs.] & $\begin{array}{c}\text { Weight } \\
{[\mathbf{l b s .}]}\end{array}$ \\
\hline Pro Basics Hydraulic Patient Lifter & 394 & 450 & 68 \\
\hline Hydraulic Lift w/Adjustable Base & 479 & 450 & 68 \\
\hline Genesis 400 Hydraulic Lift & 565 & 400 & 75 \\
\hline Delux Hydraulic Lift & 620 & 450 & 72 \\
\hline Hydraulic Lift 400 & 625 & 400 & 85 \\
\hline Hyoer Hydraulic Patient Lifter & 707 & 400 & 116 \\
\hline Classic Hoyer Lift & 707 & 400 & 105 \\
\hline Reliant Plus 450 Hydraulic Lift & 1199 & 450 & 93 \\
\hline Advance-H Patient Lift & 1283 & 340 & 64 \\
\hline Carina 350 Patient Lift & 2599 & 350 & 79.37 \\
\hline
\end{tabular}

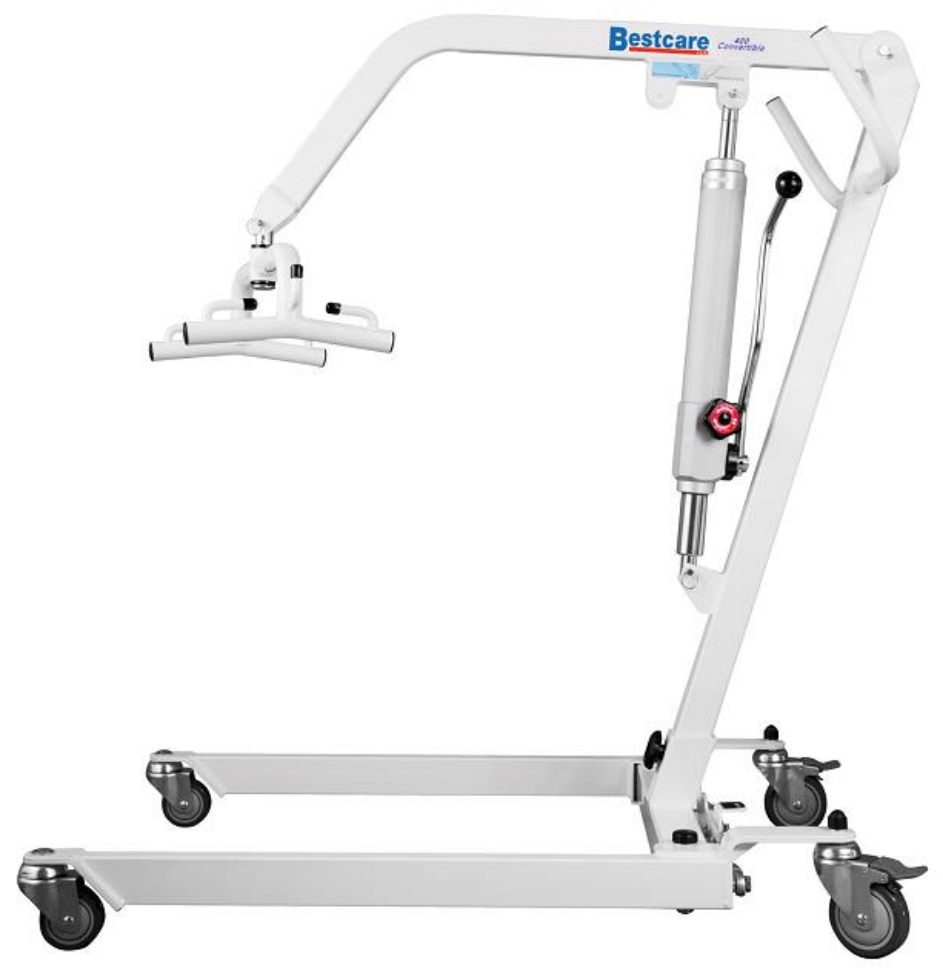

Figure 7: An example of a hoist device that is used to lift and then transfer a patient. This device is typically operated by a trained assistant. 


\subsection{Project Specification}

The goal of this project was to design a walker that could lift the $95^{\text {th }}$ percentile of elderly patients from sitting to standing in under 10 seconds while providing improved support. A key requirement was to design an intuitive device that can be used by an individual with minimal to no supervision. The benchmark prototype was used to outline initial size requirements, Table 2 . Figure 8 annotates key dimensions and detailed drawings of these dimensions are located in Appendix 1.

Table 2: Overall dimensions of benchmark prototype.

\begin{tabular}{|c|c|}
\hline Parameter & Max Value \\
\hline Length [in] & 39.98 \\
\hline Width [in] & 22.9 \\
\hline Collapsed height [in] & 9.32 \\
\hline Base height [in] & 7.5 \\
\hline Raised (Extended) Height [in] & 43.75 \\
\hline
\end{tabular}

\subsection{Dimensional Requirements and Load Capacity}

The benchmark prototype dimensions were refined further to provide maximum dimensional tolerances. The width for the walker was restricted to 32 inches to comply with the American Disability Association requirements for minimum door widths [8]. The maximum collapsed height of the walker was limited to 15 inches to allow transportation of the collapsed walker in a trunk of a mid-sized sedan as required by Dr. Bagheri. The maximum clearance from the ground to the top of the lower frame and components was set to 7.5 inches to allow the walker to be brought closer to the patient. The maximum extended height of the walker was set to 45 inches which catered to the $95^{\text {th }}$ percentile of the elderly demographic. The length of the walker was limited to a maximum of 42 inches for maneuverability. The maximum user weight was set to cater to the $95^{\text {th }}$ percentile of the geriatric population. This was set at a maximum of $250 \mathrm{lbs}$. 
Research of this data is located in Appendix 2. The maximum weight of the walker was set to 100

lbs. These requirements are summarized in Table 3, and annotated in Figure 8 for reference.

Table 3: Summary of overall dimensional requirements.

\begin{tabular}{|c|c|}
\hline Parameter & Max Value \\
\hline Length & 42 inches \\
\hline Width & 32 inches \\
\hline Collapsed height & 15 inches \\
\hline Base height & 7.5 inches \\
\hline Raised (Extended) height & 45 inches \\
\hline Load capacity & 250 lbs. \\
\hline Weight of walker & 105 lbs. \\
\hline
\end{tabular}




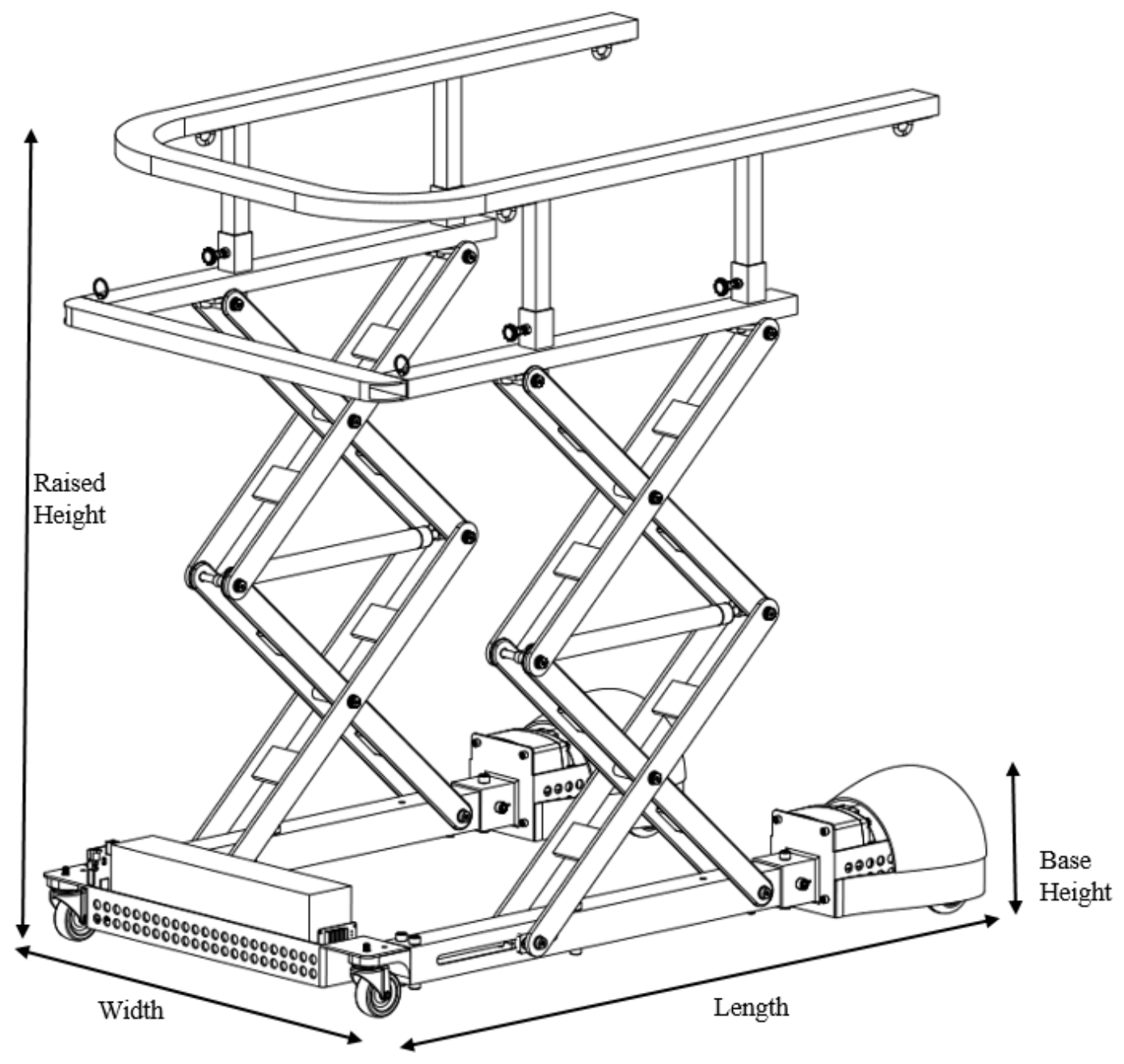

Figure 8: Annotation of key dimensions for both the benchmark prototype and completed design. 


\section{Chapter 2: Mechanical System Design}

To maintain claims on the intellectual property, the two stage scissor mechanism and U-Shape had to be maintained. Prior to selecting an actuation mechanism, the force to lift a load was determined using statics for a two stage scissor mechanism with a horizontal actuator. The stage at which this horizontal actuator is placed does not affect the lift force generated [9].

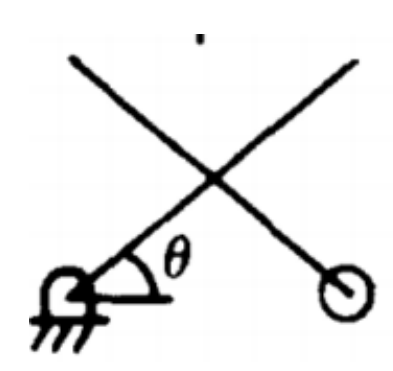

Figure 9: The angle theta referred to in this document is the angle the scissor makes with the horizontal [9].

Other locations of the actuators were explored, however they would interfere with the scissor's collapsibility and would be difficult to embed for the selected electronic actuation system selected discussed later in this document. The force required to lift a $250 \mathrm{lbs}$. person, for a massless two stage scissor with an actuator on each side ranged from $1400 \mathrm{lbs}$. at collapsed to $250 \mathrm{lbs}$. at extended, shown in Figure 10. Equation 2.1 below was derived using statics and verified for a two stage scissor [9].

$$
F_{\text {actuator }}=W \cot (\theta)
$$

The force $\mathrm{F}$ is constrained to the horizontal, $\mathrm{W}$ is the weight of a patient and the angle theta is shown in Figure 9. 


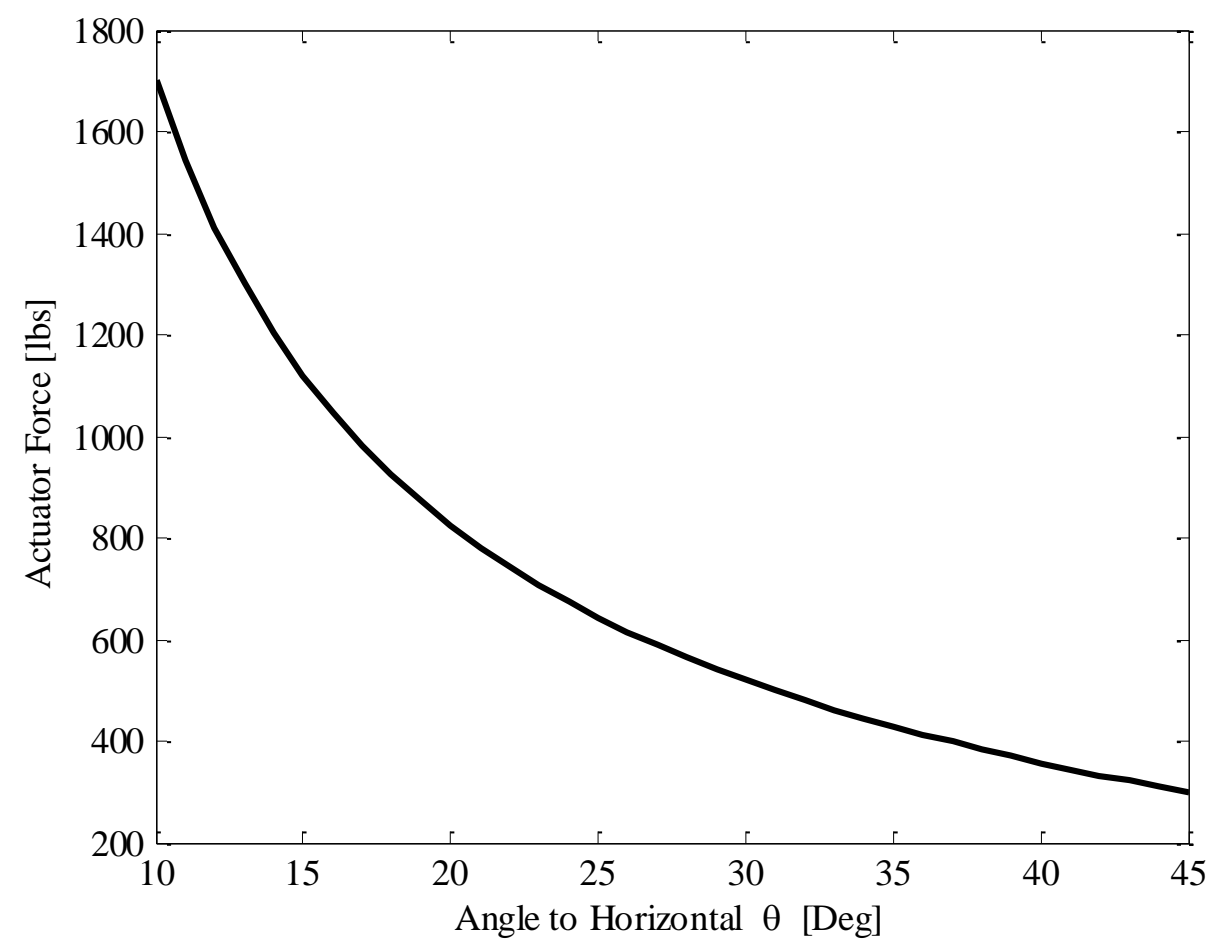

Figure 10: Actuator force requirements for a two parallel scissor mechanisms lifting a 250lbs load.

Two potential systems were explored for actuation; an electro-mechanical system or a pneumatic system. A ranking matrix was formulated to aide in deciding which system would be better. The electromechanical system was superior. Appendix 3 contains this ranking matrix.

\subsection{Actuator System Design}

The design process involved sizing an actuator system and then sizing the rest of the components around it. Appendix 8 shows the overall dimensions of the design. The sub sections below detail each sub system design. 


\subsubsection{Sliding Block}

An embedded linear actuator consisting of an acme thread screw with a rotationally constrained acme thread nut was used to produce linear motion form a rotary input. A "sliding block" that consisted of a square acme threaded nut mounted (dropped in) a bearing block was designed. The bearing block is partially encapsulated in two Teflon shells to provide a smooth sliding surface.

Figure 11 shows this design with the yokes that are mounted on to the sliding block once it is inserted in lower tube. All the bolts are selected to withstand the actuator loads.
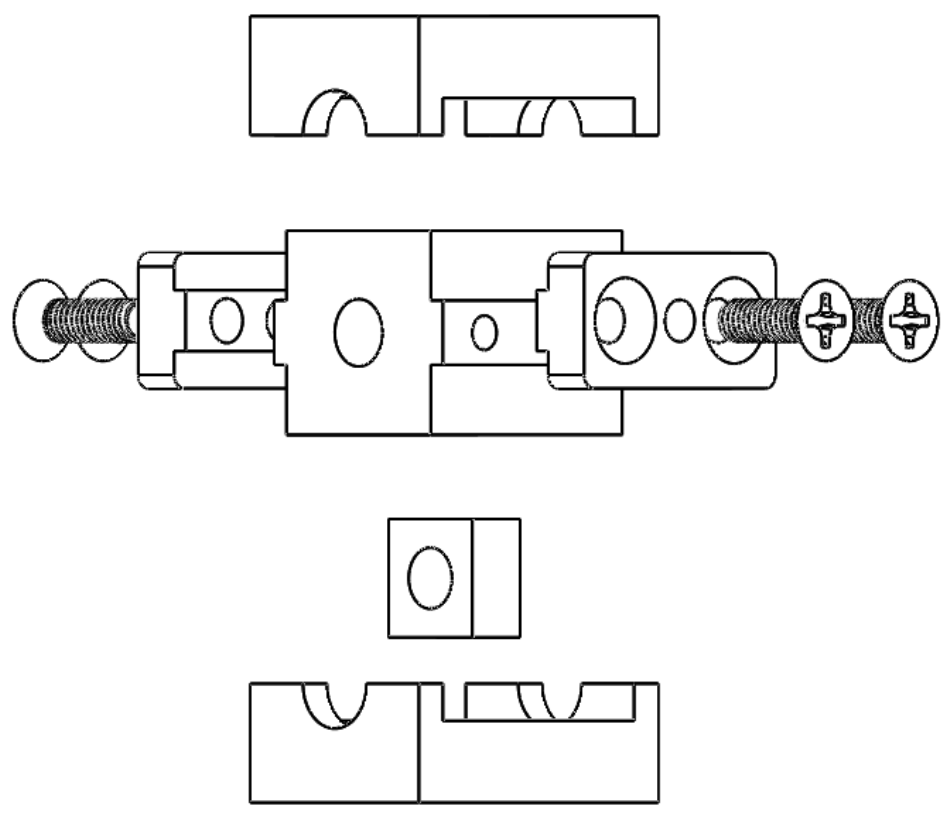

Figure 11: Sliding block design, the scissor yokes on the left and right are bolted on after the sliding block inserted in the lower tube. The Teflon shells provide a smooth sliding surface.

\subsubsection{Bearing Blocks}

Bearing blocks were designed to support the power screw enabling axial load transfer from the power screw to the lower frame. The load is transferred from the power screw to the bearing 
block through a clamp-on acme threaded steel collar via a thrust bearing. A press fit oil impregnated sleeve bearing will ensure smooth rotation of the power screw. Figure 12 shows this system. The bearing blocks are to be slid in the lower tube and secured using 40.25 in bolts.
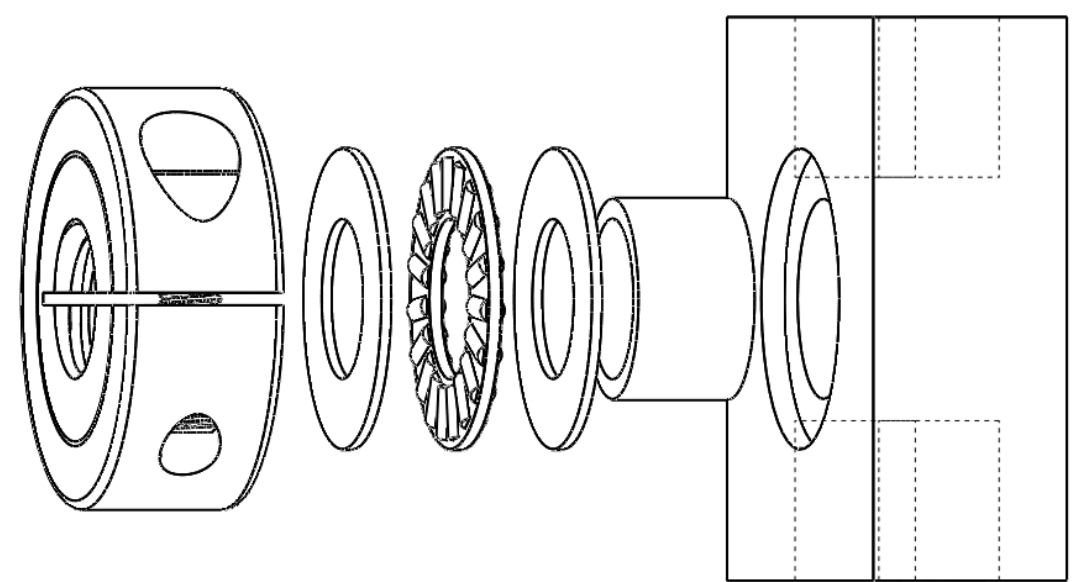

Figure 12: Mid bearing block assembly. From left to right: ACME threaded-bore clamp on collar, thrust washer, thrust bearing roller cage, thrust washer, sleeve bearing, bearing block.

The front bearing block is designed to support the power screw and incorporate a front caster.

Figure 13 shows an exploded view of this front bearing block. The section where the caster is bolted on is intentionally thick to enable the wheels to be level. 


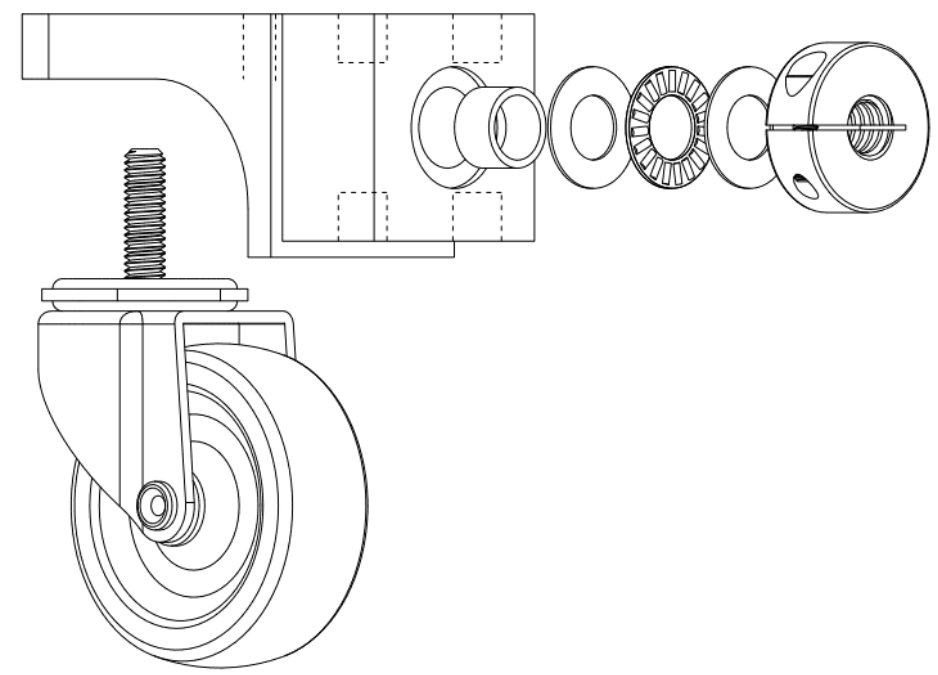

Figure 13: Front bearing block shown with caster. This assembly is similar to the mid bearing block.

The actuation system is shown in Figure 14, the motor output shaft is connected to the power screw via two couplers and a rotational shaft.

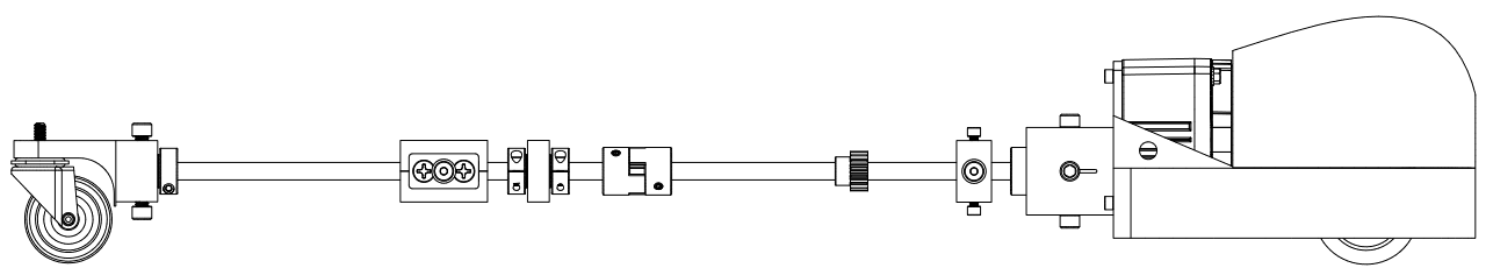

Figure 14: Schematic showing the drive system components assembly and how they are connected.

Figure 15 illustrates these components with the motor mount and lower tube that is both load bearing and a protective shroud. The scissors are designed to be attached on the exterior of the lower tube, they will be bolted on using shoulder bolts to the shaft bearing block (green in Figure 15) and the sliding block yoke (blue). 


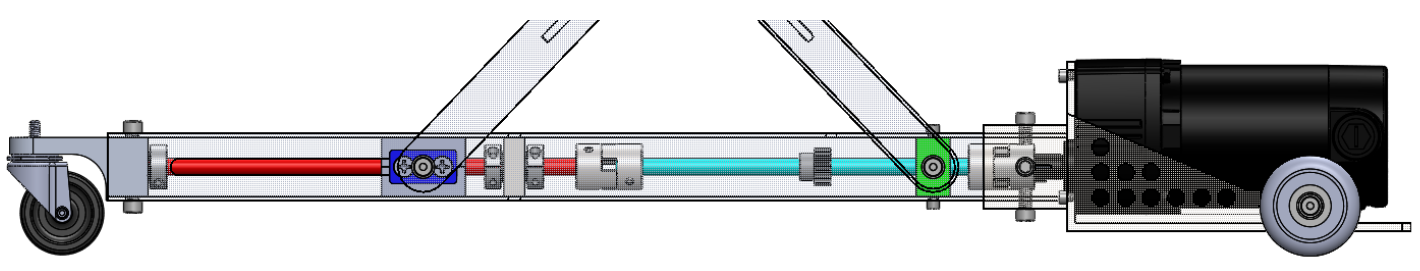

Figure 15: Screenshot of the drive system components, the shaft (cyan) transmits power from the gear motor (black) to the acme threaded rod (red).

The left and right components are identical to keep unique part count low. Figure 16 shows this sub assembly with all the functional components attached.

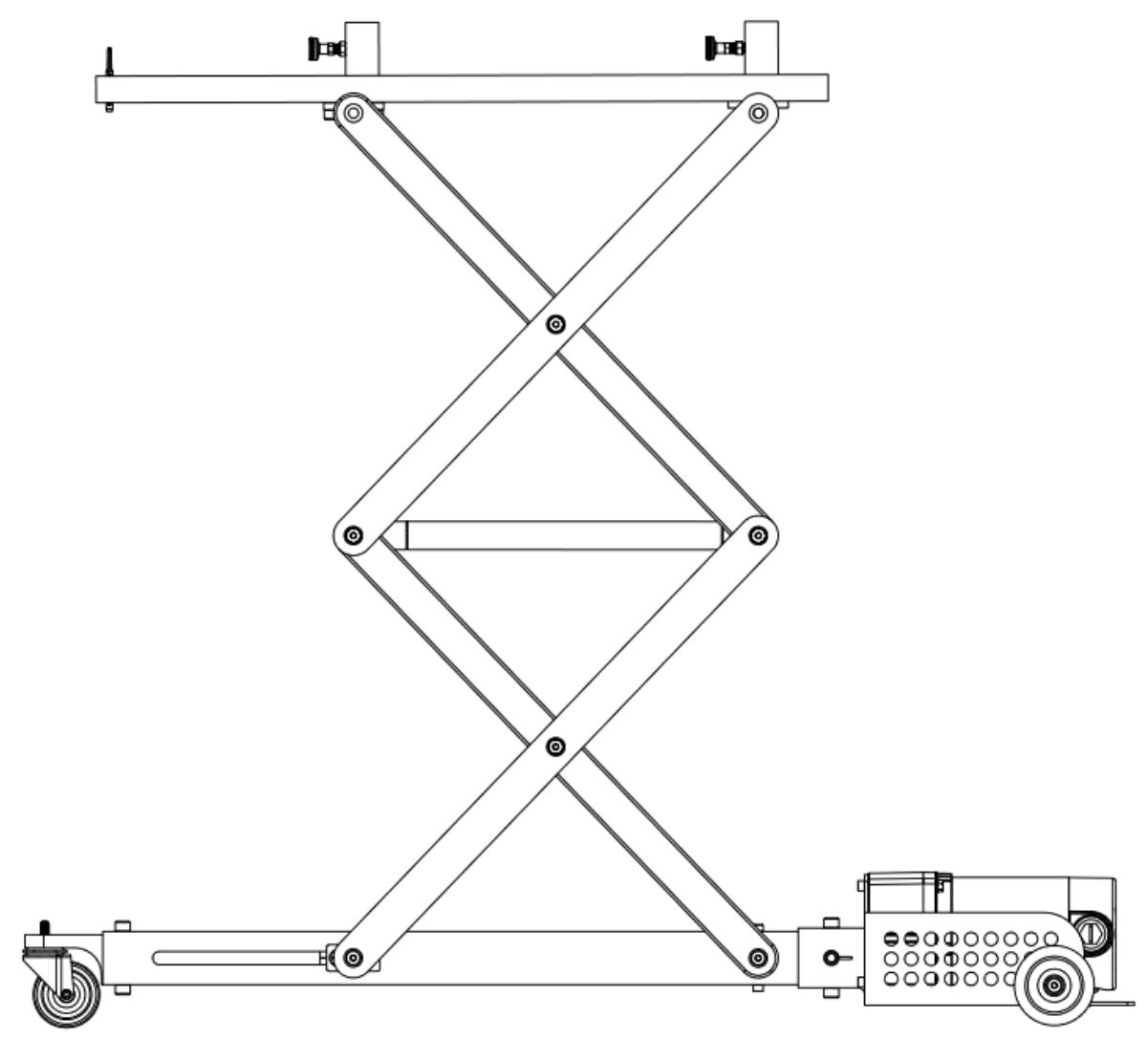

Figure 16: The overall design of the scissor assembly, both scissor assemblies are identical with the same components for manufacturing ease. 


\subsection{Scissor Design}

The scissor assembly was designed to enclose the gas spring in the middle portion. For this parallel bars were reinforced with cross members to produce a stackable scissor that fit over the lower tube.

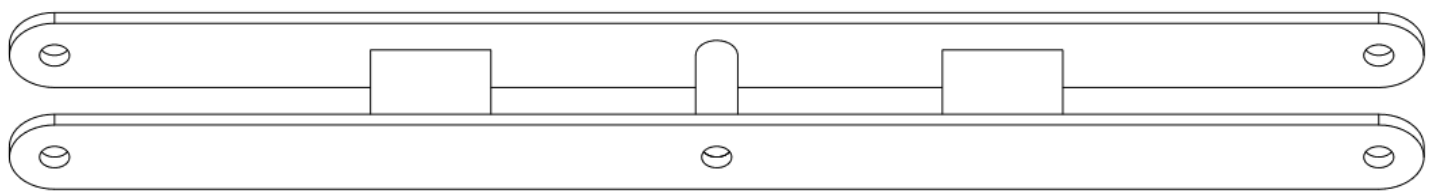

Figure 17: The Inner scissor has a cross member in the center that is a hollow tube to increase lateral stability.

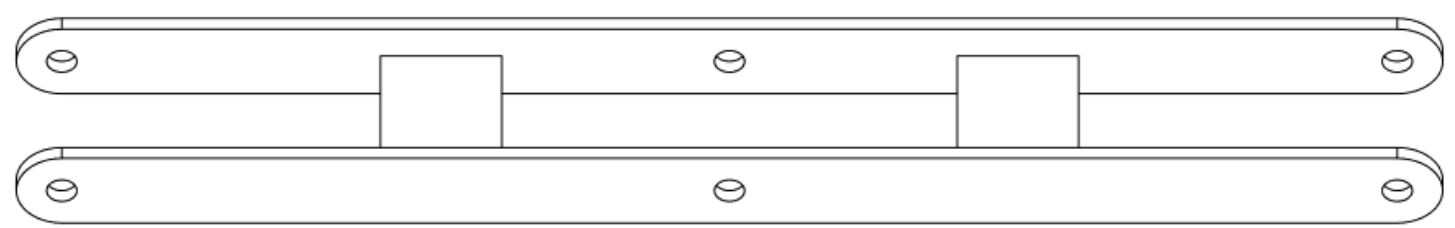

Figure 18: The outer scissor is wider than the inner scissor for them to be able stack/collapse.

The scissor mechanism will have press fit oil impregnated flange bushings to ensure a smooth rotating surface with the shoulder bolt. Figure 19 shows this with a gas spring attached in between the stages of the scissor. 


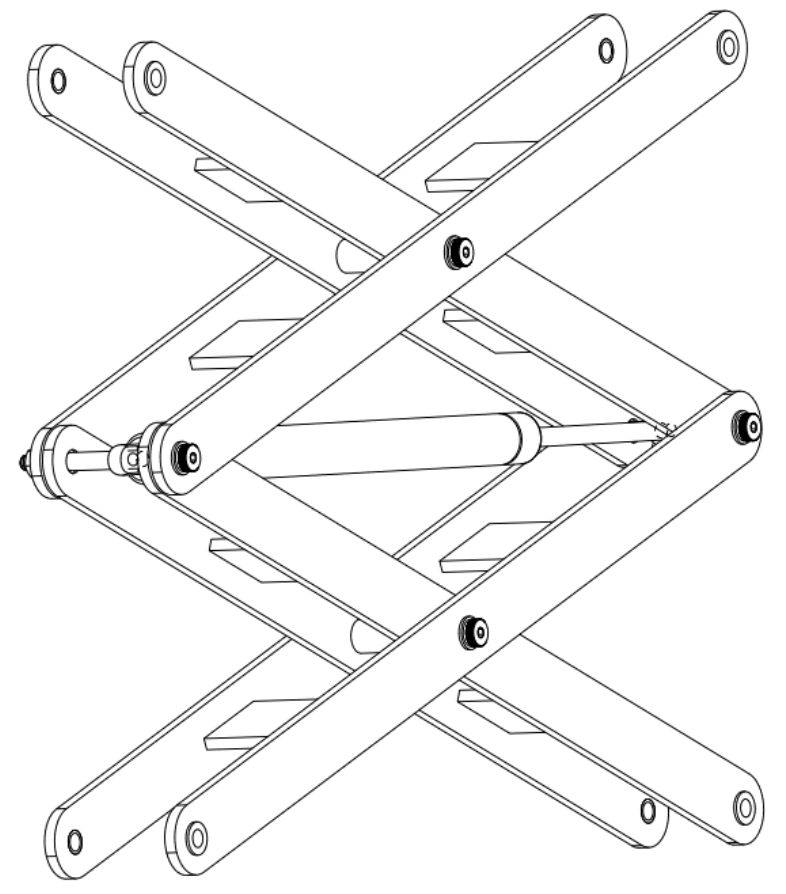

Figure 19: Scissor assembly showing gas spring attached between the stages of the scissor.

\subsection{Lower Frame Design}

A square extruded aluminum tube of width 2 inches was selected. A tube of wall thickness of 0.188 inches (6061-T6) was analyzed for the worst case loading condition (lifting a 250 pound patient from fully lowered to standing). Analysis showed that this tube could withstand the rated loads, while providing sufficient clearance for internal components. The slot in the lower frame was sized to allow full travel of the sliding block in the height range of the walker. The sliding block travels 6.1 inches $(10-45 \mathrm{deg})$. 


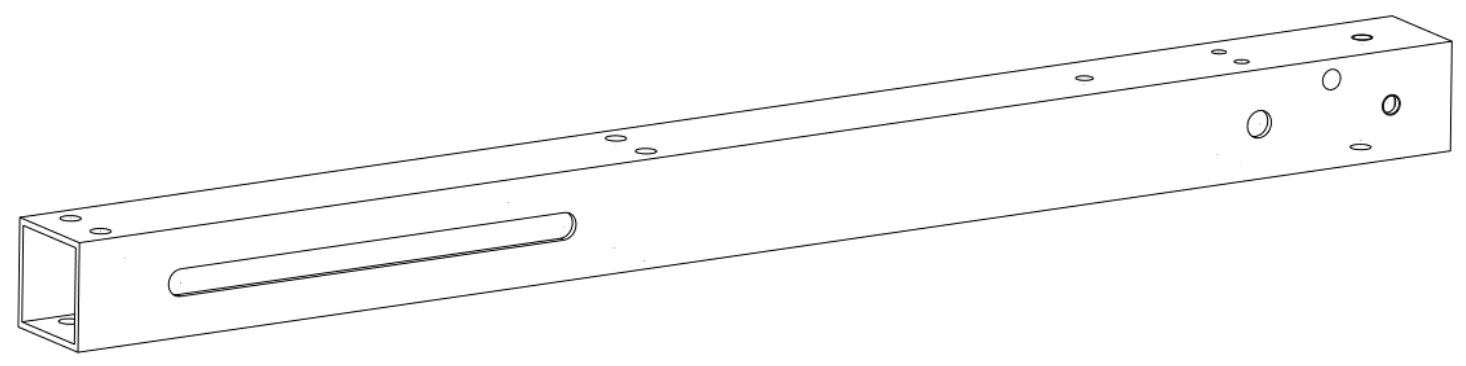

Figure 20: Lower tube showing all machined features.

\subsection{Motor Mount Design}

The motor mount is designed to partially enclose the motor providing a mounting bracket for the motor and a way to transfer load to the rear wheels. To reduce part weight holes were specified to reduce weight. The motor mount contains two threaded holes for mounting standard inline skate wheels with $8 \mathrm{~mm}$ shoulder bolts.

\subsection{Rear Wheels}

Standard inline skate wheels were chosen to ensure smooth rolling and these are readily available. The diameter of the wheel is $80 \mathrm{~mm}$ with 608 bearings. These have an $8 \mathrm{~mm}$ bore to allow easy mounting using a standard shoulder bolts. These wheels can carry a load of up to $200 \mathrm{lbs}$. each, which will be sufficient for the walker [10].

\subsection{Mid Frame Design}

The mid- frame was designed to transfer load as well enclose the upper sliding block. The mating receptacles for top frame have pull to release ball spring plungers that lock the top frame once it is inserted. The ball spring plunger will ensure that once the top frame is inserted it locks in to place and has to be physically released for the top frame to be lifted. 


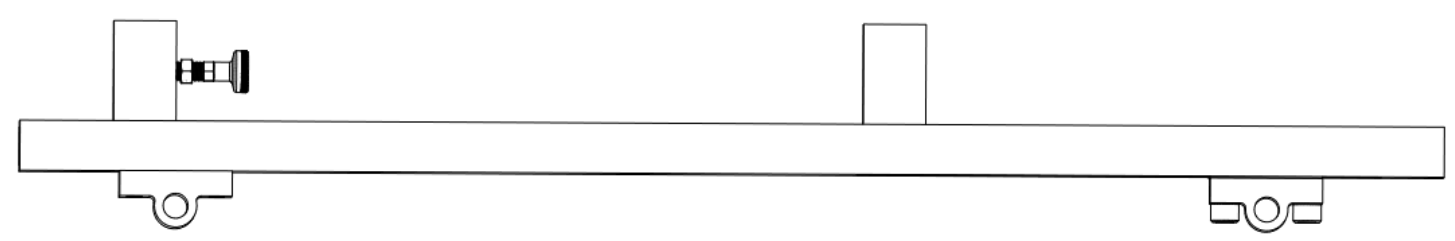

Figure 21: Overview of mid- frame, showing the fixed clevis on the left, and the sliding clevis on the right.

The sliding clevis consists of a Teflon block to which an aluminum clevis is secured using two bolts. Figure 22 shows this assembly with a Teflon gasket in between the sliding clevis and mid frame to allow a smooth sliding surface. To ensure the bolts don't loosen a locknuts with a nylon insert are specified.

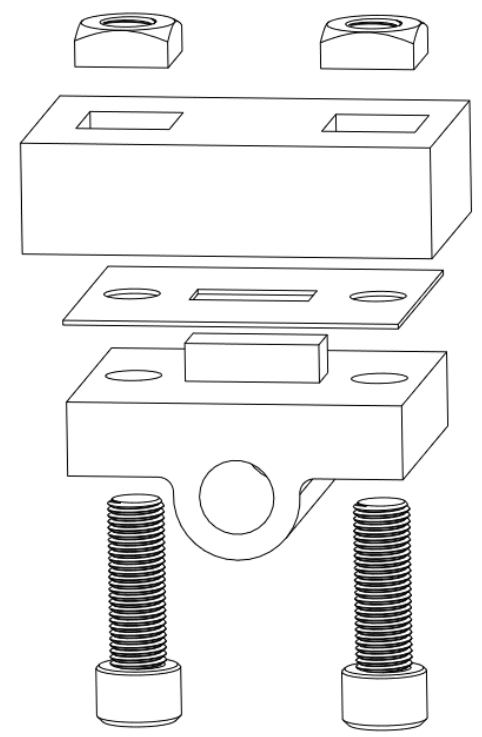

Figure 22: Exploded view of sliding clevis. From top to bottom: square lock nuts, Teflon sliding block, Teflon gasket, aluminum clevis, and hex head bolts. 


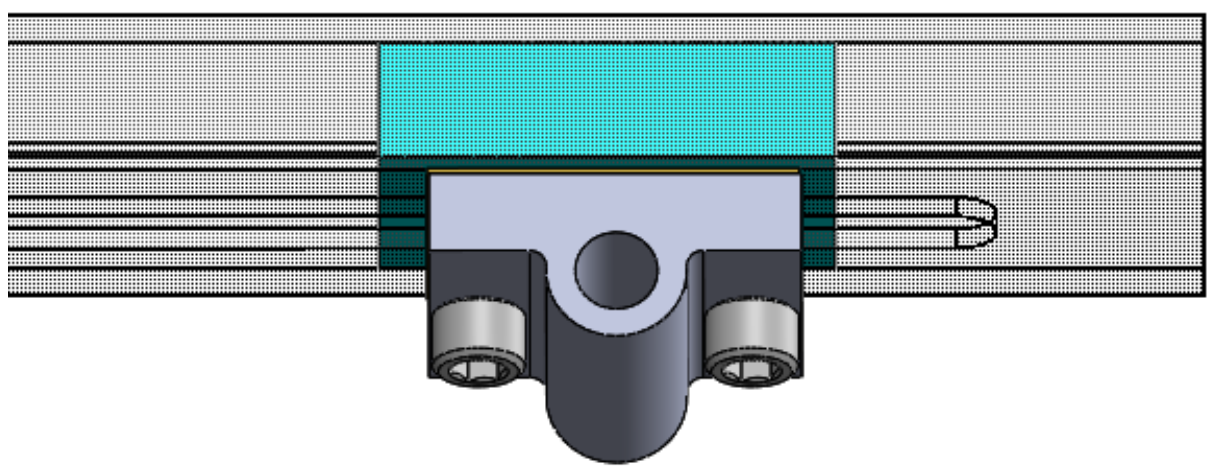

Figure 23: Screenshot of the clevis in the sliding tube, the sliding block (cyan) is made of Teflon.

The fixed clevis is designed to be bolted on to the mid frame as depicted in Figure 24.

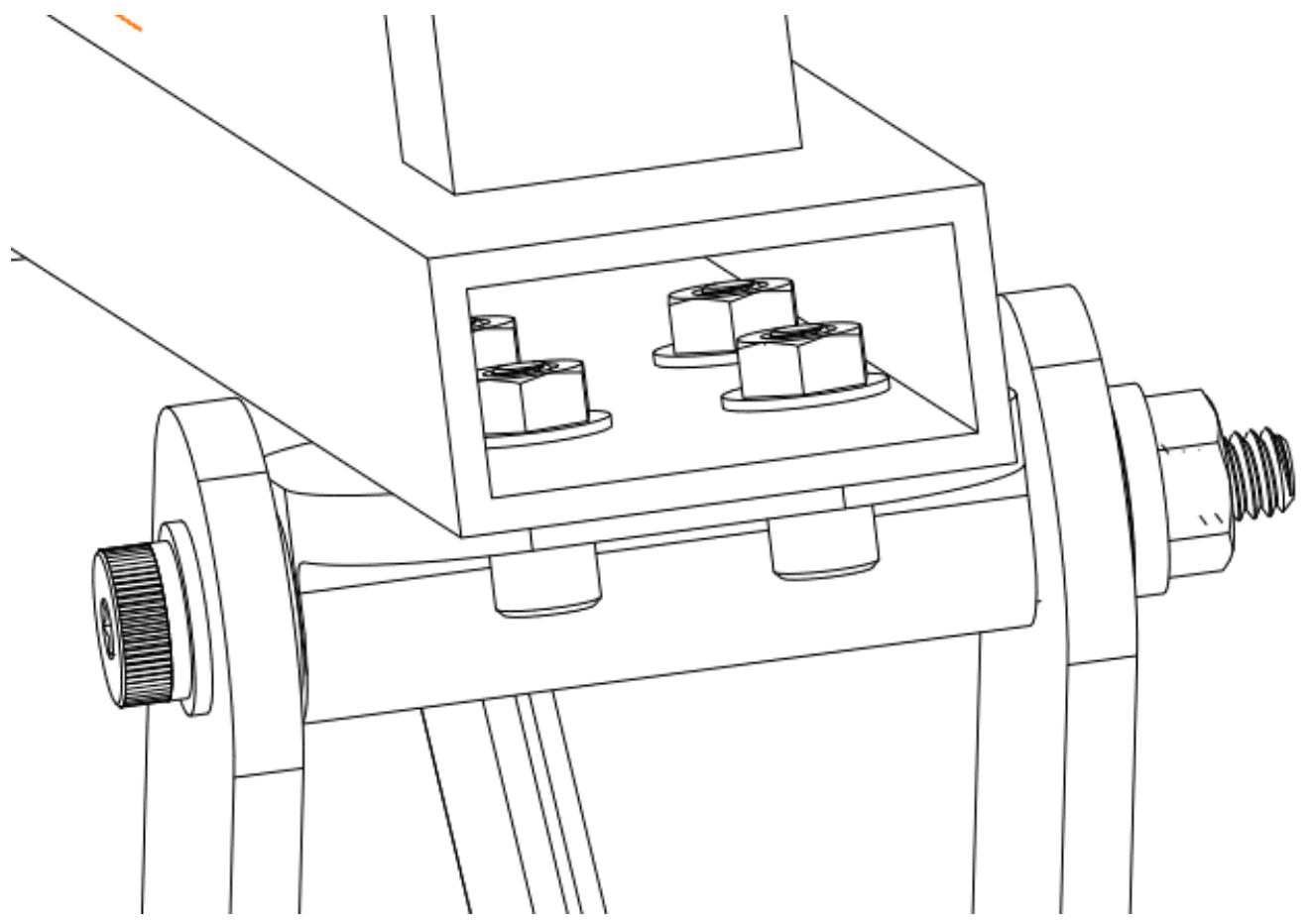

Figure 24: The rear fixed clevis will be bolted on to the mid frame. 


\subsection{Mid-cross Bar Design}

The left and right mid frames are designed to be connected using a mid-cross bar in the front. This connection is designed to be easily accessible and removable for the prototype. The midcross bar is designed to keep the scissors stable by preventing lateral movement relative to each other. Figure 25 shows this mid-cross bar, and it is shown secured using quick release pins in Figure 26.

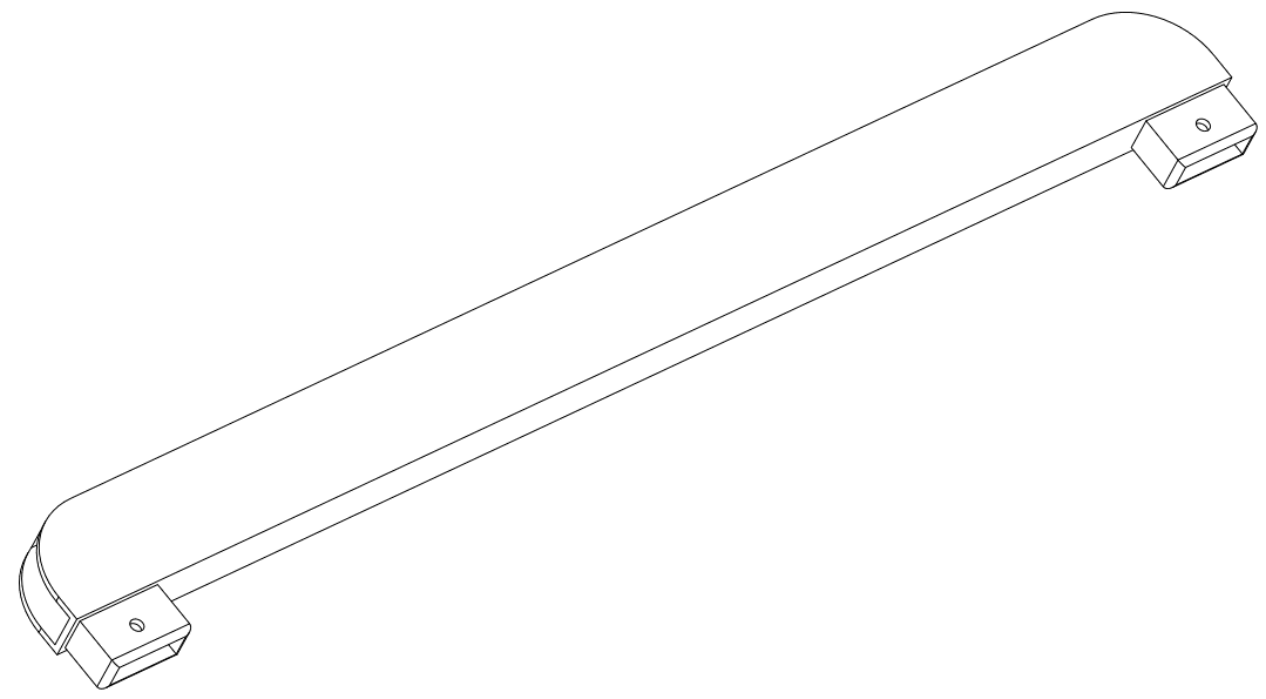

Figure 25: The mid bar is designed to be secured using a quick release pin or bolt to secure it in place for the prototype.

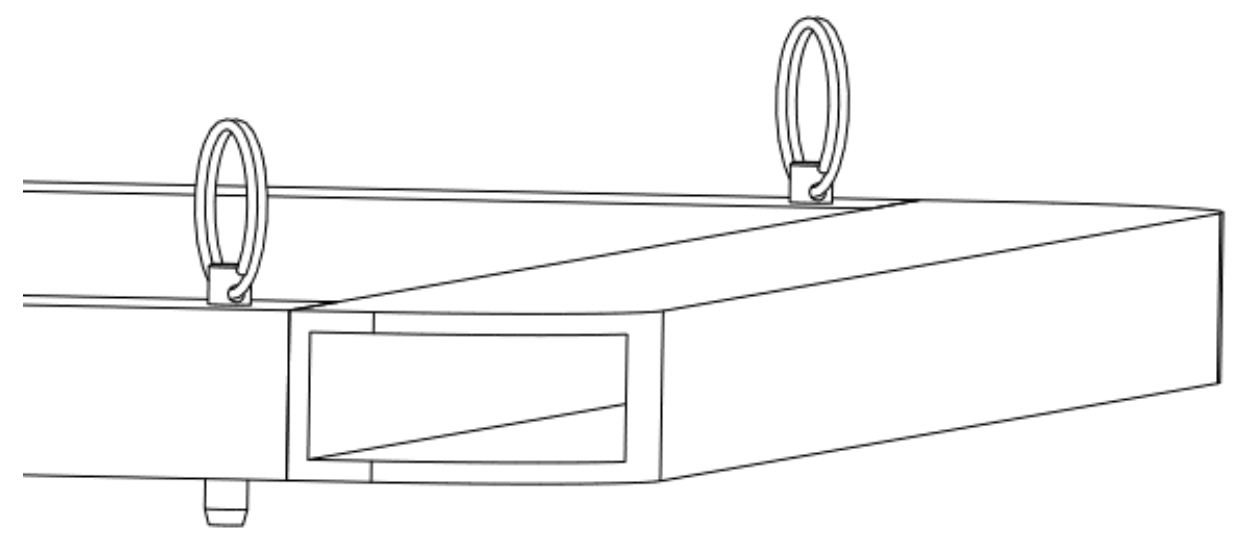

Figure 26: The middle bar is designed to be pinned or bolted in place. 


\subsection{Top Frame Design}

The top frame was designed to increase the height of the walker, and also provide harness attachment points. The u-shape from the benchmark prototype was maintained. The top surface of the upper frame will be covered with Velcro ${ }^{\mathrm{TM}}$ to provide an easy attachment point for padding. The operating buttons can be embedded in this frame or housed in a surface mountable enclosure. The legs of this upper frame will allow a magnet to be mounted in them. These will activate the proximity switches enabling detection that the upper frame is attached. A 9inch tall upper frame was selected as this covered the $95^{\text {th }}$ percentile of elderly adults allowing the top most part of the walker to be at elbow height when standing. Figure 27 shows the variation in height with scissor angle.

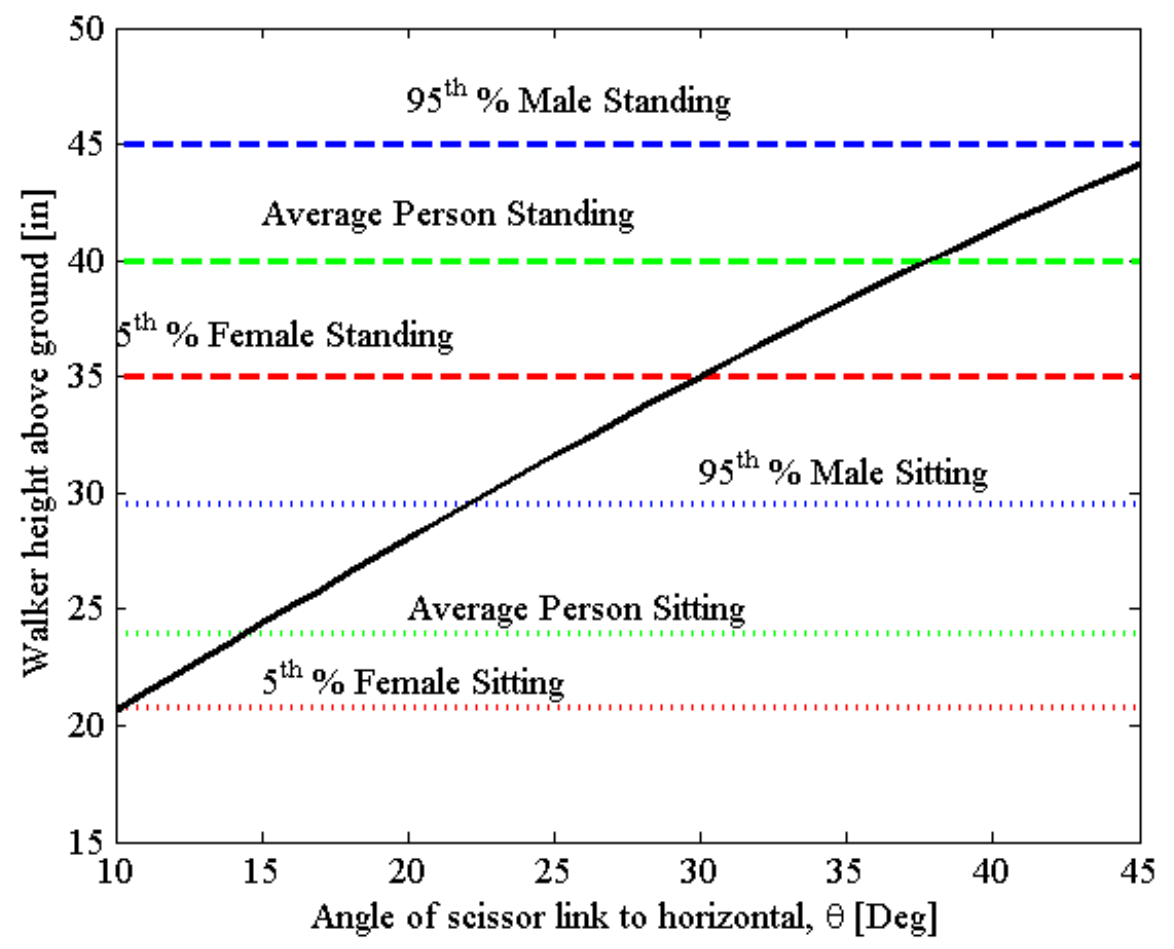

Figure 27: With a 9inch tall top frame, the walker will cater to the $95^{\text {th }}$ percentile of the elderly population. 


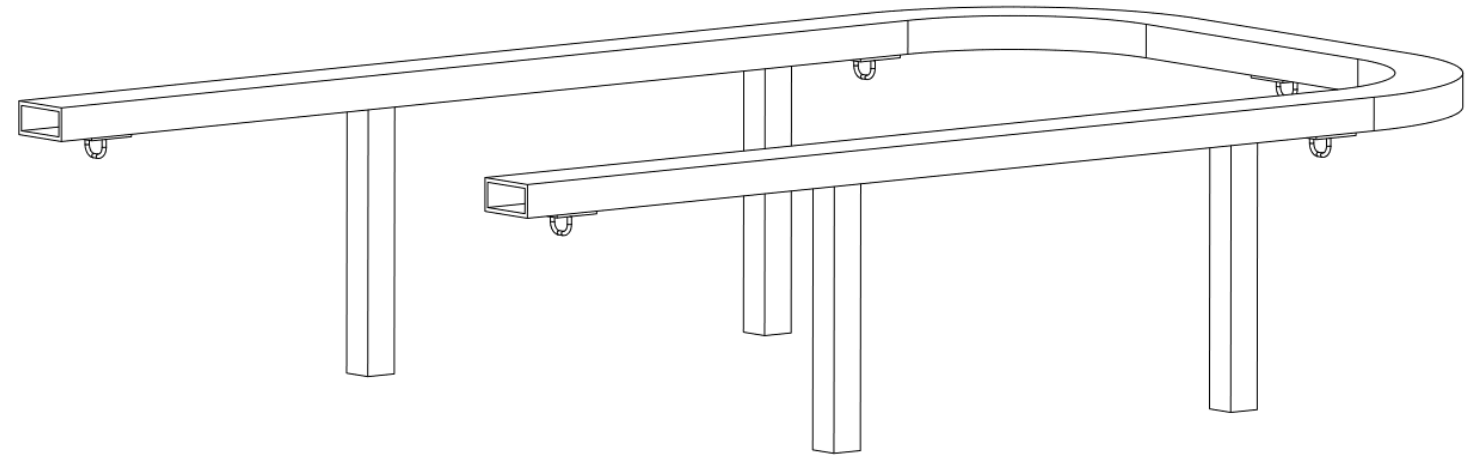

Figure 28: Schematic of the top frame showing the five harness attachment points.

\subsection{Lower-cross Bar Design}

The lower-cross bar was designed to attach to the left and right assemblies. This cross bar will utilized the stem of the lower wheel and have an additional hole where a bolt will secure it to the front bearing block. The lower cross bar also provides mount for the battery and controllers. The motor controller will be mounted to it enabling heat dissipation through conduction and convection. 


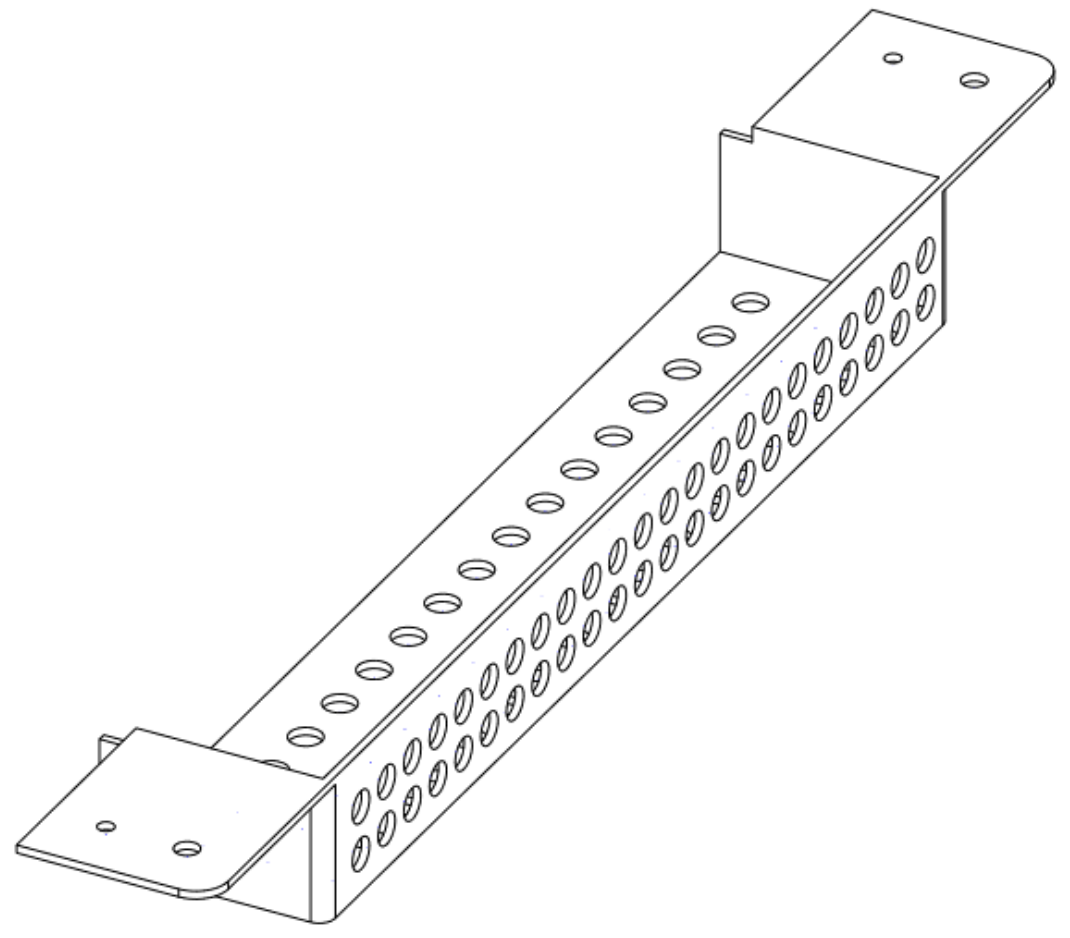

Figure 29: Lower-cross bar will be constructed out of aluminum with lots of holes drilled to lower mass.

\subsection{Motor Mount}

An aesthetic motor shroud is specified to be molded out of plastic and is not necessary for a prototype for evaluation purposes. It is designed to assist easy maneuverability of the walker through a doorway to ensure easy glide path for the walker against a door frame. It will also protect the motor by ensuring it is the primary contact in case the user accidentally rams in to objects. 


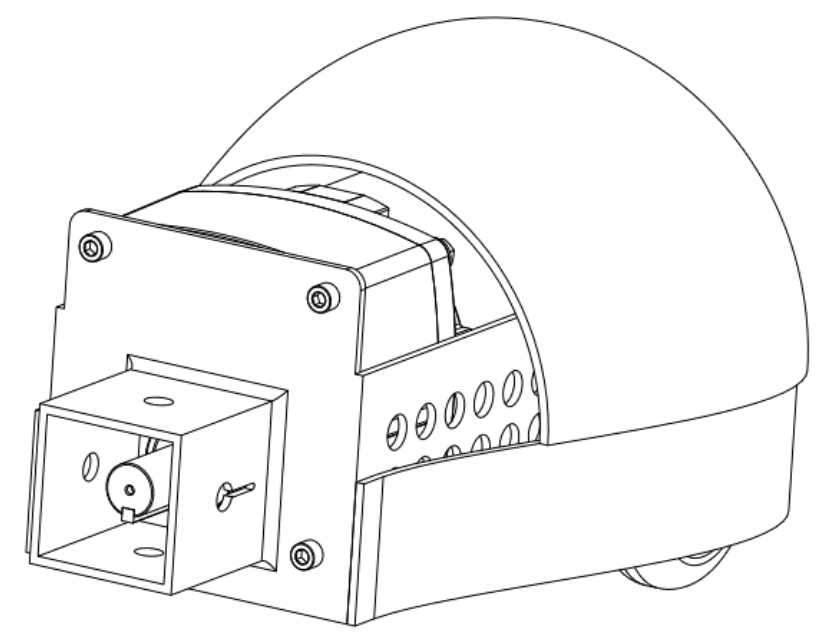

Figure 30: Motor assembly with aesthetic looking shroud. 


\section{Chapter 3: Electrical System Design}

\subsection{Micro Controller}

An Arduino Mega is specified as the micro controller to provide an easy prototyping platform.

The ideal way the components will connect to the Arduino can be through a custom shield or using a breadboard.

Table 4 lists the proposed components. A total of 42 digital I/O pins are required which makes the Arduino Mega the ideal choice as it has 54 I/O pins [11].

This shield will contain connections necessary quick connect color coded connections to the various devices and include; a switching DC-DC convertor (steps down $24 \mathrm{~V}$ to 9V), connection to a $9 \mathrm{~V}$ primary cell back up battery, SD/micro SD card holder and potentially a Bluetooth module.

Table 4: Pin requirement list for the proposed components.

\begin{tabular}{|c|c|}
\hline Component & Digital I/O Pins \\
\hline Motor Controller & 6 \\
\hline Hall Effect Encoder & 2 \\
\hline Limit Switches & 4 \\
\hline Power Switch & 1 \\
\hline Reset Switch & 1 \\
\hline Battery Voltage Sensor & 2 \\
\hline Raise/Lower Switches & 4 \\
\hline Remote Pendant Switch & 3 \\
\hline Top frame proximity & \\
switch & 4 \\
\hline Preset position switches & 4 \\
\hline Fully collapse switch & 2 \\
\hline Warning LED & 5 \\
\hline SD Card & 4 \\
\hline Buzzer & 2 \\
\hline Total & $\mathbf{4 2}$ \\
\hline
\end{tabular}


Table 5: Arduino mega specifications.

\begin{tabular}{|c|c|}
\hline Microcontroller & ATmega2560 \\
\hline Operating Voltage & $5 \mathrm{~V}$ \\
\hline Input Voltage (recommended) & $7-12 \mathrm{~V}$ \\
\hline Input Voltage (limit) & $6-20 \mathrm{~V}$ \\
\hline Digital I/O Pins & 54 (of which 15 provide PWM output) \\
\hline Analog Input Pins & 16 \\
\hline DC Current per I/O Pin & $20 \mathrm{~A}$ \\
\hline
\end{tabular}

\subsection{Hall Effect Rotary Encoder}

A Hall Effect gear tooth sensor incorporated in to the actuation system will be used to determine the height of the walker. As a high resolution is not necessary a simple plastic disk with two magnets spaced 180 degrees apart is sufficient. The sensor selected for this application is a stainless steel M12 gear tooth speed sensor from Littlefuse part no 55075. Figure 31 shows a typical setup of this Hall Effect gear tooth sensor, in this case the gear will be replaced with a plastic disk. The motor is rated to operate at $500 \mathrm{rpm}(9.17 \mathrm{~Hz})$. The frequency at which it will sense the magnets is well below the maximum switching speed of the sensor [12].

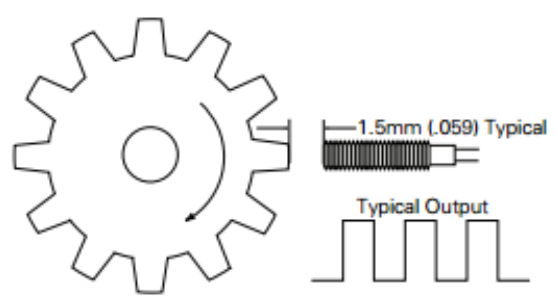

Figure 31: Proposed setup configuration and typical output signal for a gear tooth speed sensor.

The position of the gear tooth can be extraplolated from number of revolutions of the acme thread screw. Figure 32 shows the revolutions vs total height and a cubic fit which will be used for position determination. 


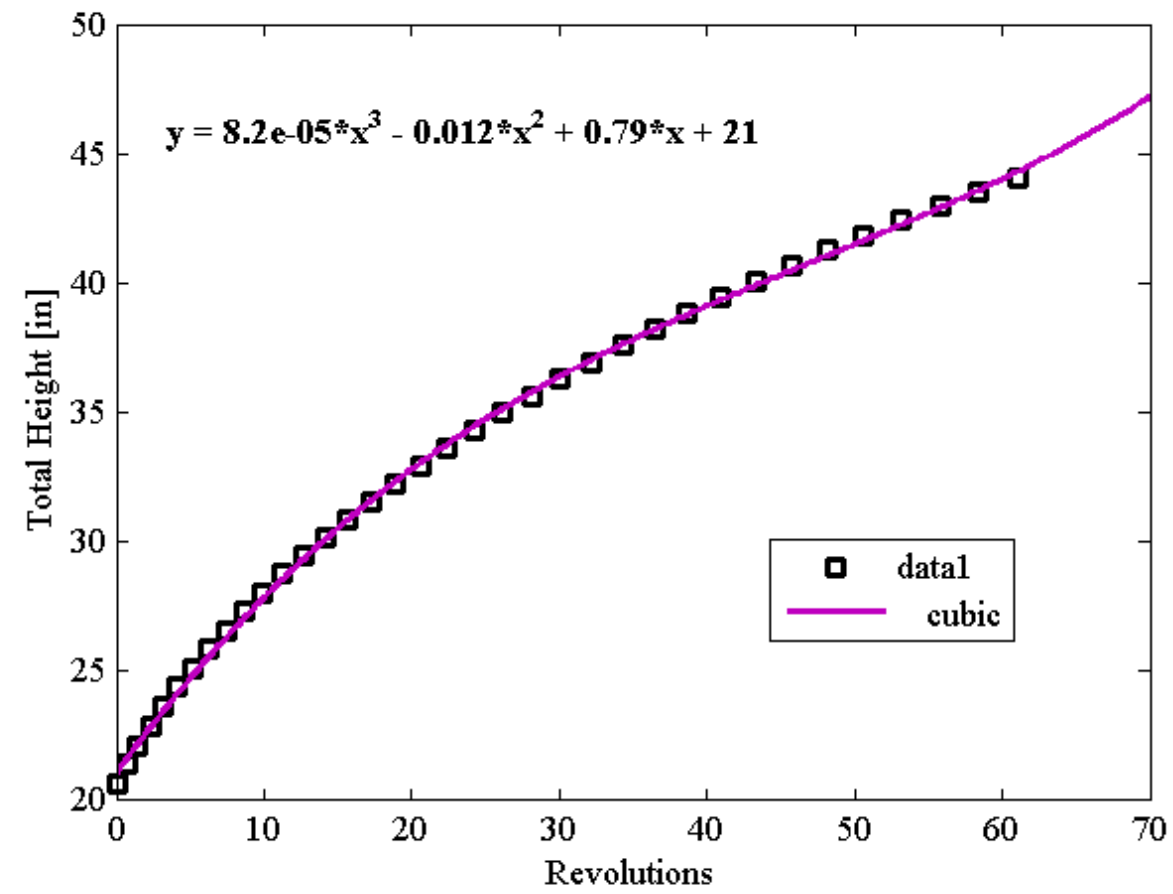

Figure 32: Revolutions vs total height of the walker. A cubic fit was used to extrapolate an equation that related rotations to the height of the walker.

\subsection{Momentary Switches and Remote Pendant}

Snap in momentary push button switches are selected to be mounted on to the top frame and the wiring routed internally through the frame. A pair of switches will be located on each side, requiring the user to press and hold both the lowering and raising switches to activate the motor. An additional illuminated pushbutton switch will be used as the power button. This provides a programmable safety in that it has to be pressed for several seconds to turn the device on or off preventing accidental depowering.

A detachable remote pendant will allow the walker to be raised or lowered by an assistant, when the pendant is being used it will lockout the raise and lower buttons on the top frame. 


\subsection{SD Card and Top Frame Proximity Switches}

A SD card enables data logging of the various parameter including: charge cycles, lift cycles, storage cycles, and general usability cycles. This will allow accelerometers and an optical positon sensors to be mounted to enable logging of motion and position that could be used for real time analytics for user feedback for a data driven design for a production version.

The top frame proximity switches will ensure that the top frame is securely attached and prevent the walker from operating in the case that it's not. The proximity switches will complete circuits that the Arduino will detect as a high digital input (5V). For a production version embedded spring contacts can be used for an easy user interface for attaching the top frame in a one step process. Figure 33 shows an example of these contacts.

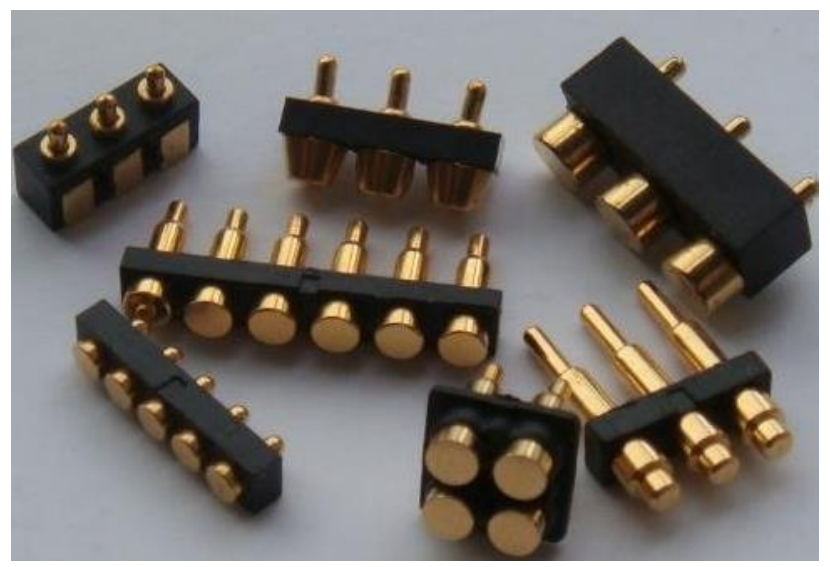

Figure 33: Example of proposed spring pin contacts to be embedded in the top frame for electrical connections and proximity sensing.

\subsection{Motor Controller}

An off the shelf motor controller is selected to control the two DC gear motors. A Sabretooth dual 25A motor controller is selected. Rated for driving two DC motors, this controller is ideal as it 
had built in safety (thermal and overcurrent protection) and can detect low battery voltages to prevent cell damage due to over-discharge of lithium battery packs if a custom battery pack is used.

Table 6: Motor controller specifications.

\begin{tabular}{|c|c|}
\hline Parameter & Value \\
\hline Rated Voltage [V] & $6-30$ \\
\hline Continuous Current [A] & 25 \\
\hline Peak Current per channel [A] & 50 \\
\hline Input Modes & Analog, R/C, serial \\
\hline
\end{tabular}




\section{Chapter 4: Analytical Calculations}

\subsection{Actuation Force}

Using statics the horizontal actuation force to lift a load $\mathrm{W}$ was calculated for a 2 stage scissor with 2 parallel actuators (left and right). This was verified against a document from the US Marine Corps. [9]

$$
F_{\text {actuator }}=2 W \cot \theta
$$

\subsection{Stress in Lower Tube}

Stresses in the lower tube were determined using analytical expressions for beams in tension, flexure and torsion. The maximum loading case was used in the calculation, raising a patient (250 lbs.) from fully collapsed (10 degrees). At this positon an axial load of $1500 \mathrm{lbs}$ is experienced by the tube, as the walker is raised the angle increases and the load decreases. The maximum flexure

occurs when the walker is fully raised, at 45 degrees, however the axial load is $300 \mathrm{lbs}$. This worse case was used a preliminary estimate and stress concentrations were not factored in.

The shear stress due to an applied motor torque was calculated for two open c-channels. This calculated the shear stress in the section where the slot it located as it is the section that experiences the most torque. For a motor torque of 43 in-lbs., the max shear stress was $1.27 \mathrm{ksi}$ 


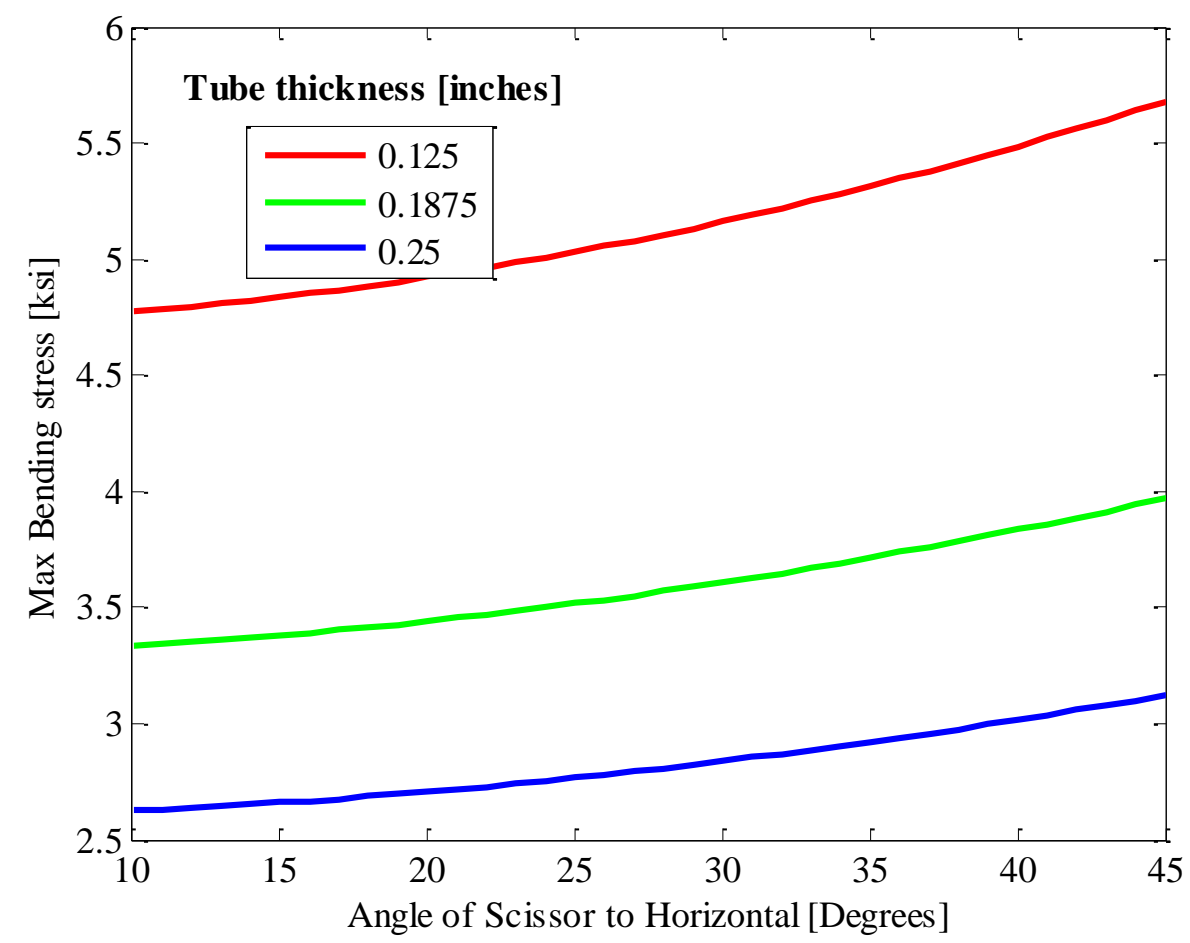

Figure 34: The maximum flexure occurs at the fully upright position, this max bending stress is $5.7 \mathrm{ksi}$ for square tube of thickness 0.125 inches with a side of 2 inches. The yield of Al $6061 \mathrm{~T} 6$ is $40 \mathrm{ksi}$.

The top section of the tube is in compression and the bottom in tension. A max von Mises stress of $8 \mathrm{ksi}$ was seen with a patient load of $250 \mathrm{lbs}$. at 10 degrees. Figure 34 shows stress due to flexure. A maximum axial stress of $3 \mathrm{ksi}$ is experienced by the lower tube and occurs at 10 degrees as seen in Figure 35.

Table 7: Summary of the analytical calculations for the stresses. The yield of Al 6061-T6 is $40 \mathrm{ksi}$ and that of stainless 304 is $31.2 \mathrm{ksi}$.

\begin{tabular}{|c|c|c|c|}
\hline Tube thickness [in] & 0.125 & 0.1875 & 0.25 \\
\hline Max Bending Stress [ksi] & 5.7 & 4 & 3.2 \\
\hline Max Axial Stress [ksi] & 2.92 & 1.98 & 1.51 \\
\hline Max Shear Stress [ksi] & 1.27 & 0.58 & 0.34 \\
\hline Max Von Mises Stress [ksi] & 8 & 5.4 & 4.2 \\
\hline
\end{tabular}




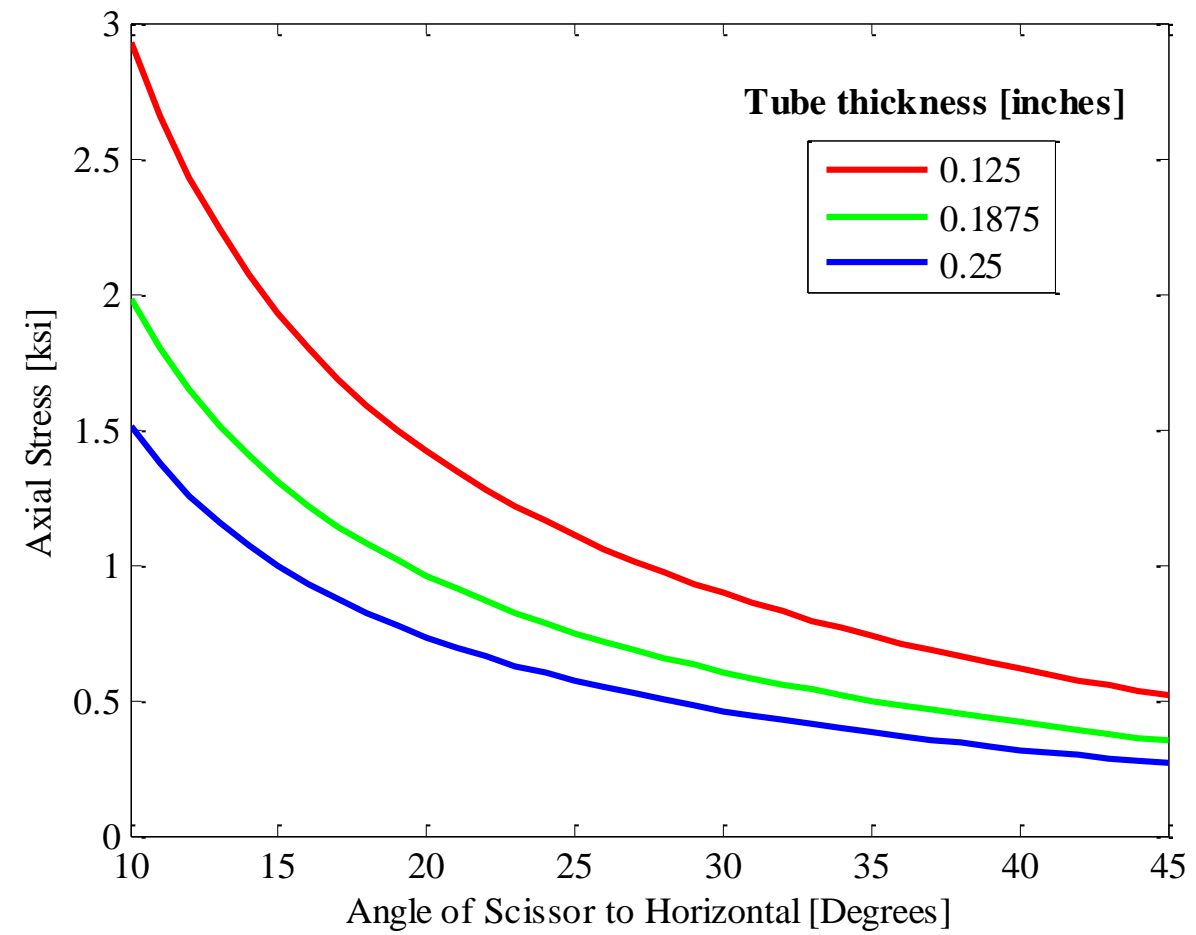

Figure 35: Maximum axial stress occurs at the fully lowered position when lifting a person. The maximum axial stress for a 0.125 inch Aluminum tube is $2.97 \mathrm{ksi}$. 


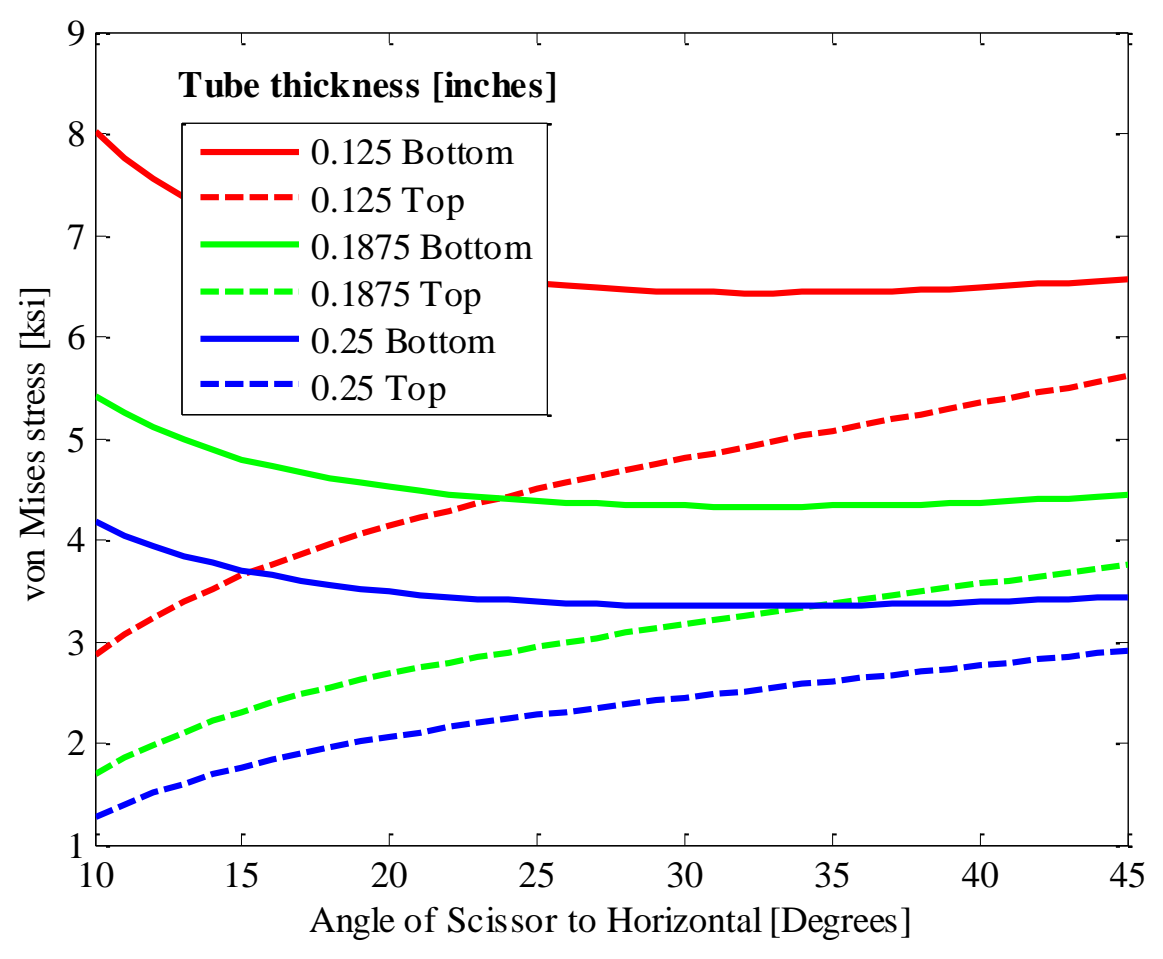

Figure 36: Analytical calculation of von Mises stress.

\subsection{Acme Thread Power Screw}

\subsubsection{Stress in Thread Nut Combination}

The largest stress in the thread nut combination was calculated for power screw supporting the load in the event of a gas spring failure $(125 \mathrm{lbs} .+25 \mathrm{lbs})$. This occurred at fully collapsed (10 degrees). The von Mises stress was calculated at the root of the engaged thread. An experimental correlation revealed that the first engaged thread carries only $38 \%$ of the load [13]. 


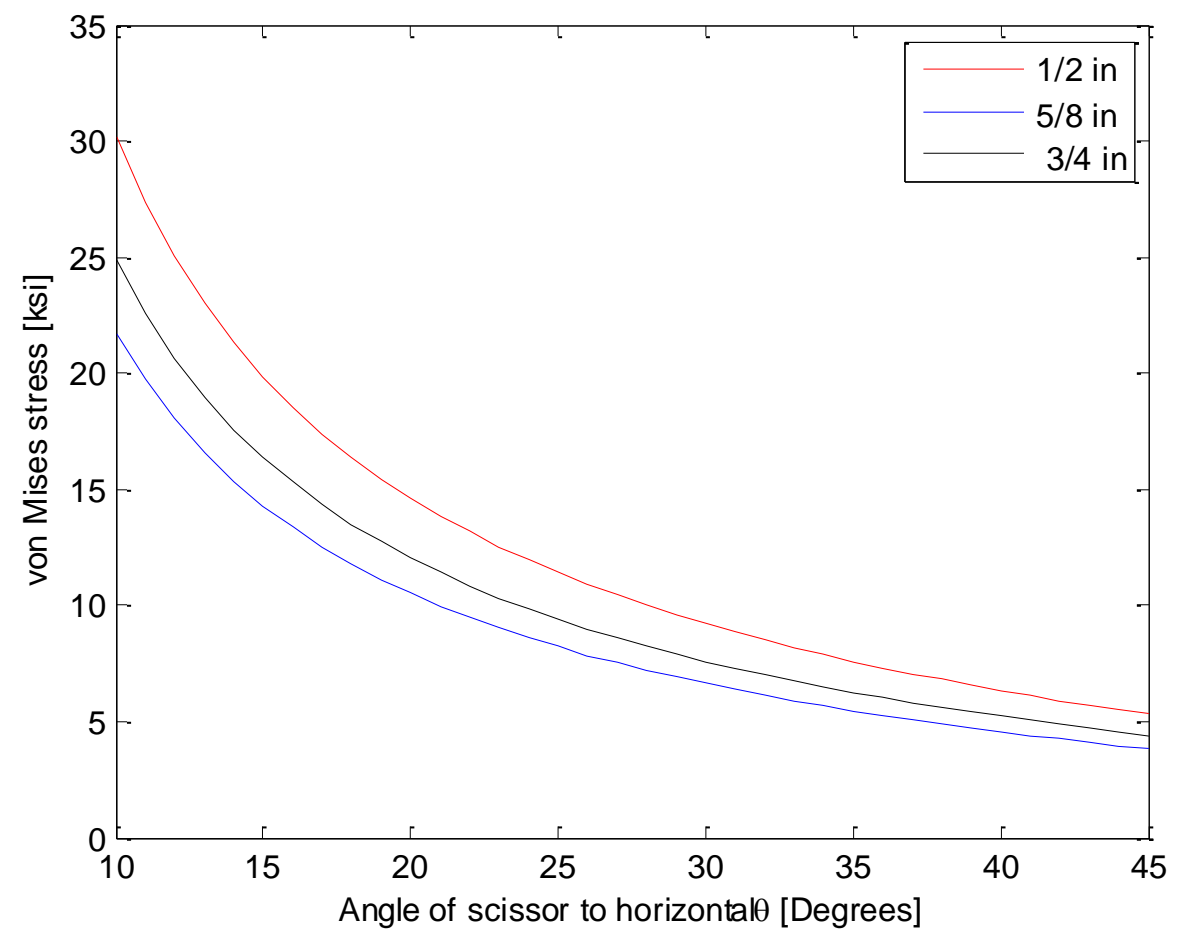

Figure 37: The von Mises stress of three power screws with half the patient load applied. The stresses for all the screws are below yield for steel (36 ksi).

\subsubsection{Buckling of Power Screw}

A buckling load calculation showed that axial compressive load on the power screw was below the critical load for a 0.5 in diameter power screw. The effective compressive length of the screw changes with load, so this factored in to the calculation and the screw was modeled as a column with pivoted ends below:

$$
\begin{gathered}
P_{c r}=\frac{C \pi^{2} E I}{l^{2}} \\
C=1
\end{gathered}
$$




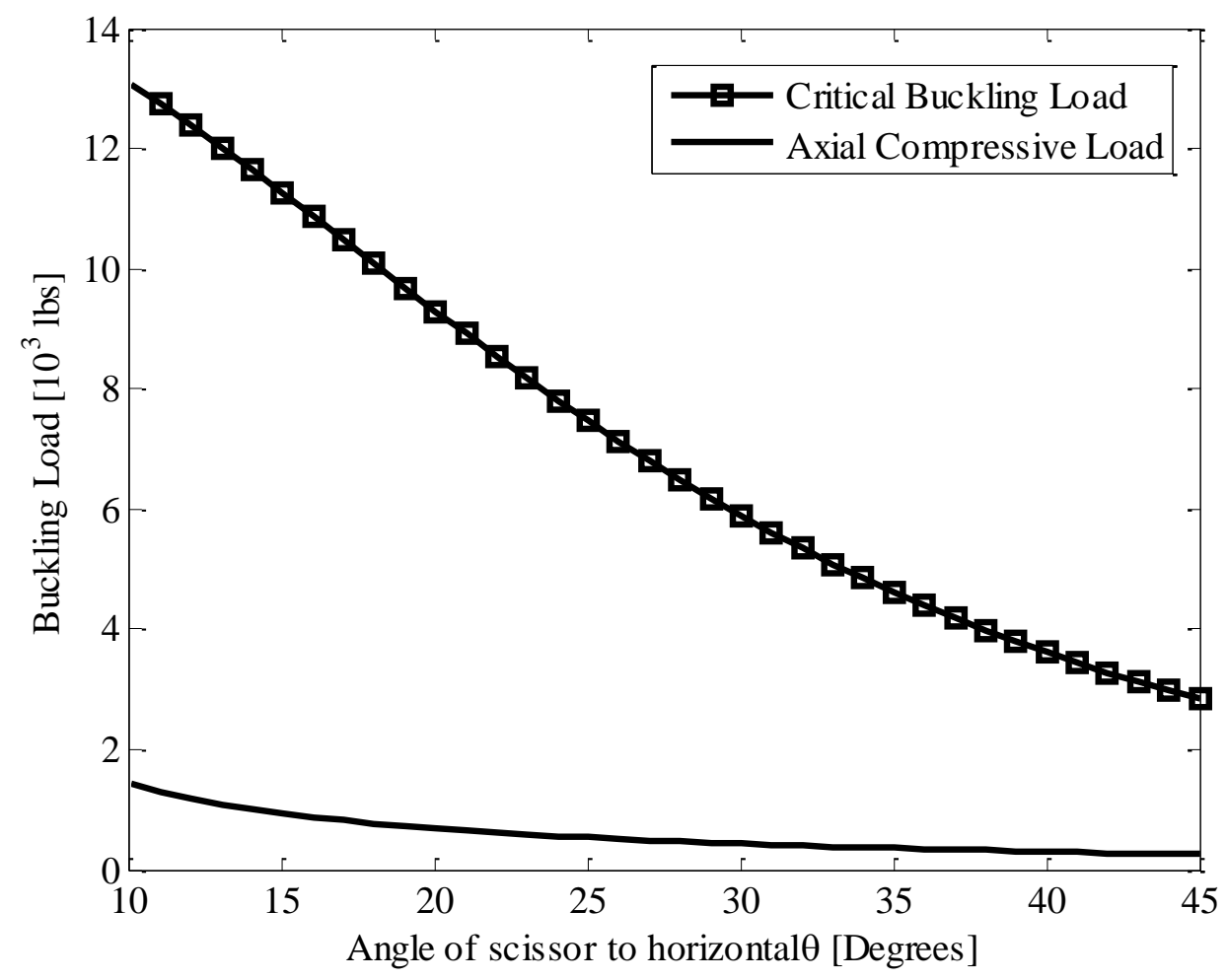

Figure 38: The compressive load on the power screw is below the critical buckling load for a 0.5 inch diameter power screw.

\subsubsection{Self-Locking Feature of Acme Thread Screw}

The acme thread screw is self-locking as the following equality is satisfied [14], since the LHS term in E.q. 4.3 ranges from 0.17-0.27in for a steel nut on a steel shaft lubricated with machine oil for an acme thread screw of major diameter 0.5 inches. The parameters are summarized in Table 8.

$$
\pi f d_{m}>l
$$


Table 8: Parameters used to determine the power screw is self locking.

\begin{tabular}{|c|c|}
\hline Parameter & Value \\
\hline Major diameter, $\boldsymbol{d}$ [in] & 0.5 \\
\hline Pitch, $\boldsymbol{p}$ [in] & 0.1 \\
\hline Mean diameter, $\boldsymbol{d}_{\boldsymbol{m}}$ [in] & 0.45 \\
\hline Thread pair coefficient of friction, $\boldsymbol{f}$ & $0.11-0.17$ \\
\hline Lead, $\boldsymbol{l}$ [in] & 0.1 \\
\hline $\boldsymbol{\pi} \boldsymbol{f} \boldsymbol{d}_{\boldsymbol{m}}$ [in] & $0.155-0.24$ \\
\hline
\end{tabular}

\subsection{Bolt/hole Strength Calculations}

For the primary bolted connections, bolt shear, bearing and shear tear-out stresses were calculated. The maximum shear stress occurs in the bolted connection of the scissor links. For this, the worst caseloads were used, $(250 \mathrm{lbs}$. patient lifted from 10 degrees with a failed gas spring). These loads were obtained from an ADAMS simulation explained in Chapter 5.

Table 9: Bolted connection stresses.

\begin{tabular}{|c|c|c|c|c|}
\hline Part & $\begin{array}{c}\text { Sliding } \\
\text { Block/Yoke }\end{array}$ & Yoke/ Scissor & $\begin{array}{c}\text { Scissor } \\
\text { Link }\end{array}$ & $\begin{array}{c}\text { Bearing } \\
\text { Block / } \\
\text { Lower } \\
\text { Tube }\end{array}$ \\
\hline Max Load [lbs.] & 1500 & 1500 & 2500 & 1500 \\
\hline Bolt Diameter [in[ & 0.3125 & 0.375 & 0.375 & 0.25 \\
\hline Type & Bolt & Shoulder & Shoulder & Bolt \\
\hline Hole Diameter [in] & 0.3125 & 0.375 & 0.5 & 0.25 \\
\hline Number & 4 & 2 & 1 & 4 \\
\hline Shear Type & Single & Single & Double & Single \\
\hline Thickness [in] & 0.25 & 0.25 & 0.25 & 0.125 \\
\hline Distance from Edge [in] & 0.43 & 0.2 & 0.5 & 0.5 \\
\hline Shear Stress [ksi] & 4.9 & 6.9 & 11.3 & 7.7 \\
\hline Bearing Stress [ksi] & 4.8 & 8.1 & 10 & 12.0 \\
\hline Shear tare out [ksi] & 1.8 & 7.6 & 5 & 3.0 \\
\hline
\end{tabular}

The shoulder bolts selected had a larger diameter than required to reduce the pressure on the flanged sleeve bearings especially in joint 3 . 


\subsection{Motor Requirements}

Using the force requirements from Figure 10, the torque needed from a motor was calculated for a 0.5 in diameter acme thread power screw with a 0.1 in pitch. Table 10 lists the coefficients of friction for the moving parts used in this calculation Eq. 4.4

Table 10: Properties used in the calculations and simulation.

\begin{tabular}{|c|c|}
\hline Item & Coefficient of Friction \\
\hline Nut-Thread pair (f) & 0.17 \\
\hline Teflon on Aluminum & 0.18 \\
\hline Trust bearing $\left(\mathrm{f}_{\mathrm{c}}\right)$ & 0.008 \\
\hline Acme thread screw on bronze sleeve bearing & $0.08-0.14$ \\
\hline Thread angle $(2 \alpha)$ & $30^{\circ}$ \\
\hline
\end{tabular}

$$
T_{R}=\frac{F d_{m}}{2}\left(\frac{l+\pi f d_{m} \sec (\alpha)}{\pi d_{m}-f l \sec (\alpha)}\right)+\frac{F f_{c} d_{c}}{2}
$$

Eq. 4.4

The minimum torque required to raise a fully loaded walker from collapsed to standing was 80 inlbs. as shown in Figure 39. For a horizontal actuator placement, the torque decreases as height increases. This set the initial torque requirement for the motor.

Dynamics was used to relate the actuator linear velocity to the lift velocity. The lift velocity was proportional to the linear actuators velocity hence, the time the sliding block moves through the slot was used to estimate lift time. The slot horizontal travel of the scissor was a maximum of 6 inches for the scissors from collapsed to fully extend. To achieve a lift and lower in about 8 seconds, the motor speed was set at 500 RPM. Table 11 lists the lift time for motor speeds ranging from 100 to $500 \mathrm{RPM}$. 
Table 11: Lift times for various motor speeds for a 0.1 in pitch power screw.

\begin{tabular}{|c|c|c|}
\hline Motor Speed [RPM] & Sliding Block Velocity [in/s] & Lift Time [s] \\
\hline 100 & 0.167 & 36 \\
\hline 200 & 0.333 & 18 \\
\hline 300 & 0.500 & 12 \\
\hline 400 & 0.667 & 9 \\
\hline 500 & 0.833 & 7.2 \\
\hline
\end{tabular}

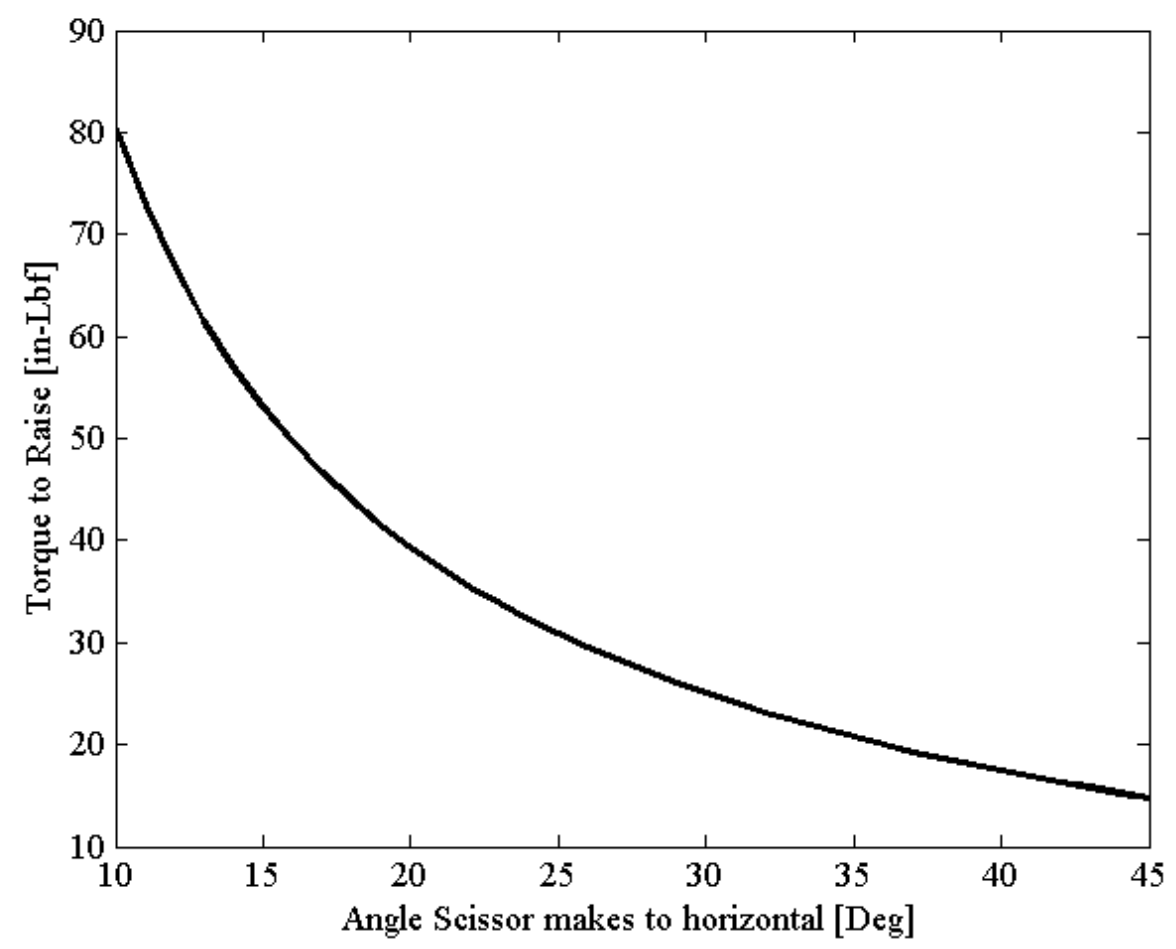

Figure 39: Torque requirements for raising a 250 pound patient.

To reduce the torque requirement of the motor, a hybrid actuation system was developed which consisted of a gas spring assisted linear actuator. An optimization script was created in Matlab to determine the best gas spring motor combination. Figure 40 and Figure 41 show the torque requirements for a 200 and $250 \mathrm{lb}$ patients respectively. 
Three positions were chosen as the initial lifting height (height of walker above ground) which were related to scissor angle; 20.6, 22.5 and 24.4 inches. The optimization was for raising a fully loaded walker and lowering the empty walker. The optimized results are summarized in Table 12. A notable observation is that the same motor and gas spring combination could lift a 200lbs person from 22.5 inches or a $250 \mathrm{lbs}$. person from 24.4 inches. The motor torque requirement was set at 39.1 in-lbs. and gas spring of $370 \mathrm{lbs}$. was chosen. This would fit the average person whose ground to elbow height is 24.9 inches with a 20.8 to $29 \mathrm{inch}$ span, $\left(5^{\text {th }}\right.$ percentile female and $95^{\text {th }}$ percentile male) [15] .

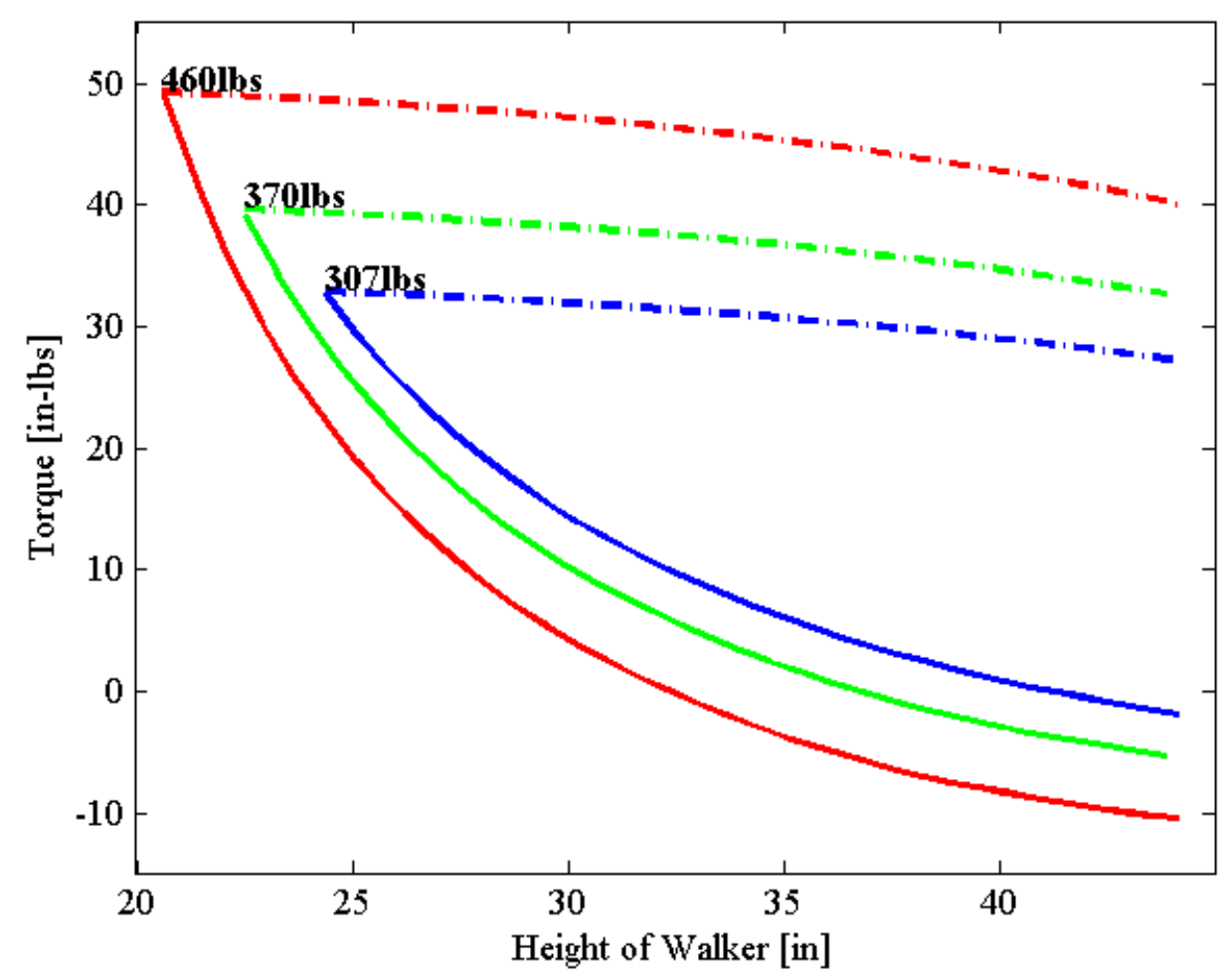

Figure 40: Optimized motor torque requirements for $200 \mathrm{lbs}$ patient from lifted from 20.6, 22.5 and 24.4 inches. The solidlines represent lifting, and dashed represent lowering. 
Table 12: Summary of gas spring and motor torque requirements from optimization.

\begin{tabular}{|c|c|c|c|c|c|}
\hline \multicolumn{2}{|c|}{} & \multicolumn{2}{c|}{ 200 lbs. patient } & \multicolumn{2}{c|}{ 250 lbs. patient } \\
\hline $\begin{array}{c}\text { Initial Lift } \\
\text { Height [in] }\end{array}$ & $\begin{array}{c}\text { Angle, } \boldsymbol{\Theta} \\
\text { [Deg] }\end{array}$ & $\begin{array}{c}\text { Gas Spring } \\
\text { Force [lbs.] }\end{array}$ & $\begin{array}{c}\text { Motor Torque } \\
\text { [in-lbs.] }\end{array}$ & $\begin{array}{c}\text { Gas Spring } \\
\text { Force [lbs.] }\end{array}$ & $\begin{array}{c}\text { Motor Torque } \\
\text { [in-lbs.] }\end{array}$ \\
\hline $\mathbf{2 0 . 6}$ & $\mathbf{1 0}$ & 460 & 49.2 & 550 & 58.9 \\
\hline $\mathbf{2 2 . 5}$ & $\mathbf{1 2 . 5}$ & 370 & 39.1 & 442 & 47.4 \\
\hline $\mathbf{2 4 . 4}$ & $\mathbf{1 5}$ & 307 & 32.1 & 370 & 39.6 \\
\hline
\end{tabular}

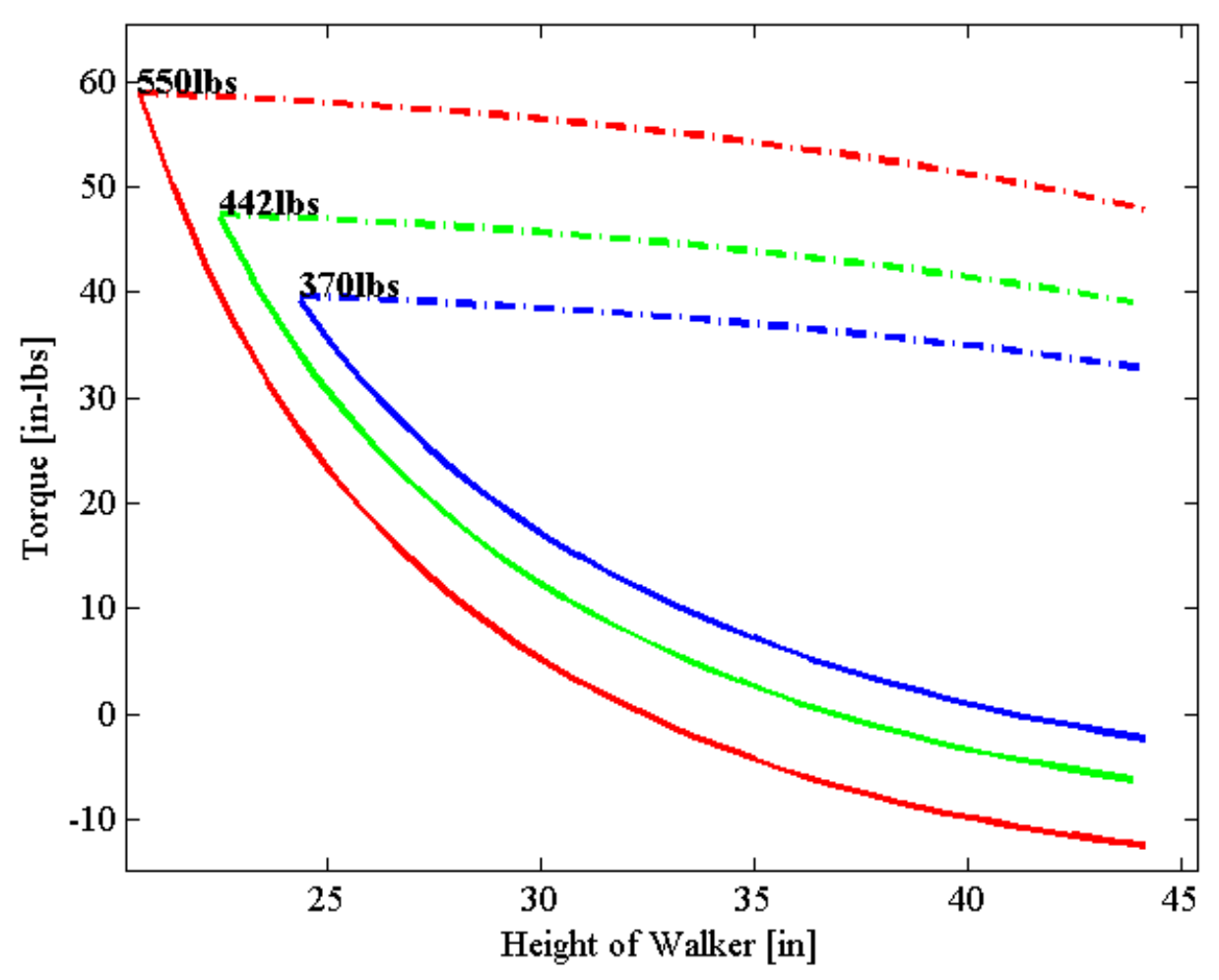

Figure 41: Optimized motor torque requirements for $250 \mathrm{lbs}$ patient from lifted from 20.6, 22.5 and 24.4 inches. Solidlines represent lifting, and dashed represent lowering.

\subsection{Motor Selection}

The cheapest off the shelf DC gear motors available were from Bodine Electric Company. Their inventory ranged from a vast listing of inline brushed and brushless DC gear motors that operated on $12 / 24$ Volts. This inventory was plotted as a scatter plot, Figure 42 , for speed vs torque. The motor picked for this application is a 24 volt DC gear motor that was rated to produce 43 in-lbs. 
at 500RPM, model no 5060. Table 13 lists these parameters. This motor did not have an accessory shaft to reduce the length.

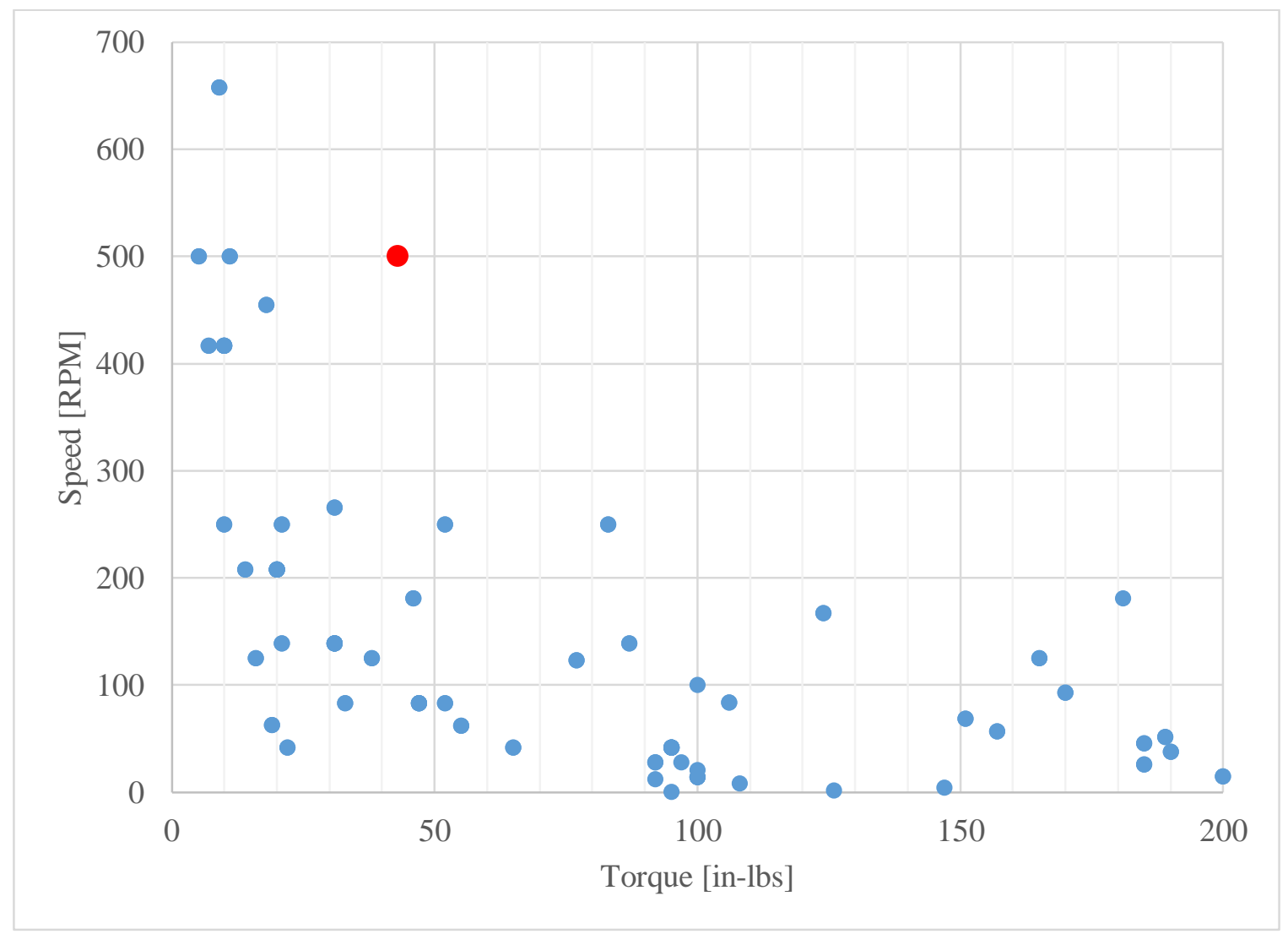

Figure 42: Scatter plot of DC gear motors available from Bodine Electric, the red point shows the selected motor.

Table 13: Rated specifications of selected DC gear motor from Bodine Electric.

\begin{tabular}{|c|c|}
\hline Parameter & Value \\
\hline Rated Torque [in-lbs.] & 43 \\
\hline Rated Speed [rpm] & 500 \\
\hline Rated Current [A] & 14 \\
\hline Rated Voltage [V] & 24 \\
\hline Peak Torque [in-lbs.] & 72 \\
\hline Gear Ratio & 5 \\
\hline Radial load [lbs.] & 60 \\
\hline
\end{tabular}

A gas spring was specified to produce a nominal contraction force of $370 \mathrm{lbs}$., with a stroke length of 7 inches and a contracted length of 15 inches. The end fittings were chosen as M8 
eyelets with a hole of diameter 0.375 inches to fit the shoulder bolts. These are designed to be permanently secured on to the threaded rod ends with a Loctite threadlocker Red 271. Table 14 lists these requirements.

Table 14: Gas spring specification.

\begin{tabular}{|c|c|}
\hline Property & Value \\
\hline Type & Contraction \\
\hline Force at P1 (Nominal Force) & $370 \mathrm{lbs}$. \\
\hline Extended Length (eyelet to eyelet) & 22 inches \\
\hline Contracted Length (eyelet to eyelet) & 15 inches \\
\hline Stroke Length & 7 inches \\
\hline End Fittings & M8 Eyelets, \\
\hline Eyelet Hole Diameter & 0.375 inches \\
\hline Thread lock Adhesive & LOCTITE® THREADLOCKER RED 271 \\
\hline
\end{tabular}

\subsection{Battery Selection}

The selected DC gear motor was rated to operate at 24 Volts, this set the battery voltage requirement. Each motor is rated to draw a current of 14Amps, totaling 28 Amps at rated load. The power used by these motors at the rated current and voltage is 672 Watts during the lifting and lowering process. For a lift time of 7 seconds, the total energy required is $9.4 \mathrm{~kJ}$ per lift cycle (defined as a lifting a full load and lowering and unloaded walker). A battery with a capacity of $10 \mathrm{Ah}$, will be sufficient for 92 lift cycles, however this assumes a full discharge which will reduce battery life. 
Table 15: Lift cycles for various battery capacities.

\begin{tabular}{|c|c|c|}
\hline Battery Capacity [Ah] & Energy Stored (kJ) & Raise and lower Cycles \\
\hline 5 & 432 & 45 \\
\hline 10 & 864 & 92 \\
\hline 15 & 1296 & 137 \\
\hline 20 & 1728 & 183 \\
\hline 30 & 2592 & 275 \\
\hline 35 & 3024 & 321 \\
\hline
\end{tabular}

An online search revealed the most common application of $24 \mathrm{~V}$ such batteries were electric bicycles and bicycle conversion kits. The minimum continuous discharge current rating had to be 28A. A 24volt 35 Ah battery was available from hallomotor [16], an electric bike conversion kit retailer. This battery was fabricated with lithium ion cells type 18650 , in a $7 \mathrm{~S} 12 \mathrm{P}$ arrangement to provide a nominal voltage of $25.9 \mathrm{~V}$ and a capacity of $34.8 \mathrm{Ah}$. This battery has an inbuilt battery management system (BMS) board and comes with a $5 \mathrm{~A}$ fast charger.

Table 16: Battery Specifications from manufacturer's website.

\begin{tabular}{|c|c|}
\hline Property & Value \\
\hline Nominal Capacity & $34.8 \mathrm{Ah}$ \\
\hline Nominal Voltage & $25.9 \mathrm{~V}$ \\
\hline Cell arrangement & $7 \mathrm{~S} 12 \mathrm{P}$ \\
\hline Cell Type & $390 x 150 x 90 \mathrm{~mm}$ \\
\hline Dimensions & $69.6 \mathrm{~A}$ \\
\hline Rated discharge current & $40 \mathrm{~A}$ \\
\hline Max continuous BMS limited discharge current & $80 \mathrm{~A}$ \\
\hline Max instantaneous BMS limited discharge current & $7.5 \mathrm{kgs}$ \\
\hline Gross Battery Weight & $1200 \mathrm{~W}$ \\
\hline Max Motor Recommendation & 8 hours \\
\hline Charge Time under 5A fast charge current & \\
\hline
\end{tabular}

\subsection{Arduino Backup Battery}

A 9Volt primary cell is chosen as a backup battery for the control system to ensure the Arduino will continue to run allowing a hot battery swap. 


\section{Chapter 5: Adams Modeling}

A rigid body dynamics model was created using MSC Adams by importing a parasolid CAD Model. It is important to note that each part had to have a unique part to prevent simulation failure. The scissor links were assigned stainless steel and the top frame aluminum for the inertia and mass calculations, listed in Table 17 . Due to symmetry initially only a half model was simulated for joint forces as seen in Figure 43. The joints used to connect the parts are listed in Table 18. To ensure an accurate simulation, the location of each joint was checked manually to ensure they were centered.

Table 17: Material assignment properties used in the ADAMS model.

\begin{tabular}{|c|c|c|}
\hline Part Name & Material & Mass [lbs.] \\
\hline Lower Inner Scissor & Stainless Steel & 5.28 \\
\hline Lower Outer Scissor & Stainless Steel & 5.59 \\
\hline Upper Inner Scissor & Stainless Steel & 5.28 \\
\hline Upper Outer Scissor & Stainless Steel & 5.59 \\
\hline Top Tube & Aluminum & 2.19 \\
\hline
\end{tabular}

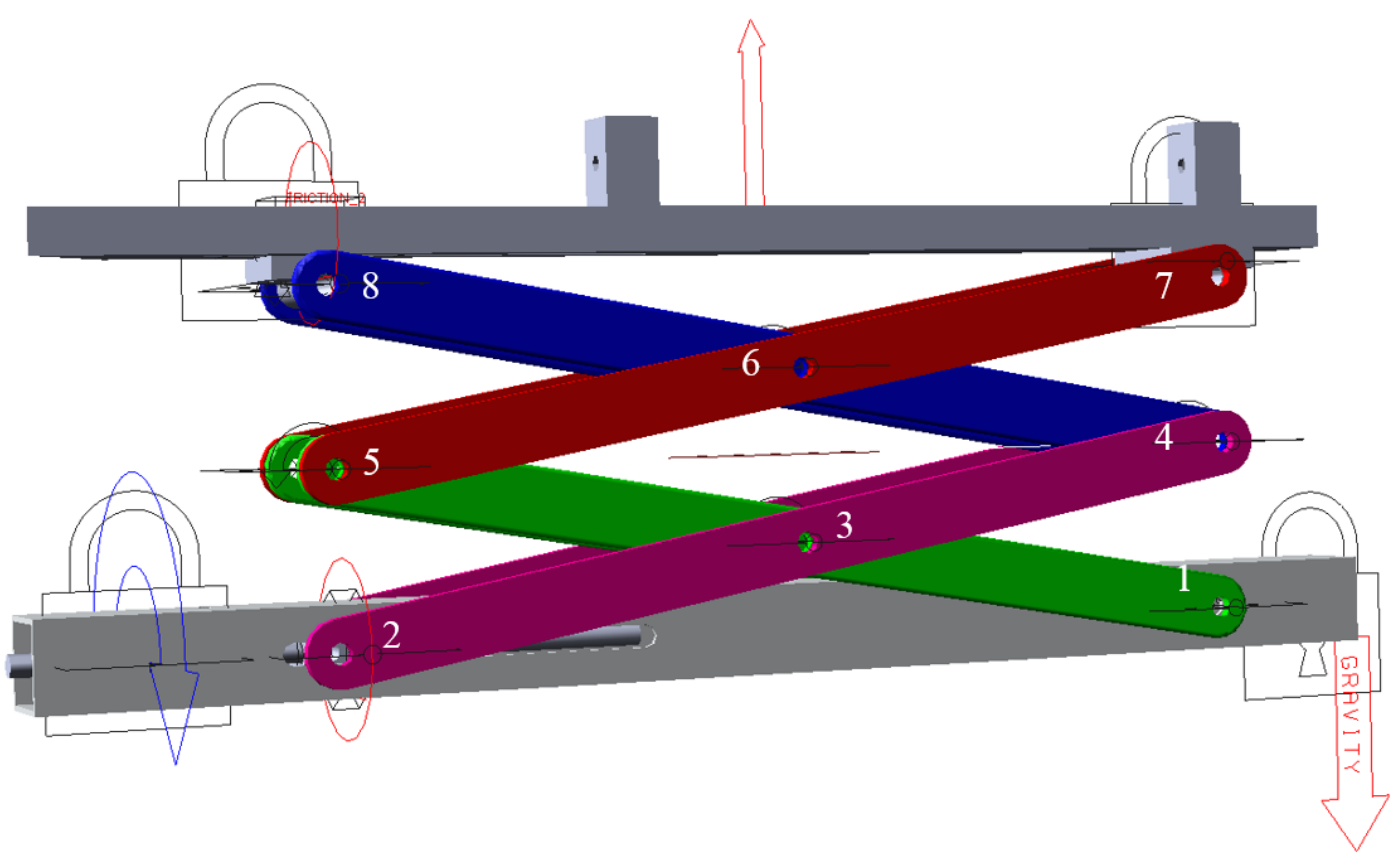

Figure 43: The half walker model showing the components connected. The icons show the forces and joints. 
Table 18: List of joint types and connecting bodies.

\begin{tabular}{|c|c|c|c|c|}
\hline Joint & Body 1 & Body 2 & Type & Friction \\
\hline 1 & Lower Inner Scissor & Lower Tube & Revolute & - \\
\hline 2 & Lower Outer Scissor & Sliding Block & Revolute & - \\
\hline 3 & Lower Outer Scissor & Lower Inner Scissor & Revolute & - \\
\hline 4 & Lower Outer Scissor & Upper Inner Scissor & Revolute & - \\
\hline 5 & Lower Inner Scissor & Upper Outer Scissor & Revolute & - \\
\hline 6 & Upper Inner Scissor & Upper Outer Scissor & Revolute & - \\
\hline 7 & Upper Outer Scissor & Top Tube & Revolute & - \\
\hline 8 & Upper Inner Scissor & Sliding Clevis & Revolute & - \\
\hline 9 & Sliding Clevis & Top Tube & Translational & 0.18 \\
\hline 10 & Sliding Block & Lower Tube & Translational & 0.18 \\
\hline 11 & Power Screw & Sliding Block & Screw & N/A \\
\hline 12 & Bearing Block & Lower Tube & Lock & N/A \\
\hline 13 & Lower Tube & Ground & Lock & N/A \\
\hline 14 & Power Screw & Bearing Block & Revolute & 0.035 \\
\hline
\end{tabular}

To simulate the weight of a patient, a force was applied in the global negative Y direction with run-time direction as body moving. A gas spring was specified as run-time direction two bodies (line of sight) this ensured that it would act between Joint 4 and Joint 5. Gravity was included to factor in the weight and inertia of the scissors. A complete summary is listed below in Table 19

Table 19: Forces and bodies used in the ADAMS simulation.

\begin{tabular}{|c|c|c|c|c|}
\hline Force & Direction & Magnitude & Body 1 & Body 2 \\
\hline Patient Weight & $-\mathrm{y}$ & $125[\mathrm{lbs}]$. & Top Tube & N/A \\
\hline Gas Spring & $\mathrm{z}$ & $370[\mathrm{lbs}]$. & Lower Inner Scissor & Lower Outer Scissor \\
\hline Gravity & $-\mathrm{y}$ & $386.09[\mathrm{in} / \mathrm{s} / \mathrm{s}]$ & - & - \\
\hline
\end{tabular}

A screw joint was created between the power screw and sliding block with a specified pitch of 0.1 inch. The joint does not support any thread-nut friction so this was not included this simulation. A motion was applied to Joint 14 as a rotational function to simulate a motor at 500 RPM (3000 degrees/sec). A simulation was run for 7 seconds to determine joint forces which were later used for FEA of scissor links. This simulation was based on kinematic assumptions, for a more realistic model a torque speed combination would have to be inputted instead of a motion. Figure 44 and Figure 45 show the joint forces for a simulation run without a gas spring to determine the worst case loading conditions for each joint in the scissor. 


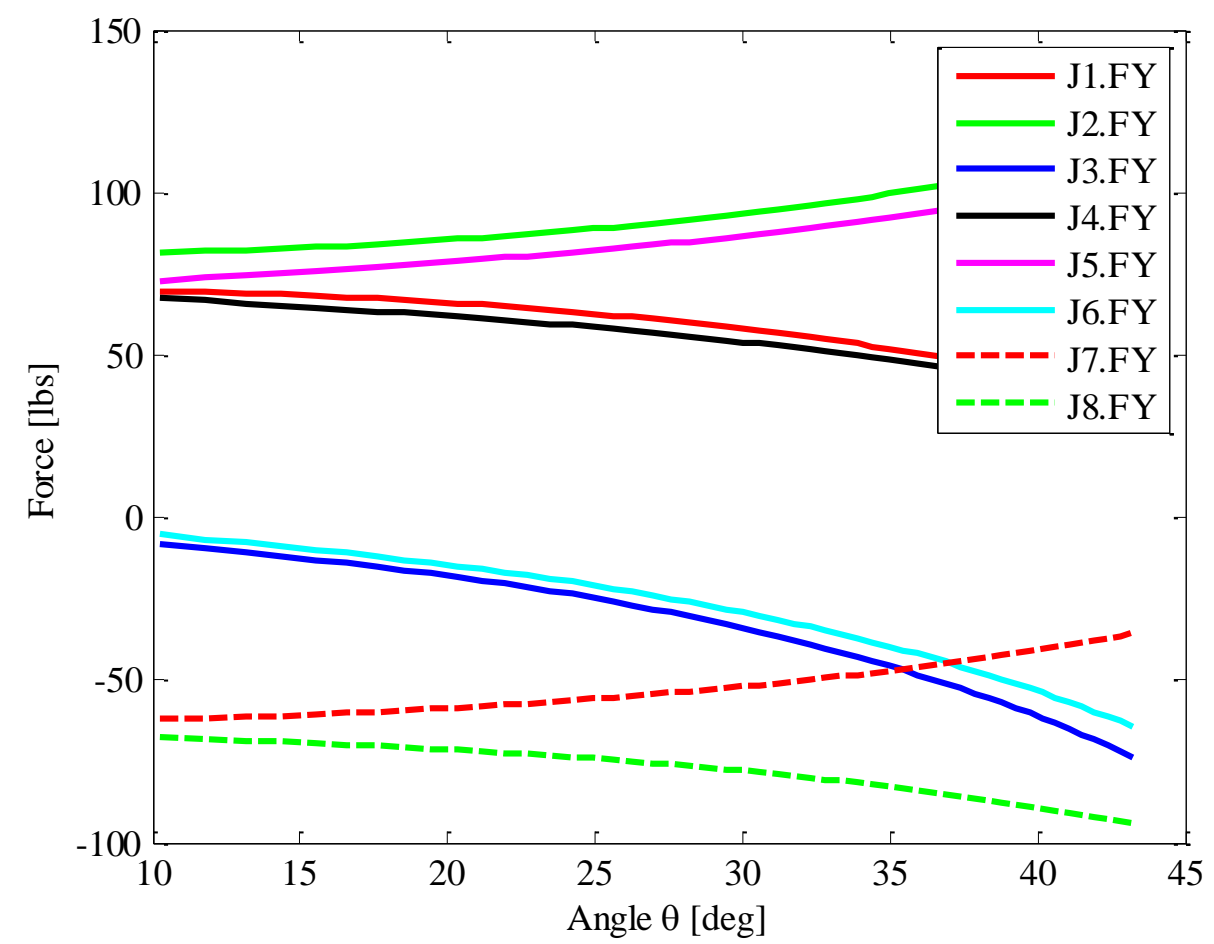

Figure 44: The joint reaction forces in the vertical direction stay within a range of $+/-125 \mathrm{lbs}$. This is consistent with the applied load, weight of $250 \mathrm{lbs}$, with failed gas springs.

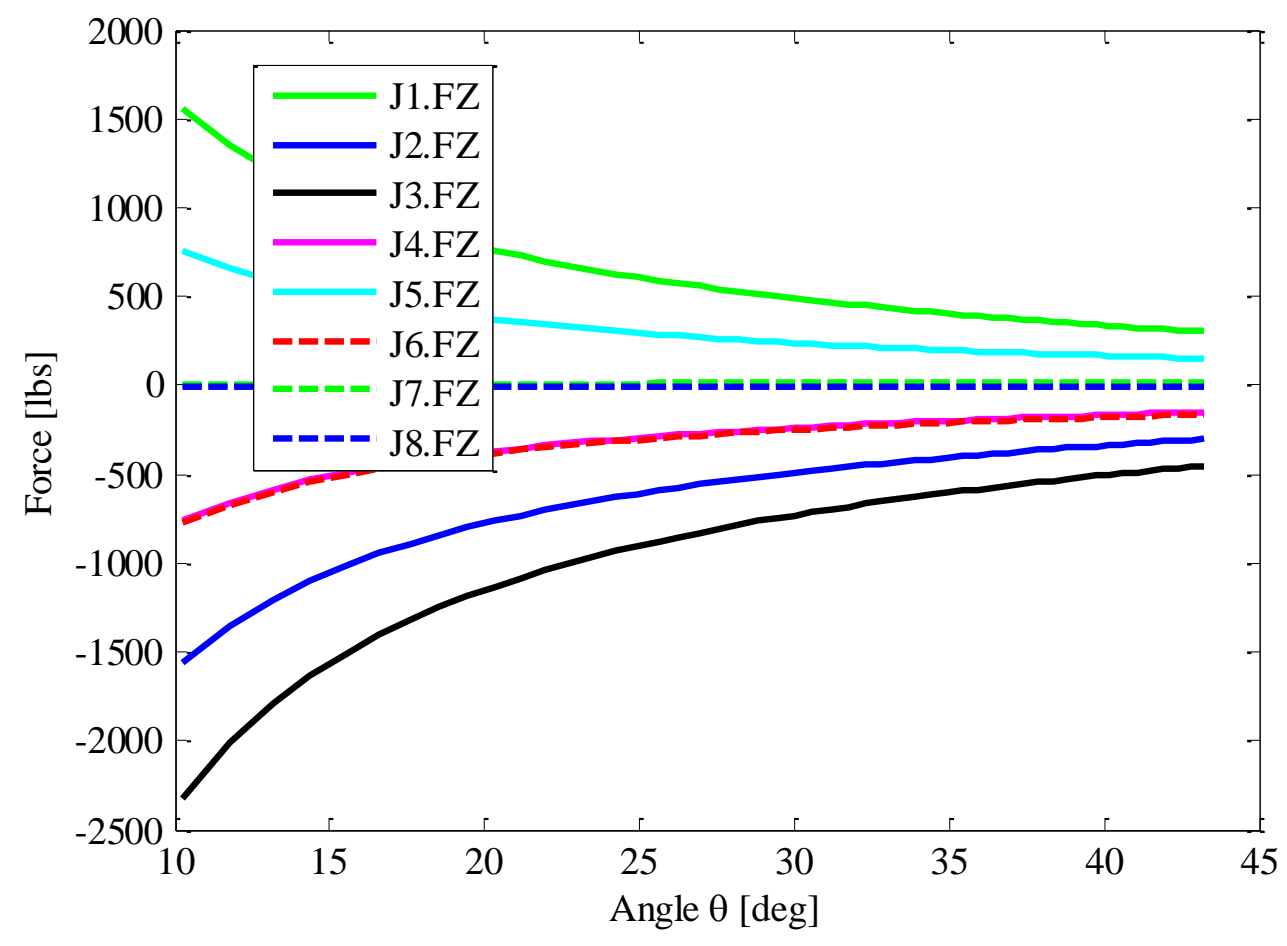

Figure 45: The Joint forces in the $\mathrm{z}$ direction, the maximum force is experienced is by Joint 3 . This is for a patient weight of $250 \mathrm{lbs}$, with failed gas springs. 
Joint 3 experiences the greatest load in the $\mathrm{z}$ direction as expected. This is since the lower scissors are confined in the $\mathrm{z}$ direction at Joints 1-2 and the load is transferred through joints 4-5. Joint 6 does not experience large load as the sliding clevis is not confined in the $\mathrm{z}$ direction.

Table 20: Summary of joint forces for the case with and without a gas spring.

\begin{tabular}{|c|c|c|c|c|c|c|c|c|}
\hline Case & \multicolumn{4}{|c|}{ Gas Spring } & \multicolumn{3}{c|}{ No Gas Spring } \\
\hline & \multicolumn{2}{|c|}{ Fy [lbs.] } & \multicolumn{2}{|c|}{ Fz [lbs.] } & \multicolumn{2}{c|}{ Fy [lbs.] } & \multicolumn{2}{|c|}{ Fz [lbs.] } \\
\hline Angle & $\mathbf{1 0}^{\circ}$ & $\mathbf{4 5}^{\circ}$ & $\mathbf{1 0}^{\circ}$ & $\mathbf{4 5}^{\circ}$ & $\mathbf{1 0}^{\circ}$ & $\mathbf{4 5}^{\circ}$ & $\mathbf{1 0}^{\circ}$ & $\mathbf{4 5}^{\circ}$ \\
\hline Joint 1 & 69.5 & 56.8 & -1177.5 & -88.4 & 69.7 & 56.8 & 1557.4 & 468.5 \\
\hline Joint 2 & 80.6 & 93.8 & 1177.5 & 88.4 & 81.5 & 94.8 & -1557.4 & -468.5 \\
\hline Joint 3 & -7.9 & -31.3 & -1564.3 & 54.5 & -8.4 & -36.4 & -2319.8 & -697.3 \\
\hline Joint 4 & 67.1 & 52.5 & -756.8 & -227.0 & 67.6 & 52.9 & -762.5 & -228.8 \\
\hline Joint 5 & 72.3 & 87.2 & 756.8 & 227.0 & 72.8 & 87.9 & 762.5 & 228.8 \\
\hline Joint 6 & -5.2 & -31.1 & -767.1 & -238.1 & -5.3 & -31.3 & -772.8 & -239.9 \\
\hline Joint 7 & -61.6 & -50.5 & 10.3 & 11.1 & -62.1 & -50.9 & 10.4 & 11.2 \\
\hline Joint 8 & -67.1 & -78.3 & -10.3 & -11.1 & -67.6 & -78.9 & -10.4 & -11.2 \\
\hline
\end{tabular}

The simulation was validated by comparing the vertical (lift velocity) from the Adams model to an analytical expression derived using dynamics (Eq. 5.1) that related power screw angular velocity $(\omega)$ and pitch (p) the lift velocity. Figure 46 shows the lift velocity form Adams matching the analytical expression validating the simulation.

$$
\text { Lift Velocity }=2 \omega p \cot \theta
$$




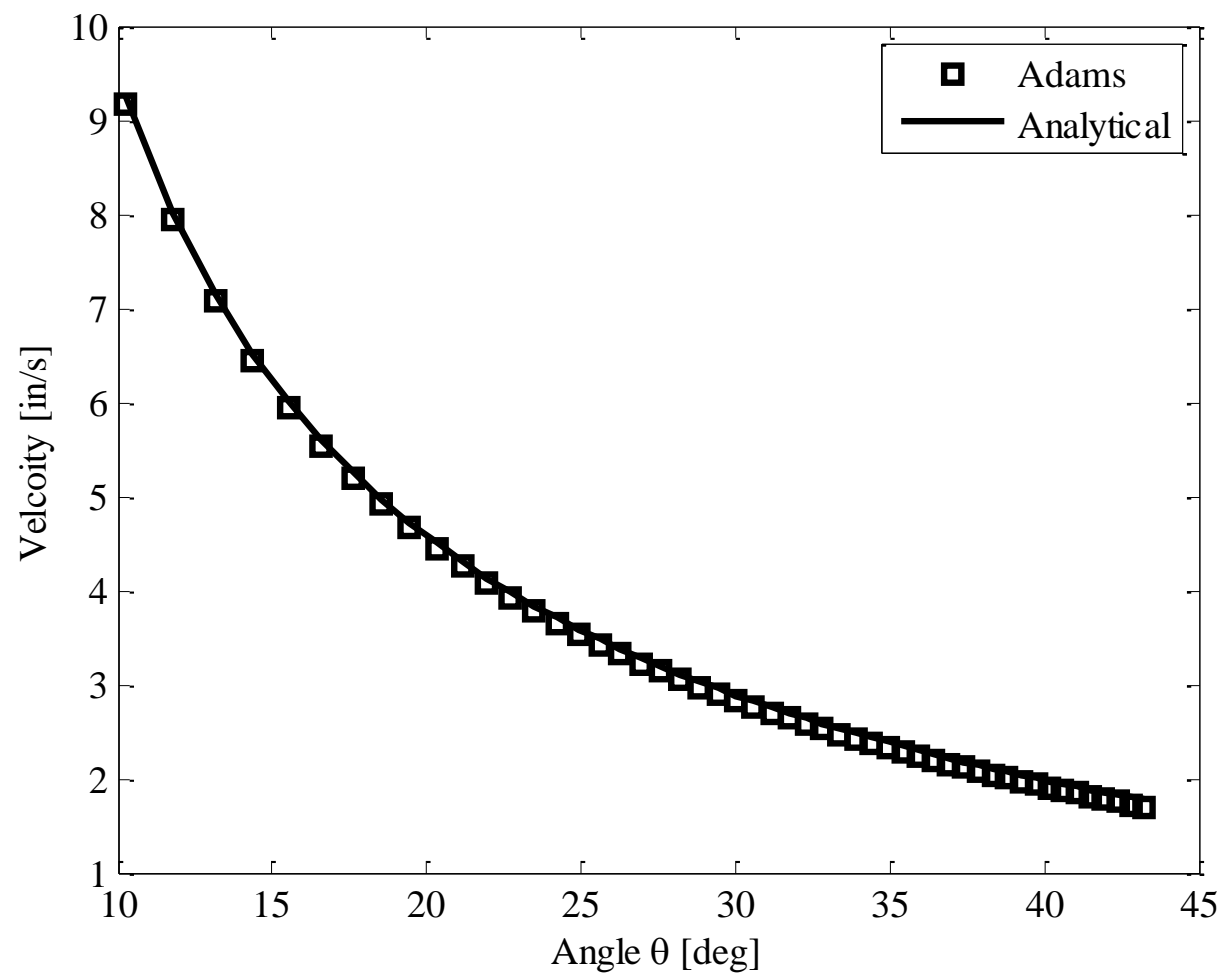

Figure 46: The top tube vertical velocity (y-direction) matched the analytical calculation validating the rigid body simulation. 


\subsection{Dynamic Stress Recovery}

The Adams durability plug in was used to determine the stresses in the scissor links by converting these rigid bodies in to flexible components. The maximum von Mises stress experienced by the scissor links was $10 \mathrm{ksi}$, which is below the yield aluminum (40 ksi) for a maximum patient load of $250 \mathrm{lbs}$. Figure 47 shows the stress contour plot in this simulation aluminum was used as the material for scissor links and mid frame and lower tube.

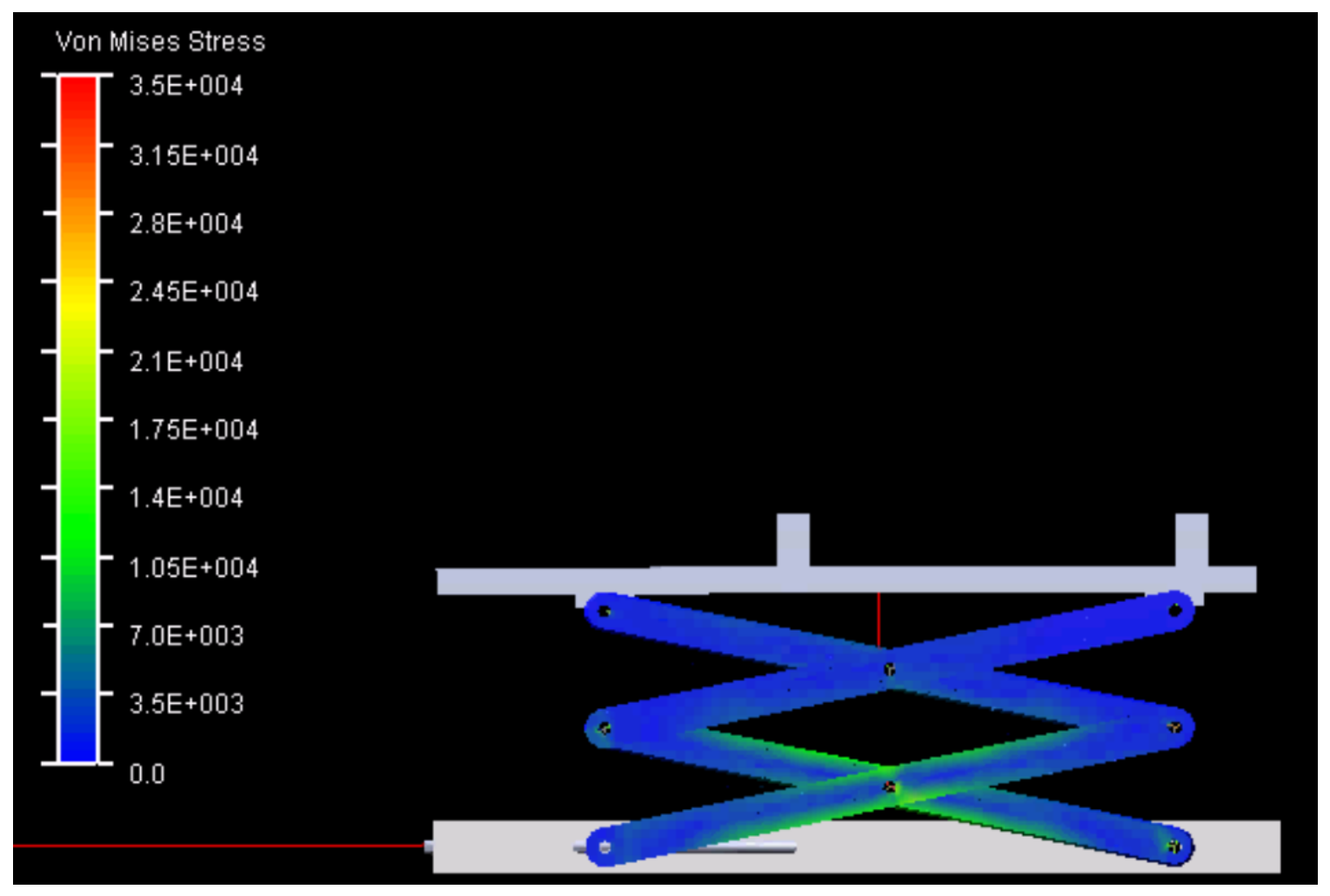

Figure 47: The von Mises stress is around $10 \mathrm{ksi}$ and is concentrated around joint 3 in the model. 


\section{Chapter 6: Finite Element Analysis}

The structural and primary load bearing components were analyzed to ensure that the design was structurally safe. The analyses of these are broken up in to sub sections as follows.

\subsection{Lower Tube}

The lower tube was analyzed for two primary load cases which resulted in the largest stress in the analytical calculations. Table 21 lists these load cases that were used for the analysis.

Table 21: Loading cases used for FEA.

\begin{tabular}{|c|c|c|c|c|}
\hline Case & $\begin{array}{c}\text { Patient } \\
\text { Load } \\
\text { [lbs.] }\end{array}$ & $\begin{array}{c}\text { Angle } \\
\text { [Deg] }\end{array}$ & $\begin{array}{c}\text { Gas } \\
\text { Spring } \\
\text { [lbs.] }\end{array}$ & $\begin{array}{c}\text { Motor } \\
\text { Torque } \\
\text { [in-lbs.] }\end{array}$ \\
\hline 1 & 250 & 10 & 0 & 43 \\
\hline 2 & 250 & 45 & 0 & 43 \\
\hline
\end{tabular}

A fixed boundary condition was where the front bearing block connects to the lower tube. This allowed a torque to be applied where it is connected to the motor. The torque was applied by creating a reference point and attaching it to the inner surface with a kinematic coupling and a moment applied to the reference point. Surface tractions were applied to the rear bearing block. These location of the loads and boundary conditions are annotated in Figure 48 with specified conditions listed in Table 22. Al 6061 was the material used in this analysis.

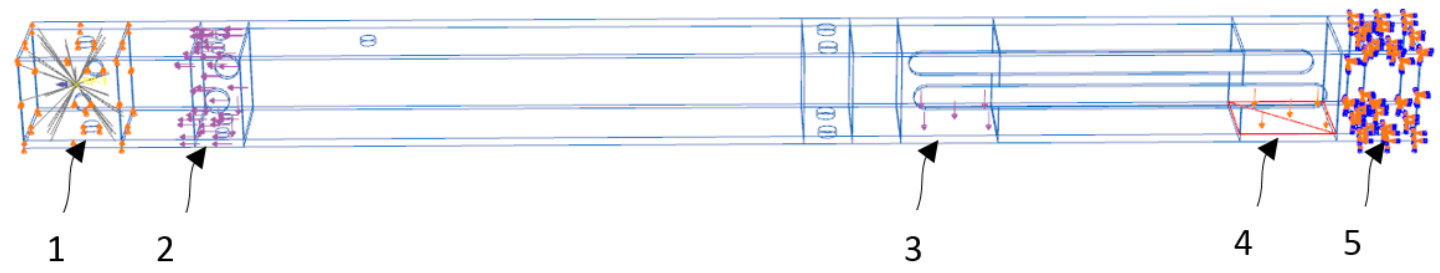

Figure 48: Loads and Boundary conditions for the lower tube. 
Table 22: Loads used in FEA analysis.

\begin{tabular}{|c|c|c|c|c|c|c|}
\hline \multicolumn{2}{|c|}{ Location } & $\mathbf{1}$ & $\mathbf{2}$ & $\mathbf{3}$ & $\mathbf{4}$ & $\mathbf{5}$ \\
\hline & BC & $\mathrm{U} 2=0$ & - & - & - & $\begin{array}{c}\text { U1,U2,U3, } \\
\text { UR1,UR2, } \\
\text { UR3 }=0\end{array}$ \\
\hline Case 1 & Load & $\begin{array}{c}\text { CM3 }=43 \\
{[\text { in-lbs. }]}\end{array}$ & $\begin{array}{c}\text { F3 }=1557 \\
\text { F2 } 125[\mathrm{lbs} .]\end{array}$ & - & $\begin{array}{c}\text { F 3 }=125 \\
{[\mathrm{lbs} .]}\end{array}$ & - \\
\hline Case 2 & Load & $\begin{array}{c}\text { CM3 }=43 \\
\text { [in-lbs. }]\end{array}$ & $\begin{array}{c}\text { F3 }=468 \\
\text { F2 }=125[\text { lbs. }]\end{array}$ & $\begin{array}{c}\text { F 3 }=125 \\
{[\text { lbs. }]}\end{array}$ & - & - \\
\hline
\end{tabular}

Figure 49: Analysis of a 2 inch Extruded Aluminum tube of wall thickness 0.120 inches. The stress around the holes is at yield.

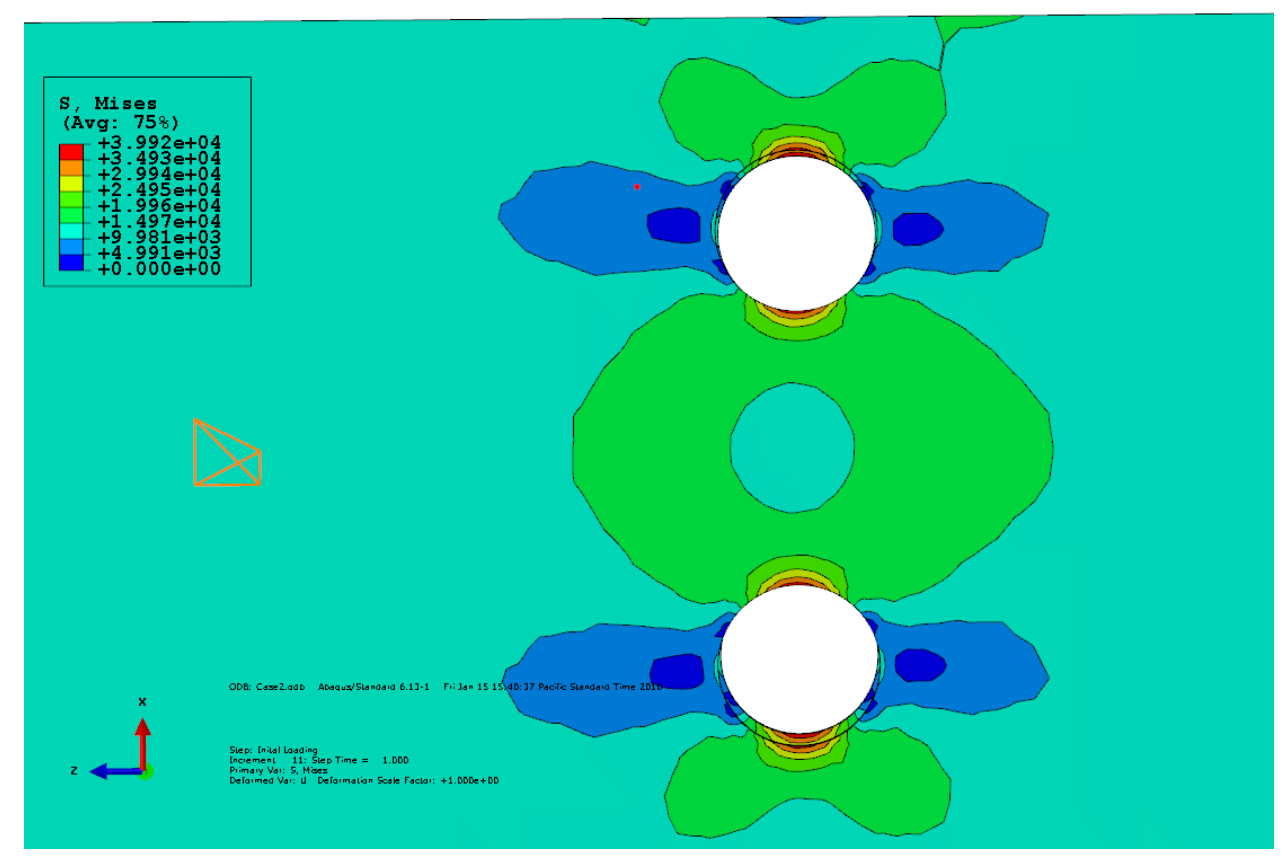

Figure 50: Close up of stress distribution around the holes, there are some areas that are at yield which is expected with a stress concentration. 
To reduce the stress due to the holes, a thicker tube was selected, increasing the wall thickness from 0.120 to 0.188 inches reduced this stress by a factor of 2.4. Figure 51, shows the contour plot of this stress distribution.

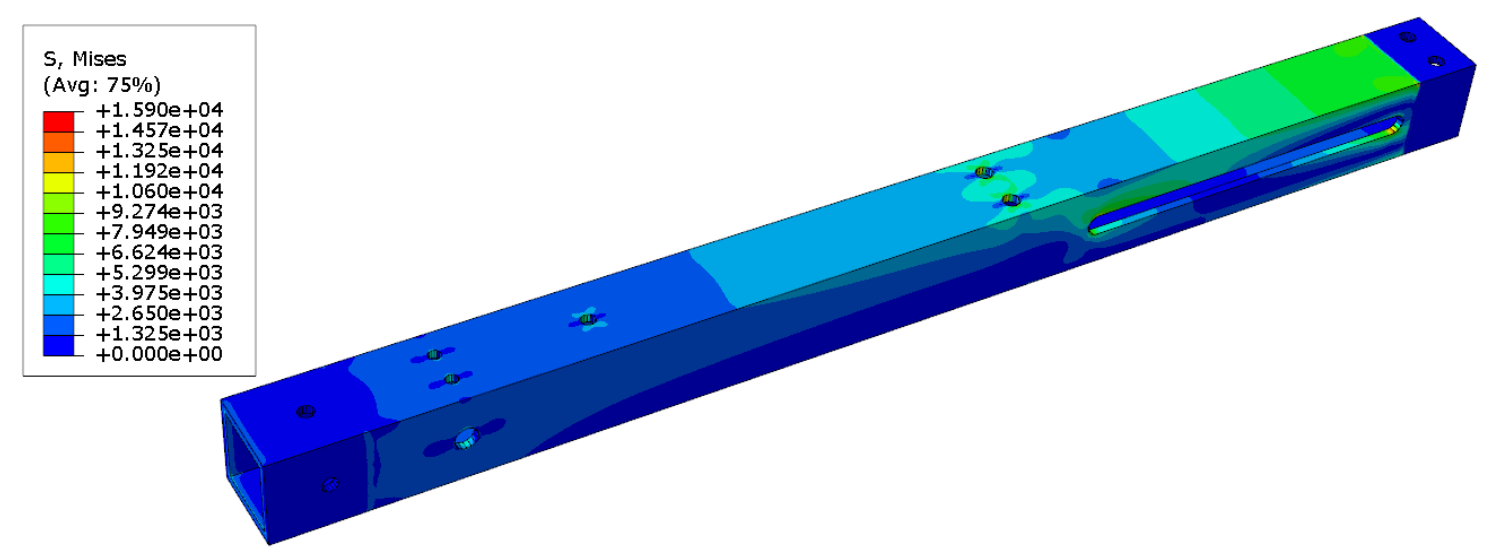

Figure 51: The von Mises Stress distribution in the lower tube, the stress of the lower tube is reduced with an increase in wall thickness from 0.120 to 0.188 inches

\subsection{Front Bearing Block}

For the front bearing block the attachment holes were constrained and a pressure load applied to the region where the thrust bearing contacts the bearing block as well as the region where front caster. Figure 52 annotates the load and boundary condition regions. A load of $1557 \mathrm{lbs}$. was applied to region 1, and a load of $200 \mathrm{lbs}$. was applied to region 3. The attachment holes, region 2, were fixed. Figure 53 shows the stress distribution with a maximum stress of $20 \mathrm{ksi}$, below yield of Aluminum. 


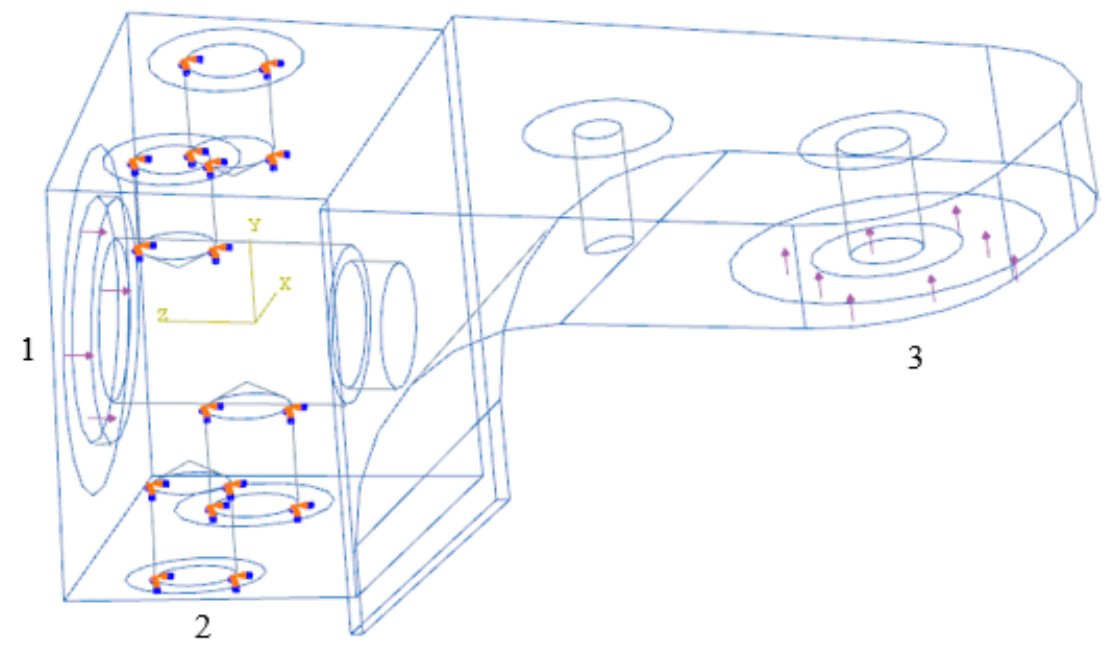

Figure 52: The boundary conditions applied to the bearing block. A pressure load with total force of $1557 \mathrm{lbs}$. applied to region 1, with a ground reaction force of $200 \mathrm{lbs}$ applied to region 3 . A fixed boundary condition was applied to the holes in region 2.
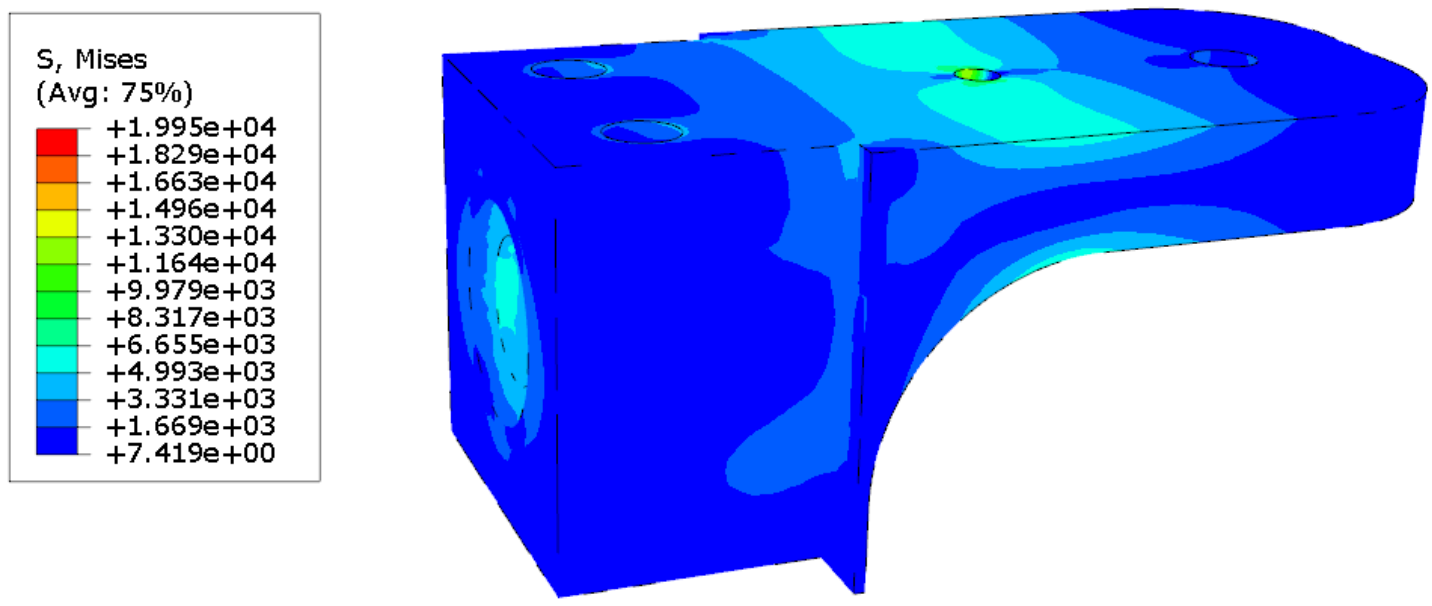

Figure 53: The von Mises stress distribution, it is significantly below yield of Al 6061-T6 which has a yield of $40 \mathrm{ksi}$. 


\subsection{Scissor Links}

The worst case load was analyzed for the scissor links, this occurred in the lower scissor link and was lifting a load of $250 \mathrm{lbs}$. from 10 degrees. Symmetry was used and only one scissor needed to be analyzed. The center was pinned with loads applied as surface tractions, as listed in Table 23 and annotated in Figure 54.

Table 23: Load cases.

\begin{tabular}{|c|c|c|c|}
\hline & $\mathbf{1}$ & $\mathbf{2}$ & $\mathbf{3}$ \\
\hline BC/Load & $\mathrm{F}=1586$, & $\mathrm{U} 1, \mathrm{U} 2, \mathrm{U} 3, \mathrm{UR} 2, \mathrm{UR} 3=0$ & $\mathrm{~F}=729$, \\
& Vector $(0,-0.1292,-$ & & Vector $(0,-0.2634,-$ \\
& $0.9916)$ & & $0.9647)$ \\
\hline
\end{tabular}

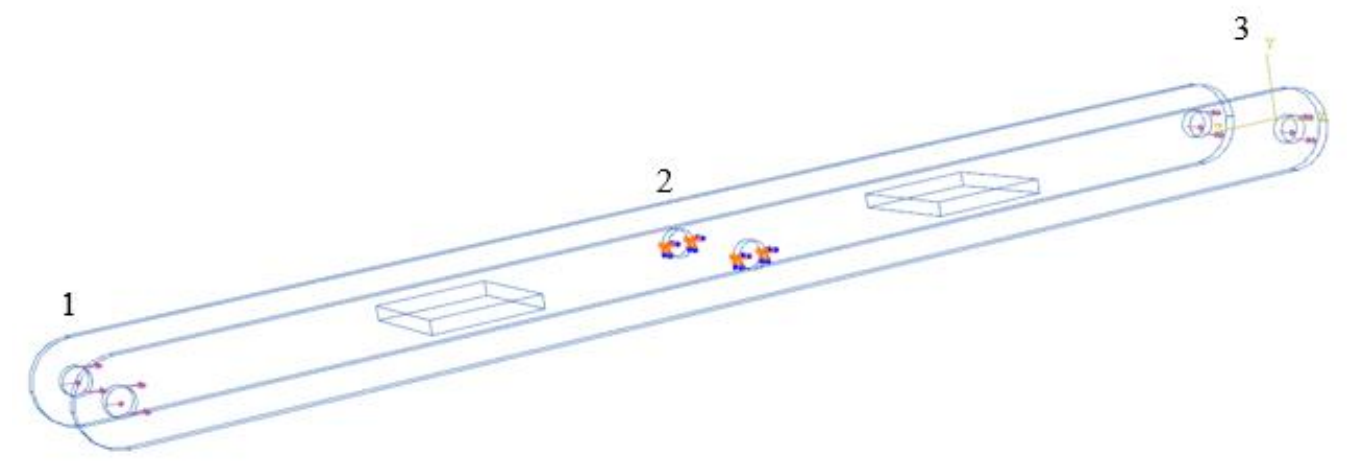

Figure 54: Annotation for prescribed loads and boundary conditions for the scissor link.

The maximum stress was around $10 \mathrm{ksi}$ which occurred around the center joint. This was below the yield. Figure 55 shows the stress contour plot, with a stress distribution similar to the results of the Adams simulation in Figure 47. 

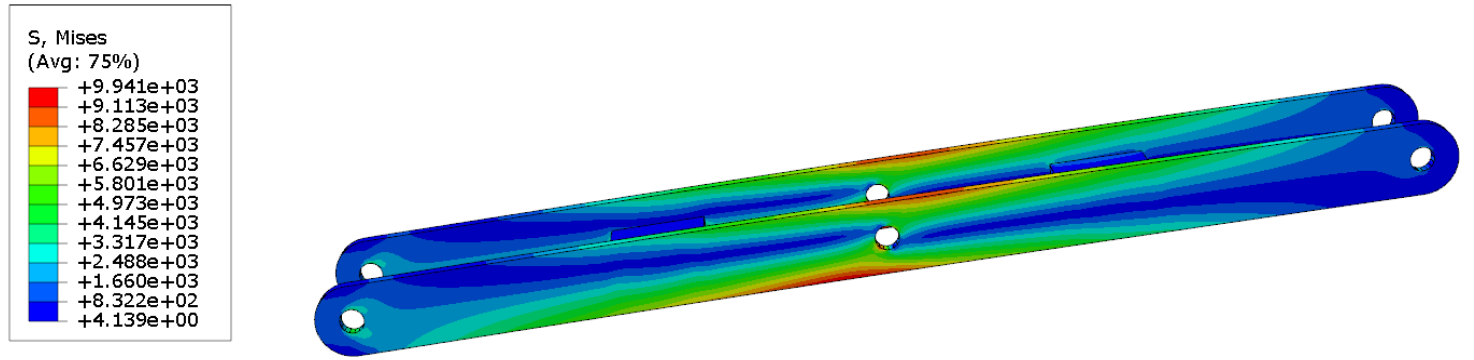

Figure 55: The von Mises stress for load case 1. The maximum stress is less than $10 \mathrm{ksi}$.

\subsection{Top Frame}

The top frame was analyzed for a harness that would distribute the patient weight evenly. For this analysis a maximum patient weight of $250 \mathrm{lbs}$ was used. A surface traction was applied to potential harness attachement points. The attachment points of the legs were fixed by applying an encaster boundary condition.

Table 24: Surface traction loads and vectors applied to the top frame.

\begin{tabular}{|c|c|c|}
\hline Region & Force [lbs] & Vector \\
\hline $\mathbf{1}$ & 100 & $(-0.707,-0.707,-0.707)$ \\
\hline $\mathbf{2}$ & 100 & $(-0.707,-0.707,0.707)$ \\
\hline $\mathbf{3}$ & 100 & $(0,-0.707,-0.707)$ \\
\hline $\mathbf{4}$ & 100 & $(0.707,-0.707,0.707)$ \\
\hline $\mathbf{5}$ & 100 & $(0.707,-0.707,-0.707)$ \\
\hline
\end{tabular}




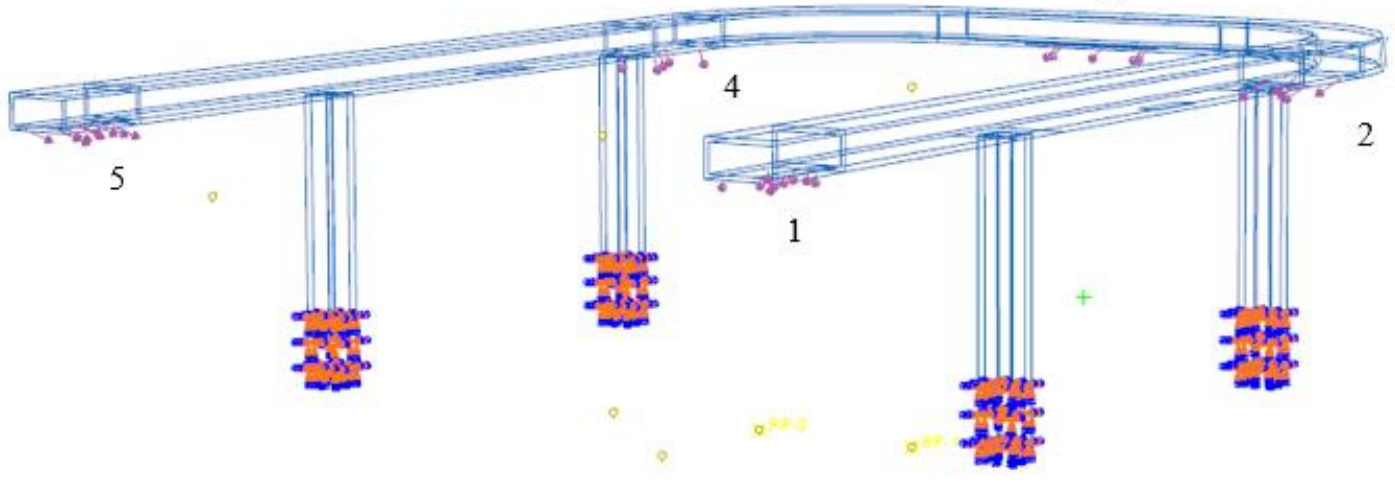

Figure 56: Top frame region annotations, the applied surface tractions are listed in Table 24. Encaster boundary conditions were applied to the attachment point of the top frame to the middle frame.
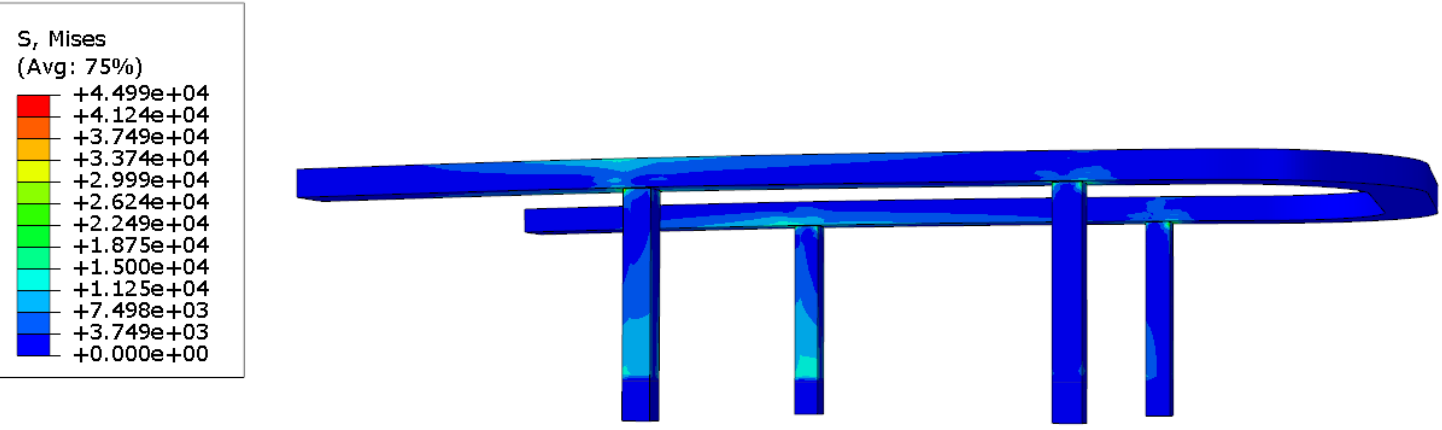

Figure 57: Stress contour plot of the top frame, there are some hot spots, but these will be eliminated during manufacturing by rounding any edges. The von Mises stress of most of the components is around $15 \mathrm{ksi}$.

\subsection{Motor Mount}

The motor mount was fixed at the thru-holes for mounting the motor region 2, a torque of 43 inlbs. was applied a region 1 and a surface traction at region 3, annotated in Figure 58. The maximum stress for a motor mount out of 0.25 inch thick was significantly less than yield. 


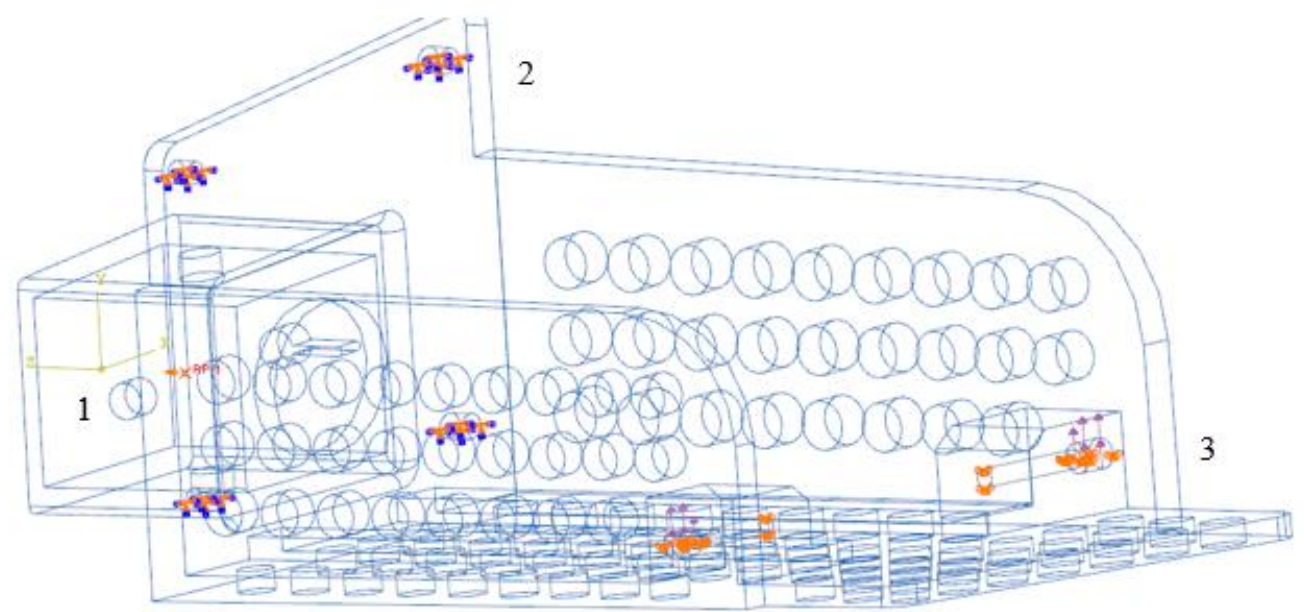

Figure 58: Load and boundary condition annotation on the motor mount.
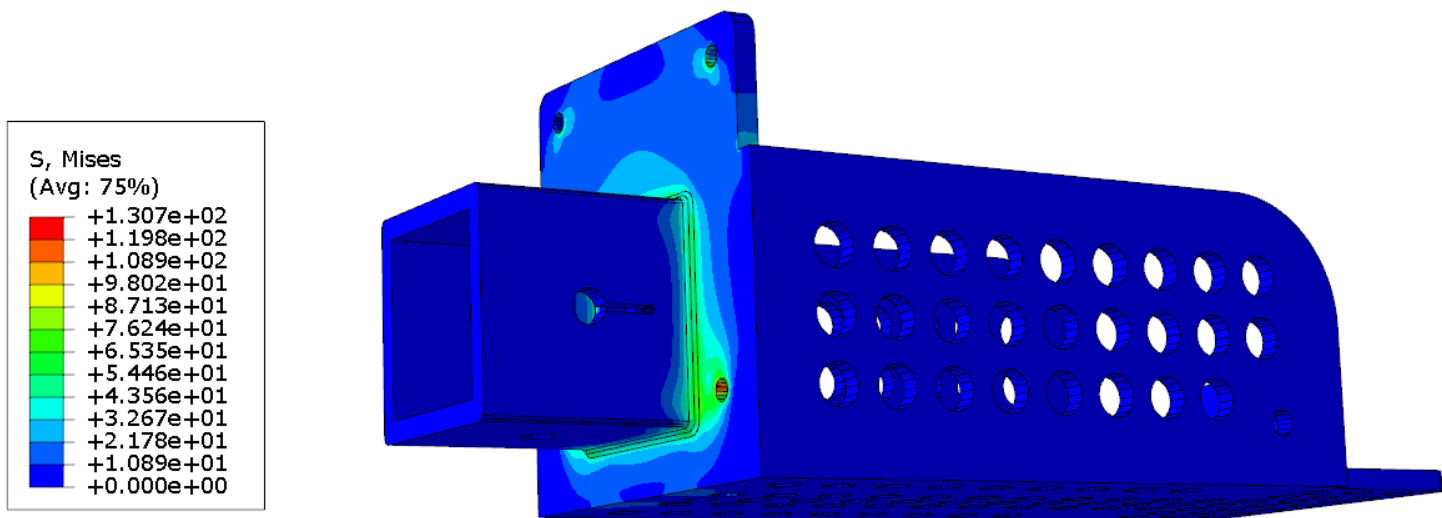

Figure 59: The von Mises stress on the motor mount for the worse loading case.

\subsection{Front Bearing Block Topology Optimization}

The built in optimization function in Abaqus was used to reduce the volume of the front bearing block. Two design responses were selected; Volume and Strain Energy. The objective function was to minimize volume and the constraint limited strain energy to less than $90 \%$ of the original, 
summarized in Table 25. 29 design cycles yielded a geometry with $79 \%$ volume reduction.

Figure 60 shows this geometry which after smoothing would be a suitable part for casting (for mass production) resulting in a lighter and strong part.

Table 25: Summary of topology optimization parameters.

\begin{tabular}{|c|c|c|}
\hline Design Response & Objective Function & Constraint \\
\hline Volume & Minimize & - \\
\hline Strain Energy & - & $<90 \%$ initial \\
\hline
\end{tabular}

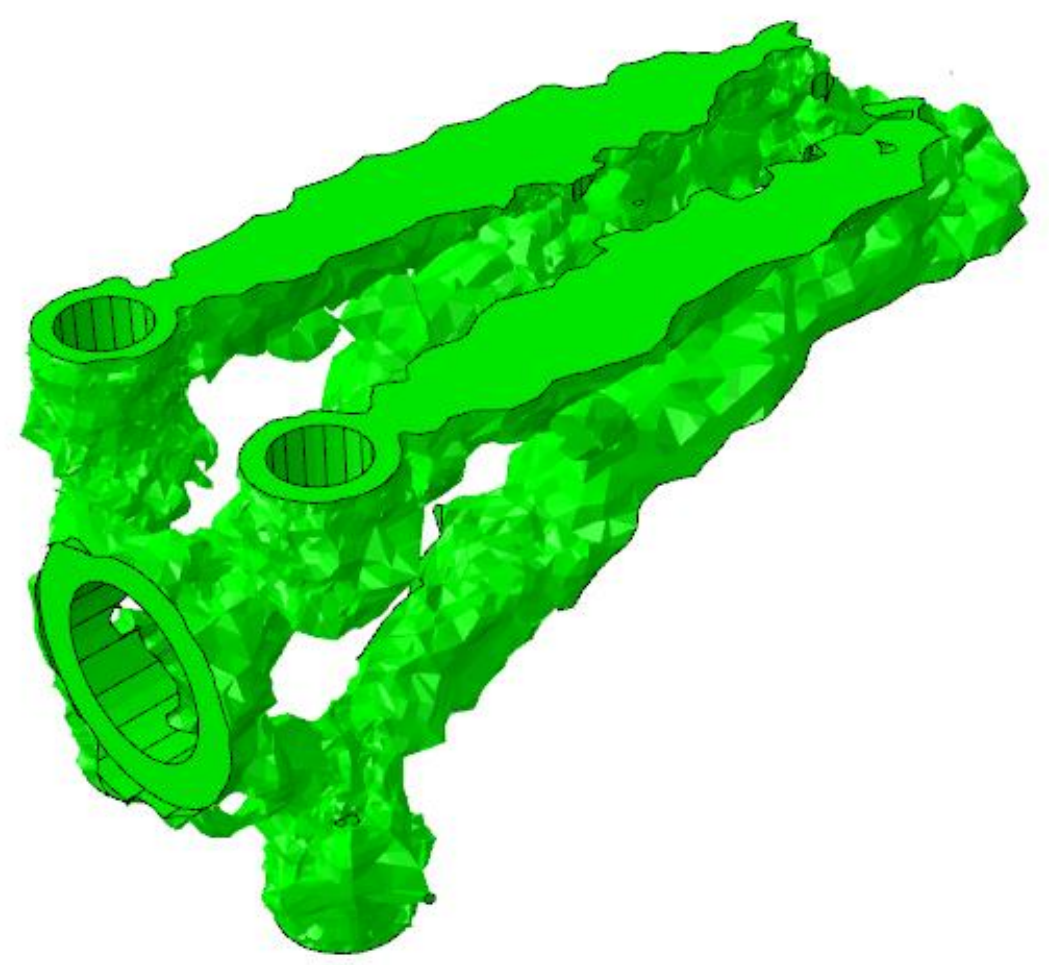

Figure 60: Optimized bearing block geometry using topology optimization. 


\section{Chapter 7: Safety Requirements}

\subsection{Pinch Protection}

Two types of pinch protection systems were evaluated for the walker; an active system that included tactile edge sensors (commonly used in machine guards) and passive system that comprised of physical barriers. Due to the added complexity and costs of an active system a physical barrier was specified in this design. Bellowing offers a pinch protection by hindering fingers from being inserted in to moving parts in this case primarily the scissors links. The bellowing's size and parameters are specified for custom fabrication.

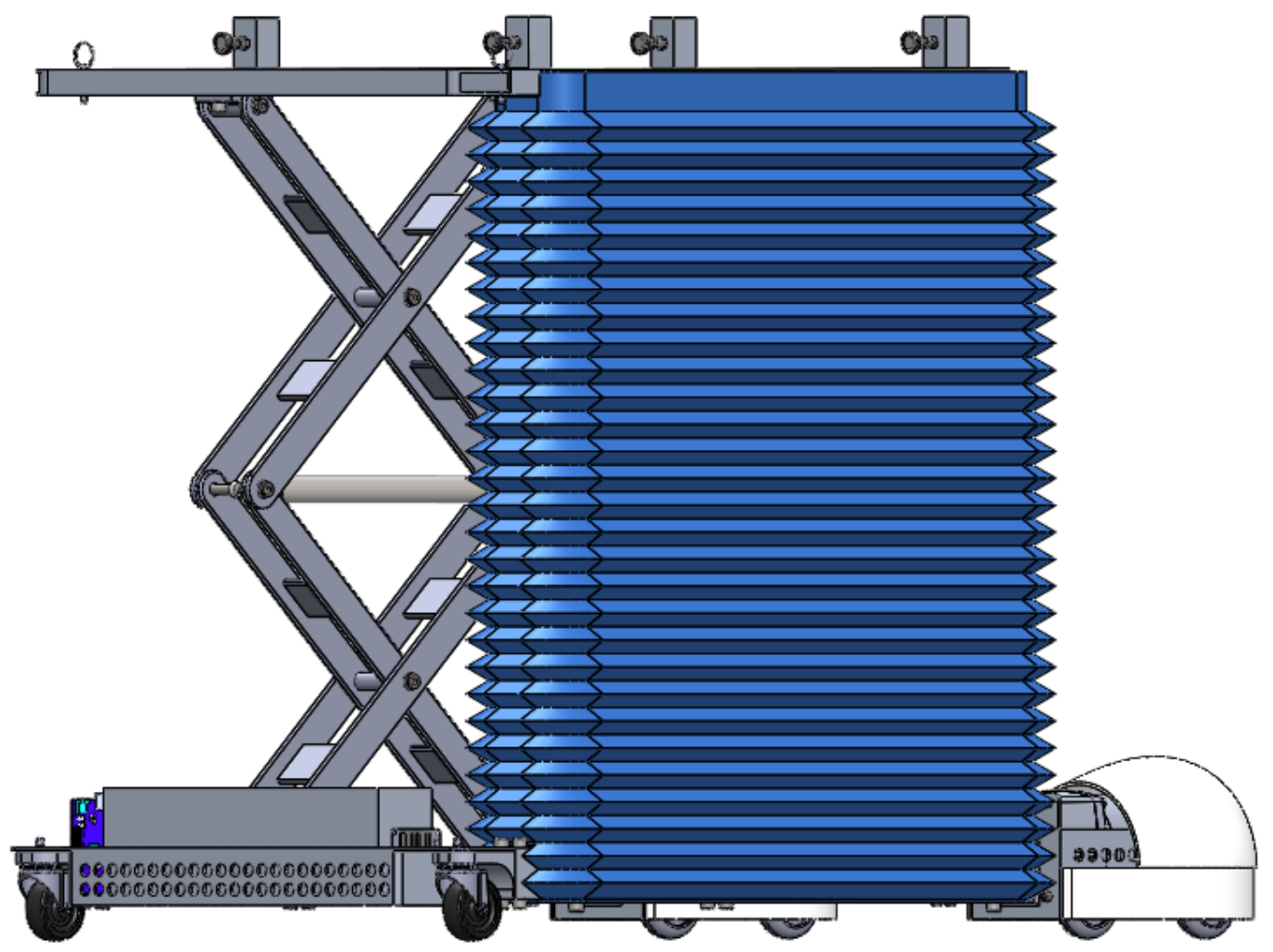

Figure 61: The proposed bellowing would encompass all moving parts. 


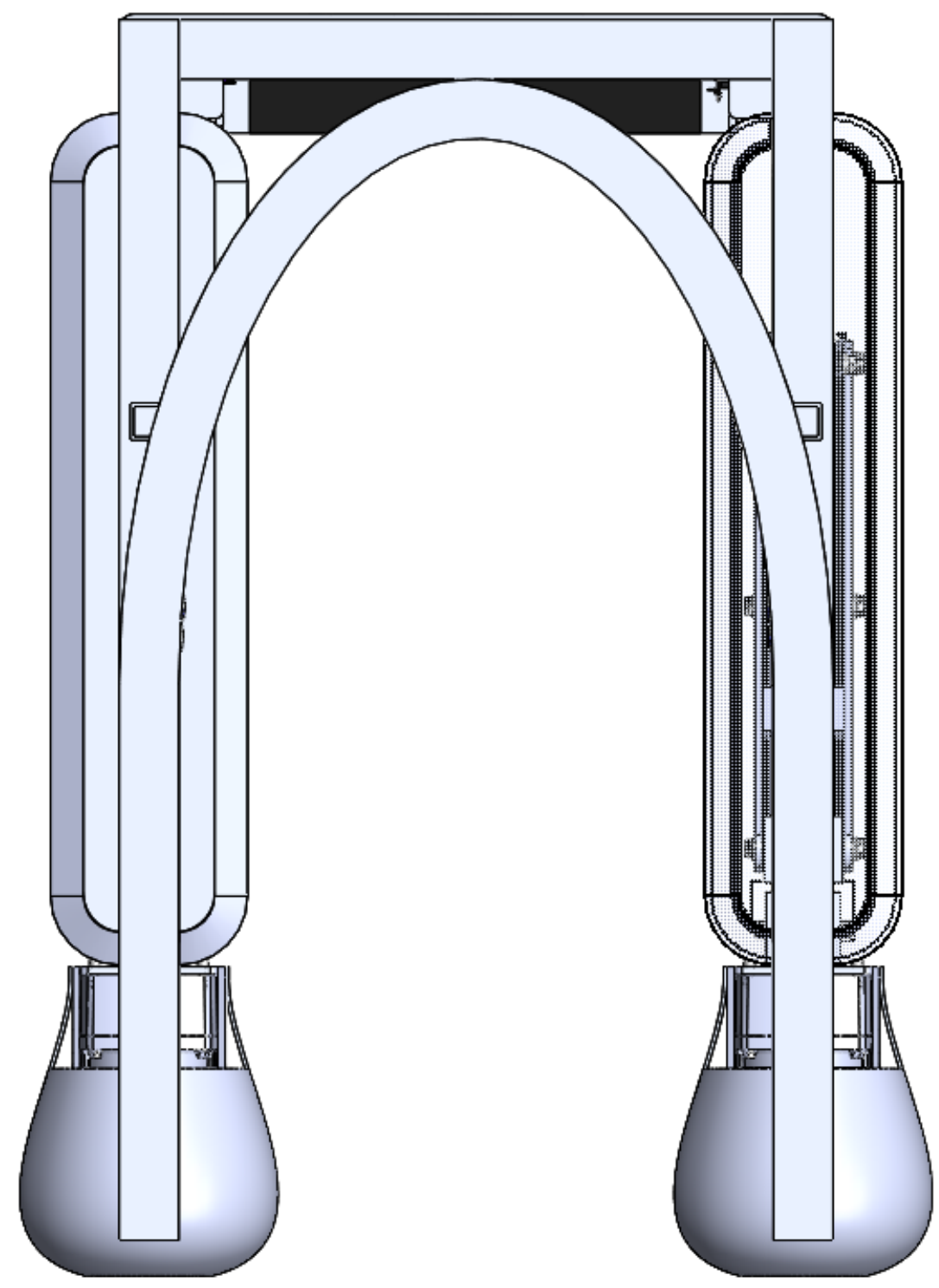

Figure 62: Top view of walker showing bellowing and a modified top frame. The bellowing encompasses the scissor links as seen. 


\section{Chapter 8: Conclusion}

The goal of this project was to design a prototype lift assist walker that was capable of lifting up to a 250 pound person from sitting to standing in under seven seconds. The accomplishments of this projects are listed below:

1. An easy to manufacture design in a university machine shop with off the shelf components.

2. An optimized gas spring assisted linear actuator for a two stage scissor mechanism.

3. Structural and kinematic analysis of several key components to ensure the design is safe.

4. A modular design to allow disassembly of the walker in to several components.

\subsection{Summary of Results}

A walker capable of lifting a 250 pound person from sitting to standing in under seven seconds was designed for easy manufacturability in a university machine shop. The walkers mass is 105 pounds, which is comparable to a hoist type of device [17]. This design is modular to allow easy disassembly for easy transportation of the device. As seen in Figure 63 the walker can be disassembled in to 5 major pieces with no sub component weighing more than 35 pounds.

The final design met all the specification as summarized in Table 26. This design is suitable for prototyping purposes for system evaluation. 
Table 26: Summary of attained final design parameters.

\begin{tabular}{|c|c|c|}
\hline & Design Specifications & Final Design \\
\hline Length [in] & 42 & 41.94 \\
\hline Width [in] & 32 & 31.52 \\
\hline Collapsed height [in] & 15 & 14.73 \\
\hline Base clearance [in] & 7.5 & 7.09 \\
\hline Raised height [in] & 45 & 45 \\
\hline Load Capacity [lbs.] & 250 & 250 \\
\hline Weight of device [lbs.] & 105 & 105 \\
\hline Lift time full load [s] & $<10$ & 7 \\
\hline
\end{tabular}

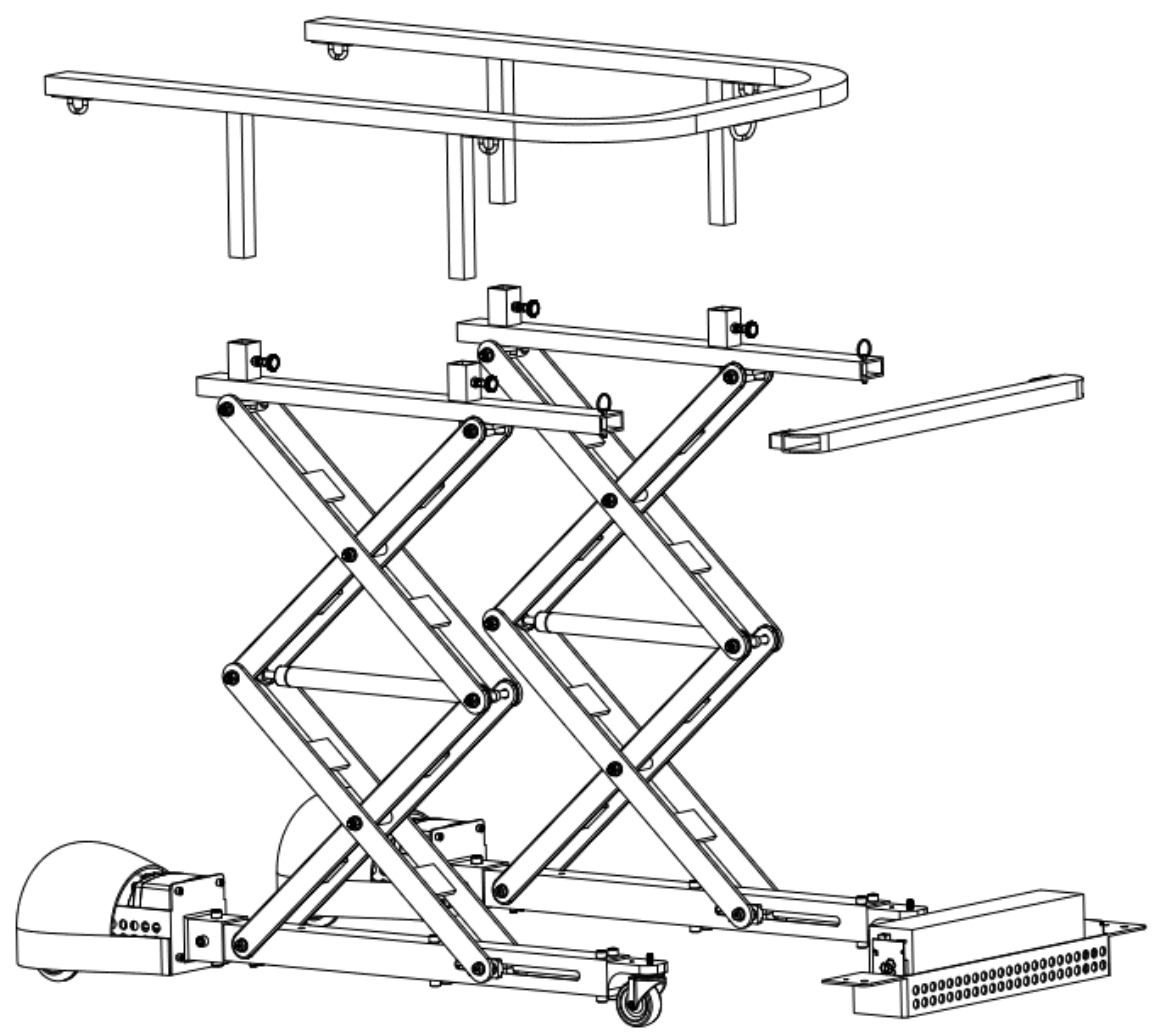

Figure 63: The design allows the walker to be disassembled in to 5 pieces for transportation. The heaviest component is the scissor assembly with a weight of $35 \mathrm{lbs}$. 


\subsection{Future Work and Recommendations}

There are components that have to be carefully designed for this walker for a full system use that were out of the scope of this project. These components are listed below and will have to be researched more in-depth:

1. Harness Design: An ergonomically designed harness is necessary for this walker to provide patients a comfortable seat. The harness has to be designed to be shock absorbing so that if a patient faints or their legs give out, it reduces the impact of a fall by absorbing some of the fall energy.

2. An active drive system will be needed for this walker, the walker weighs around 105 pounds, which will make it difficult for a person to move around.

3. Creation of a light weight gearbox and potential ally a custom motor for weight reduction of the actuation system.

4. In addition to the active drive system, creation of composite components out of carbon fiber will decrease the weight of the system by about at $20 \%$.

5. Summoning feature, if drive system is attached, it could be used to automatically summon the walker so that it could park itself for convenience or automatically park itself on a recharge base. 


\section{REFERENCES}

[1] Aminzadeh F, Edwards N. Exploring seniors' views on the use of assistive devices in fall prevention. Public Health Nurs 1998; 15:297-304J Gerontol 1993; Spec No 48:35-8

[2] Bradley S, Hernandez C. Geriatric assist devices. Am Fam Physician. 2011 Aug $15 ; 84(4): 405-411$

[3] Dean E, Ross J. Relationships among cane fitting, function and falls. Phys Ther 1993;73:493500

[4] Prieb J, Kram R, Why is walker-assisted gait metabolically expensive? Gait \& Posture , Volume 34 , Issue 2, 265 - 269

[5] DK Dey, E Rothenberg, V Sundh, I Bosaeu, B Steen. "Height and body weight in the elderly. I. A 25-year longitudinal study of population aged 70 to 95 years. European Journal of Clinical Nutrition (1999) Volume 53, 905-914

[6] Maki, Brian E., William E. Mcilroy, and Geoff R. Fernie. "Change-in-support reactions for balance recovery." Engineering in Medicine and Biology Magazine, IEEE 22.2 (2003): 2026

[7] "Merry Walker Corporation." Merry Walker Corporation. Web. 19 Feb. 2016. http://www.merrywalker.com/

[8] "ADA Compliance Doors." ADA Compliance Doors. N.p., n.d. Web. 19 Feb. 2016.http://www.ada-compliance.com/ada-compliance/ada-doors.html

[9] H.M. Spackman - Technical Document 1550, June 1989, Mathematical Analysis of Scissor Lifts 
[10] "MORE INFO." Industrial Wheels, Skate Wheels, Skateboard Wheels, Carts. N.p., n.d. Web. 19 Feb. 2016. http://www.kryptane.com/products/industrial-skate-wheels.php

[11] "Arduino - ArduinoBoardMega." Arduino - ArduinoBoardMega. N.p., n.d. Web. 19 Feb. 2016. https://www.arduino.cc/en/Main/arduinoBoardMega

[12] "55505 Series - Flange Mount Geartooth Sensor." 55505 Series. N.p., n.d. Web. 19 Feb. 2016. http://www.littelfuse.com/products/magnetic-sensors-and-reed-switches/hall-effectsensors/55505.aspx

[13] Richard G. Budynas - J. Keith. Nisbett - Joseph Edward. Shigley - Shigley's mechanical engineering design - Boston - McGraw-Hill - 2008 page 405

[14] Richard G. Budynas - J. Keith. Nisbett - Joseph Edward. Shigley - Shigley's mechanical engineering design - Boston - McGraw-Hill - 2008 page 402 8-3

[15] Kamal Kothiyal, Samuel Tettey, Anthropometry for Design for the Elderly, International Journal of Occupational Safety and Ergonomics 2001, Vol 7, No. 1, 15-34

[16] "2015 Latest 24V 35AH Panasonic Cell NCR18650PF Rear Carrier Li-ion Battery with Flat Aluminum Case Charger and BMS." English. N.p., n.d. Web. 19 Feb. 2016. http://www.hallomotor.com/2015-latest-24v-35ah-panasonic-cell-ncr18650pf-rear-carrier-liion-battery-with-flat-aluminium-case-charger-and-bms.html

[17] Hoyer lifts [online] https://www.1800wheelchair.com/product/hoyer-heavy-duty-power-liftwith-optional-scale/

[18] Figure 3,1 from Winter, D.A., Biomechanics and Motor Control of Human Movement. Wiley Intersciences, NewYork, 1990.) 
[19] "Magnus Mobility Systems, Inc." Gas Spring Specifications \& Technical Data. N.p., n.d. Web. 19 Feb. 2016. http://www.magnusinc.com/knowledge-center/gas-springs101/technical-data.html 


\section{APPENDICES}

\section{Appendix 1: Benchmark Prototype Drawings}

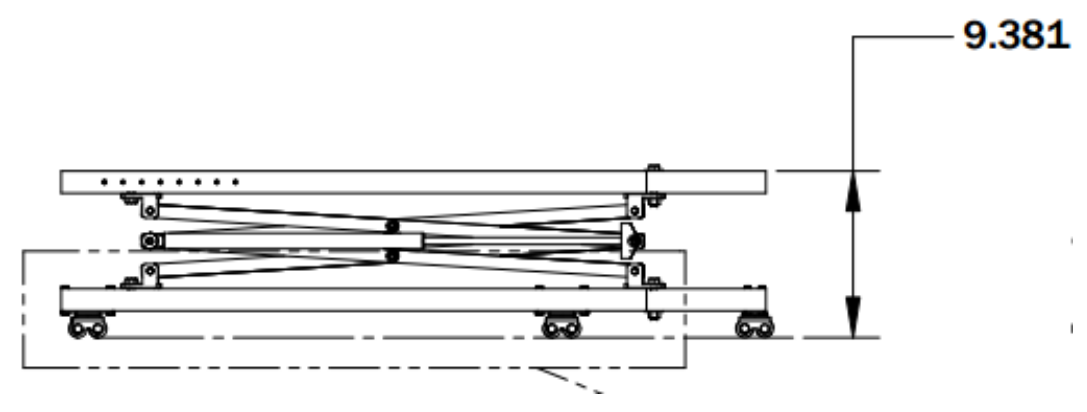

Figure 64: Collapsed height of benchmark prototype walker was 9.4 inches.
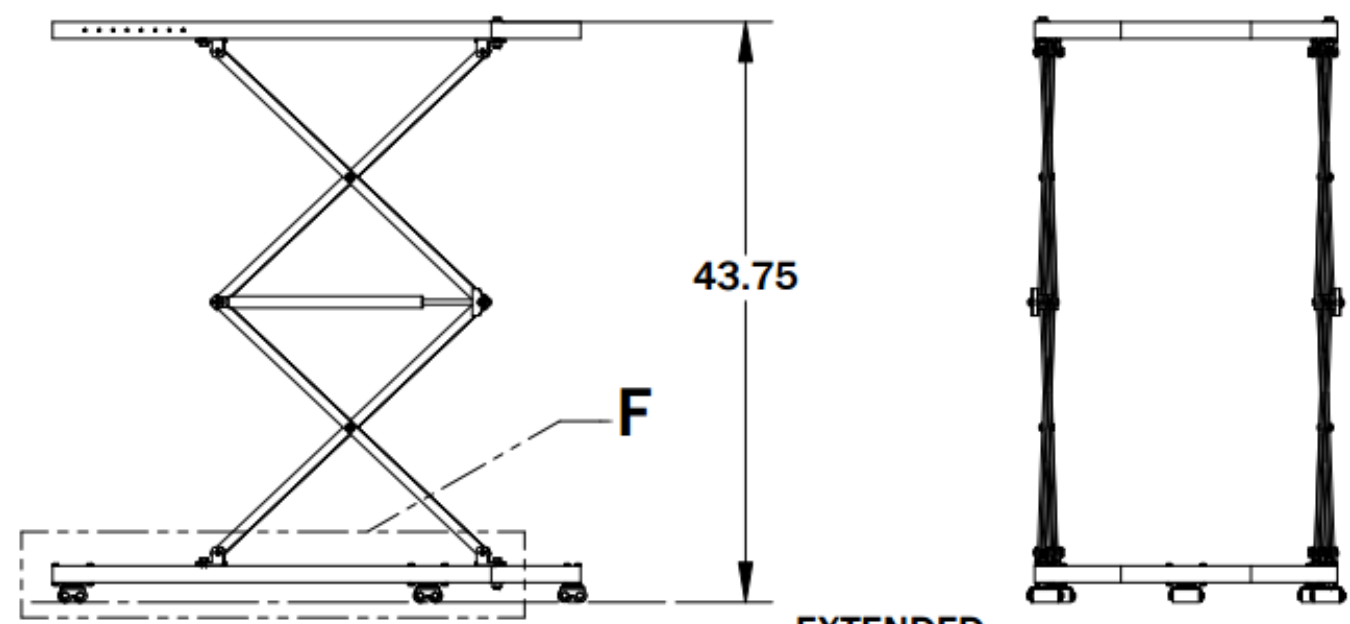

Figure 65: Extended height of benchmark prototype was 43.75 inches. 


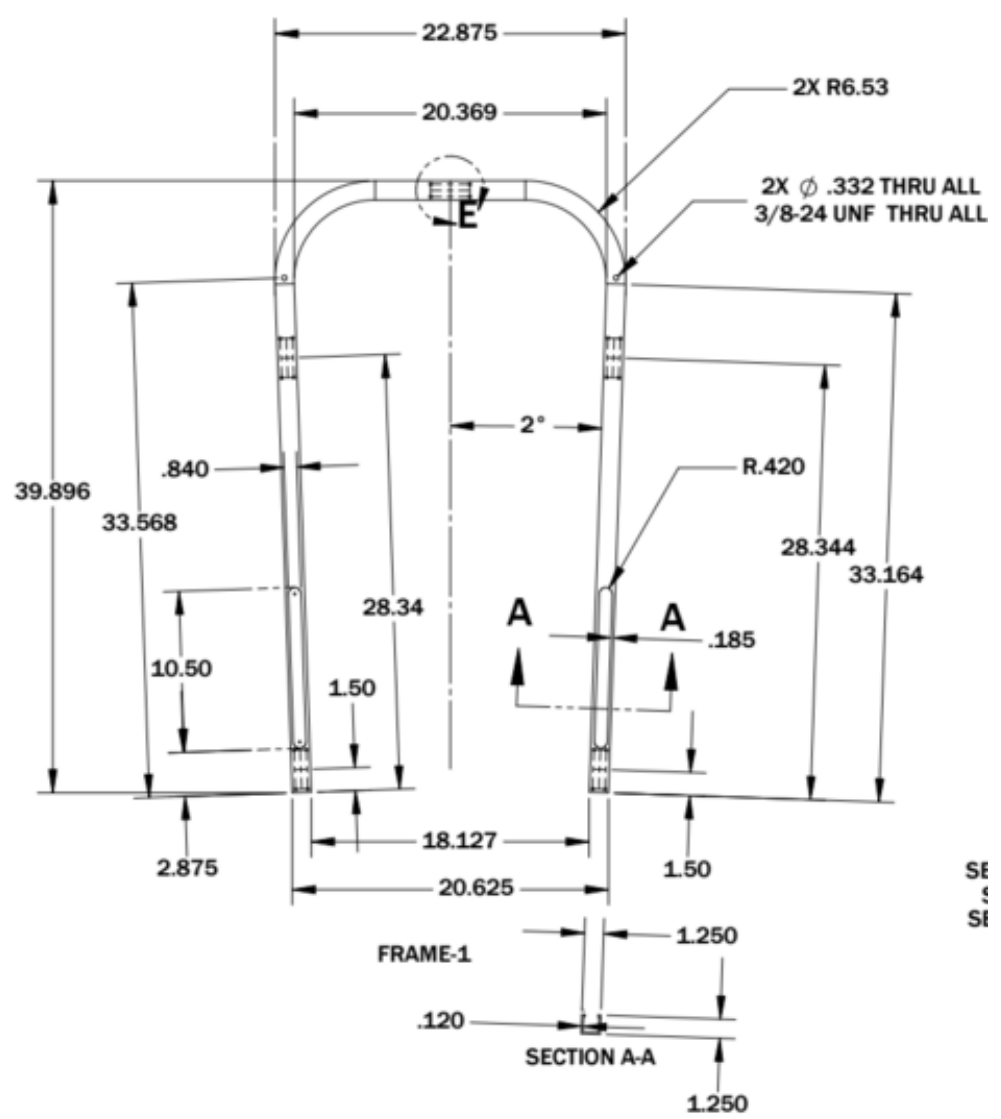

Figure 66: Dimension of the u-shaped frame for the benchmark prototype, the max length was 39.9 inches with a width of 22.9 inches. 


\section{Appendix 2: Dimensional Requirements Research}

Anthropometric data was researched to determine the weight and height requirement to cater to the $95^{\text {th }}$ percentile of elderly. Figure 67 shows this data summarized in a table where the elbow height was extrapolated by using a conversion factor of 0.6 [18].

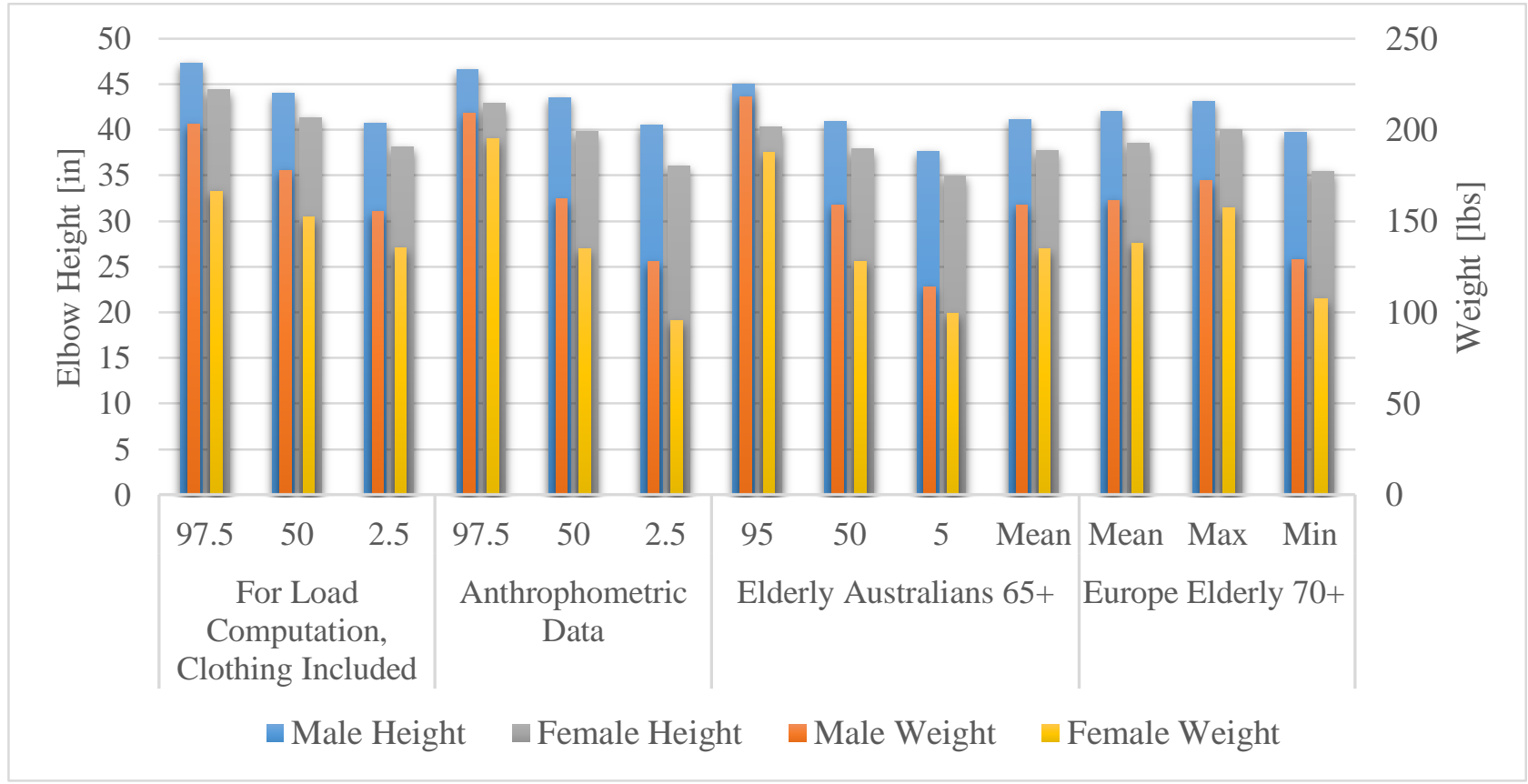

Figure 67: Anthropometric data for the elderly population. The maximum 65 year + weight is 218 with a max elbow height of 45 inches. 


\section{Appendix 3: Ranking Matrix}

A ranking matrix revealed that the Electric system would be superior compared to a pneumatic system.

Table 27: Ranking matrix comparing a pneumatic vs electric actuation design.

\begin{tabular}{|c|c|c|c|c|c|}
\cline { 3 - 6 } \multicolumn{2}{c}{} & \multicolumn{2}{c|}{ Pneumatic } & \multicolumn{2}{c|}{ Electric } \\
\hline Criteria & Weight & Score & Weighted & Score & Weighted \\
\hline Ease of Operation & 8 & 3 & 24 & 3 & 24 \\
\hline Controllability & 7 & 1 & 7 & 3 & 21 \\
\hline Weight & 3 & 2 & 6 & 2 & 6 \\
\hline Lift Speed & 3 & 3 & 9 & 1 & 3 \\
\hline Ease of maintenance & 5 & 1 & 5 & 3 & 15 \\
\hline Critical failure points & 6 & 2 & 12 & 3 & 18 \\
\hline Lack of Need of secondary safety & 7 & 0 & 0 & 3 & 21 \\
\hline Actuation sound & 1 & 2 & 2 & 2 & 2 \\
\hline Cost & 5 & 2 & 10 & 2 & 10 \\
\hline Safety & 10 & 2 & 20 & 3 & 30 \\
\hline Collapsibility & 5 & 3 & 15 & 3 & 15 \\
\hline Durability & 7 & 2 & 14 & 3 & 21 \\
\hline Weight Capacity & 6 & 3 & 18 & 2 & 12 \\
\hline Hot swappable energy store & 4 & 1 & 4 & 3 & 12 \\
\hline Ease of recharging energy storage & 3 & 1 & 3 & 3 & 9 \\
\hline Total & & & $\mathbf{1 4 9}$ & & $\mathbf{2 1 9}$ \\
\hline
\end{tabular}

Table 28: Description of the score and weight used in the ranking matrix.

\begin{tabular}{|c|c|}
\hline Weight & Meaning \\
\hline 5 & Very high importance \\
\hline 4 & High importance \\
\hline 3 & Medium importance \\
\hline 2 & Low importance \\
\hline 1 & Very low importance \\
\hline 0 & Not important \\
\hline & \\
\hline Score & Meaning \\
\hline 3 & Fully satisfies \\
\hline 2 & Substantially satisfies \\
\hline 1 & Partially Satisfies \\
\hline 0 & Does not satisfy \\
\hline
\end{tabular}




\section{Appendix 4: Matlab Scripts}

\section{A4.1 Power Screw Function}

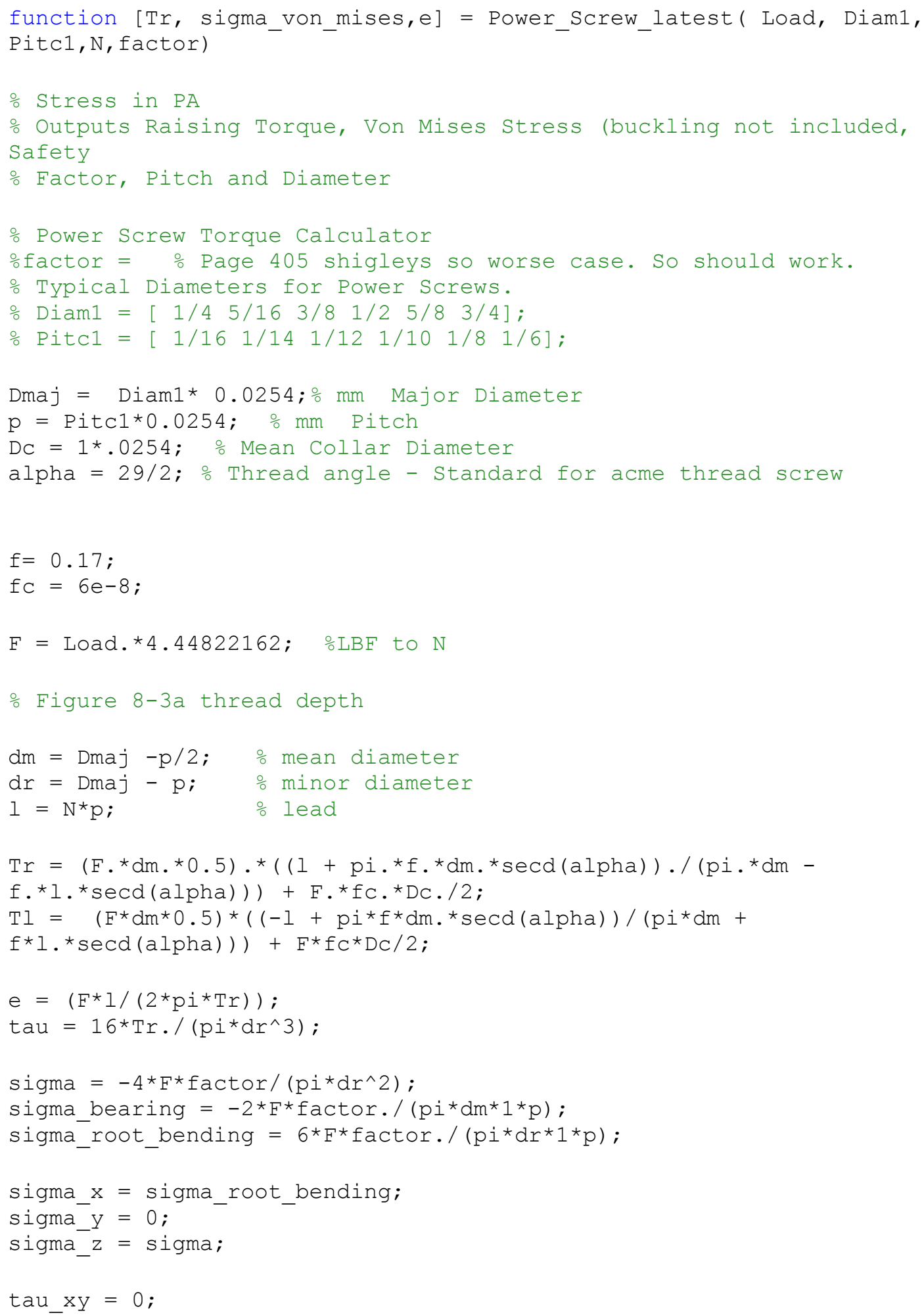




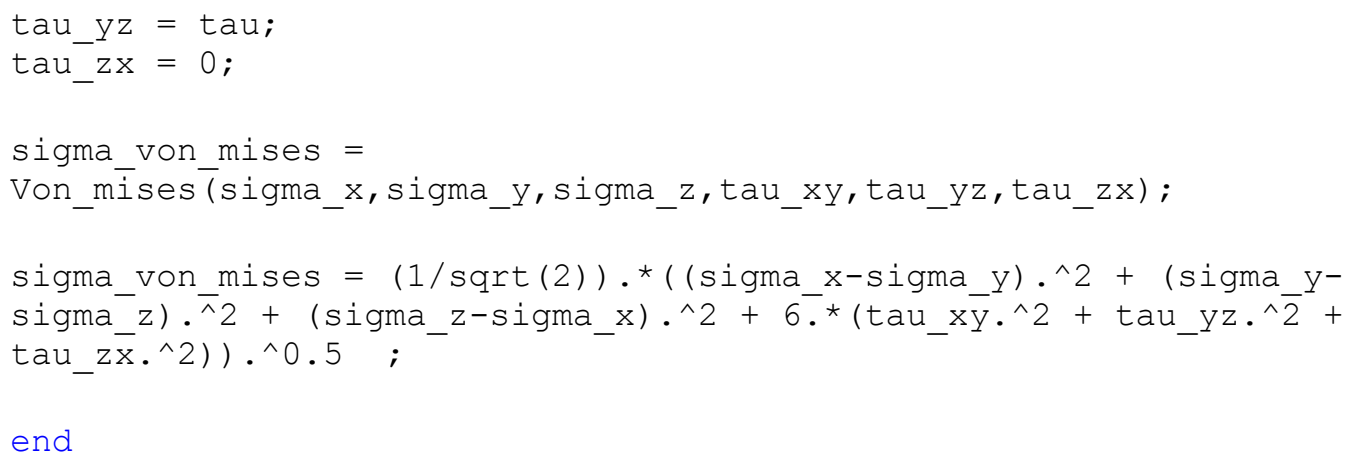

end

\section{A4.2 Hybrid Gas Motor Function}

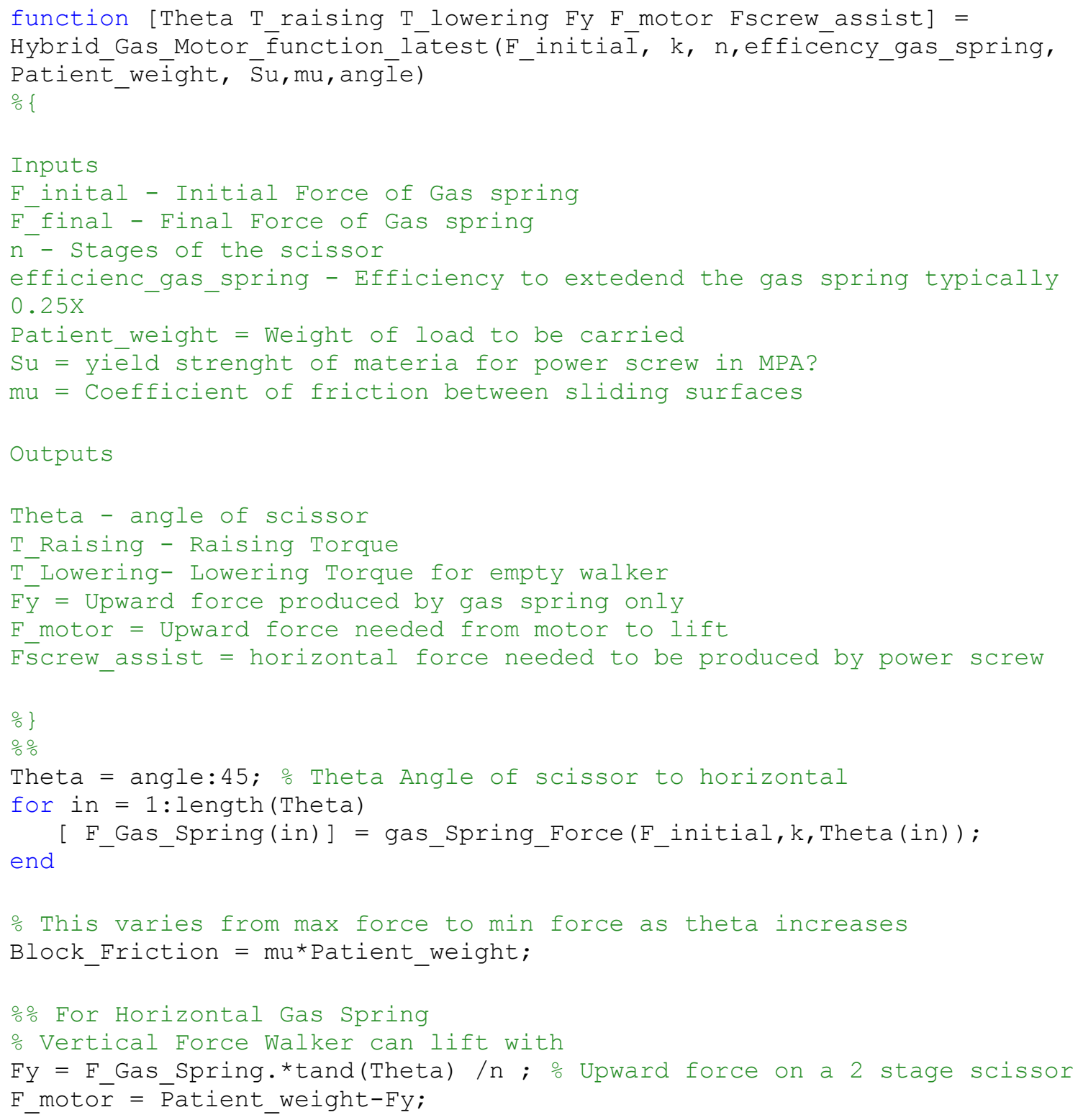




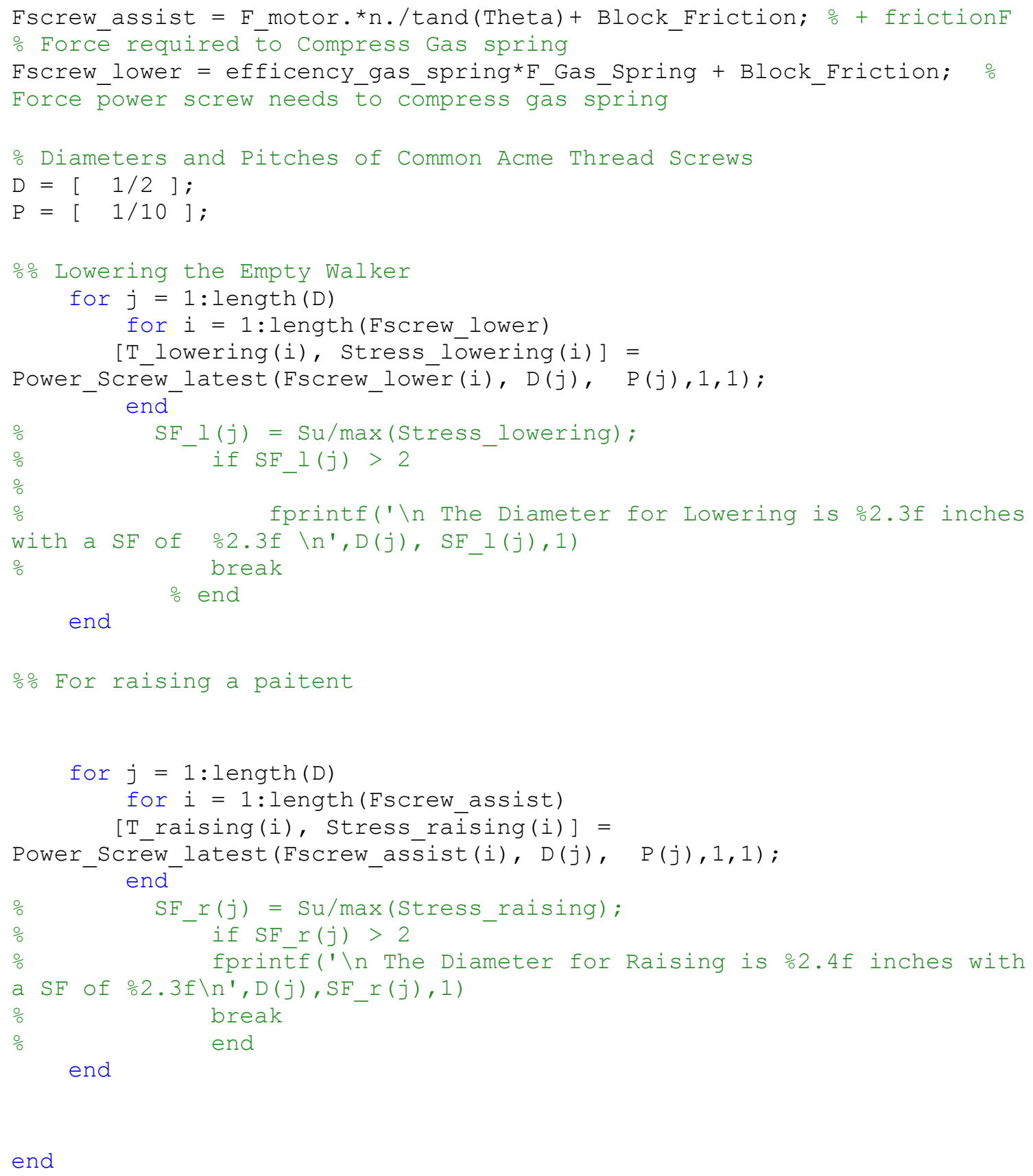

\section{A4.3 Optimization of Gas Spring Motor Master}

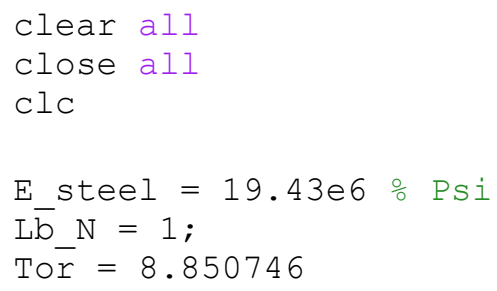




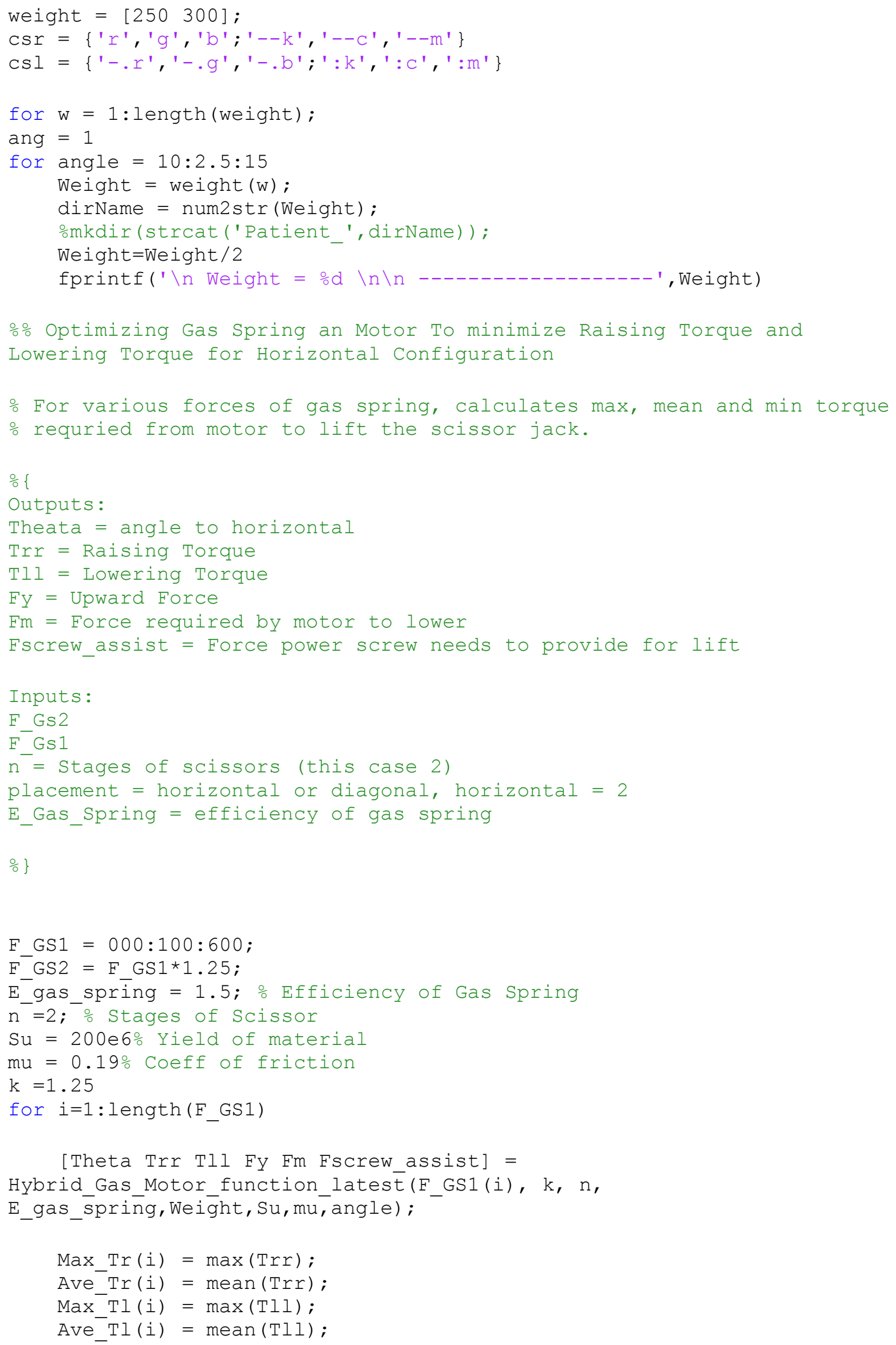


$\operatorname{Min} \operatorname{Tr}(i)=\min (\operatorname{Trr}) ;$
$\operatorname{Min} \operatorname{Tr}(i)=\min (\operatorname{Tll}) ;$

end

figure(1)

clf

plot (F_GS1*Lb_N,Max_Tr*Tor, 'r')

hold on

plot (F_GS1*Lb_N,Max_Tl*Tor, 'b')

plot ( $F^{-}$GS $1{ }^{*} \mathrm{Lb}{ }^{-} \mathrm{N}$, Ave ${ }^{-}$Tr*Tor, '. $\left.-r^{\prime}\right)$

plot (F GS1* Lb- N, Avēe Tl*Tor, '.-b')

plot ( F GS $1 *$ Lb N, Min Tr*Tor, 's-r')

plot (F_GS1*Lb_N, Min_Tl*Tor, ' $\mathrm{s}-\mathrm{b}$ ')

xlabel ('Gas spering Force [lbs]')

ylabel ('Torque [in-lbs]')

legend('Max Raising ', 'Max Lowering ', 'Mean Raising', 'Mean Lowering

', 'Min Raising', 'Min Lowering', 'Orientation', 'Vertical',2)

$\div \mathrm{T}=$ strcat (num2str(n),' Stage Scissor', 'Horizontal Gas

Spring', num2str(E_gas_spring), 'Efficiency Gas Spring')

응title $(\mathrm{T})$

응 $\frac{0}{2}$

\%inp = ginput $(3)$;

$\div \circ$

o Takes three points from figure 1 and calculates the motor torque required

응 the full range for lifting and lowering the walker

을etal Trr1 Tll1 Fyl Fml Fscrew assist1] =

Hybrid_Gas_Motor_function_latest(inp (w, 1)/Lb_N, 1.3, n, E_gas_spring, Weight, Su, mu , angle);

을eta2 Trr2 Tl12 Fy2 Fm2 Fscrew assist2] =

Hybrid_Gas Motor function_latest(inp $(w, 2) / L b$ N, k, n, E_gas_spring, Weight, $\mathrm{Su}, \overline{\mathrm{m} u}$, angle $\mathrm{l})$;

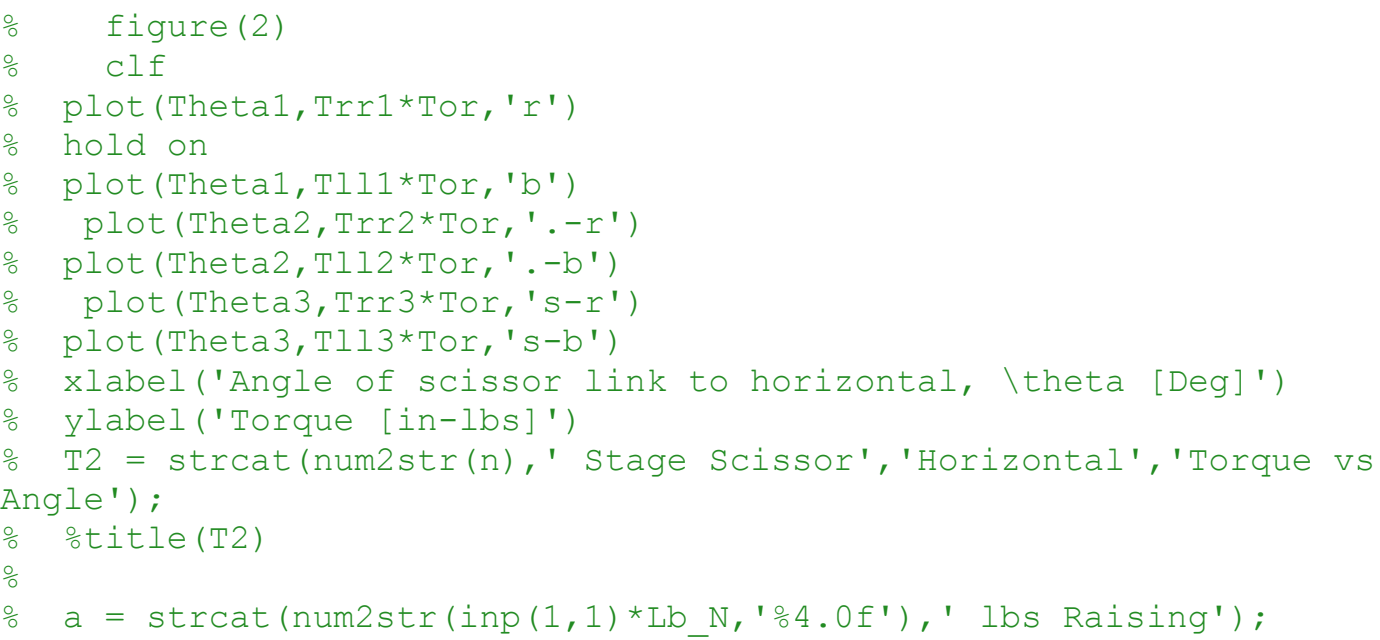




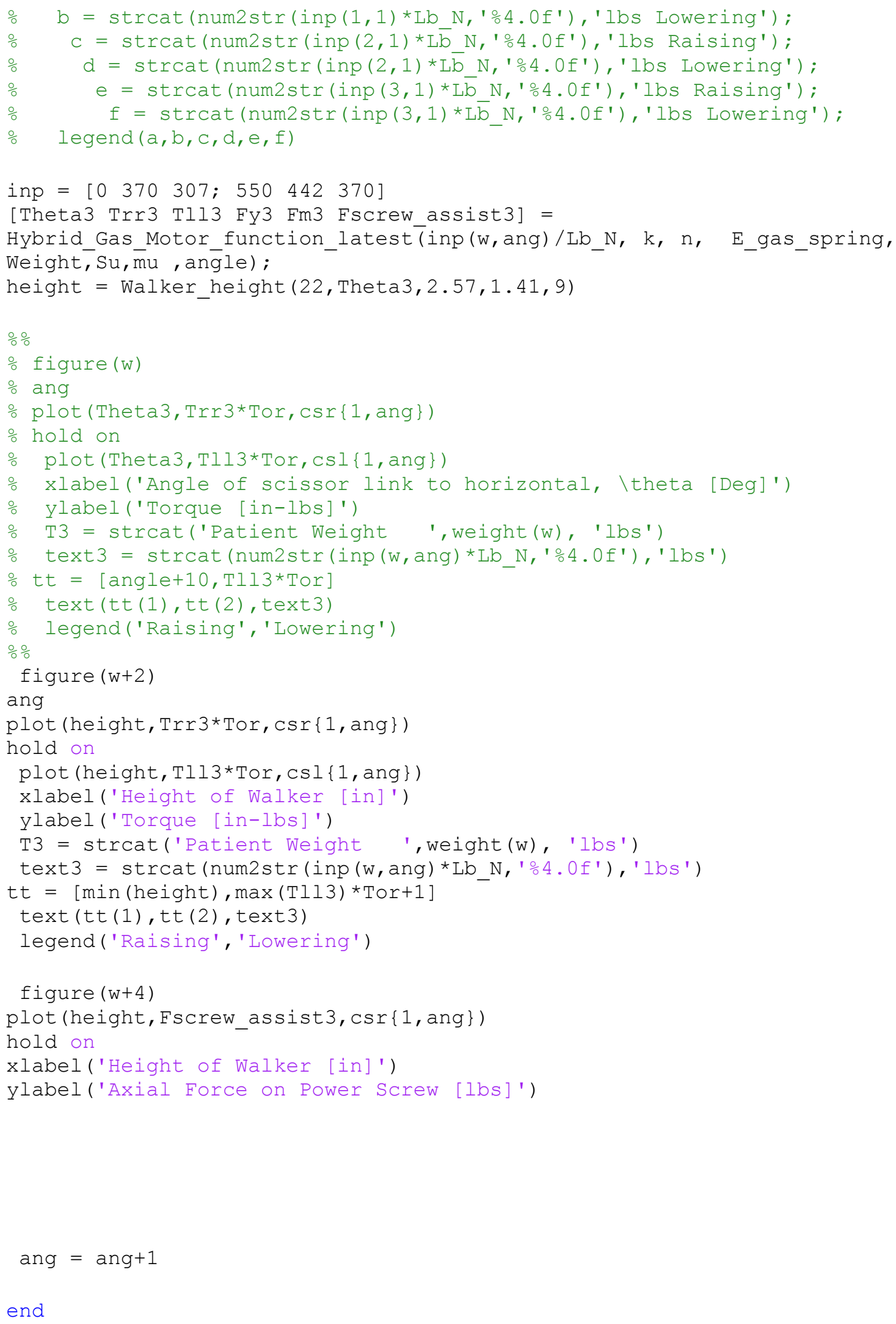




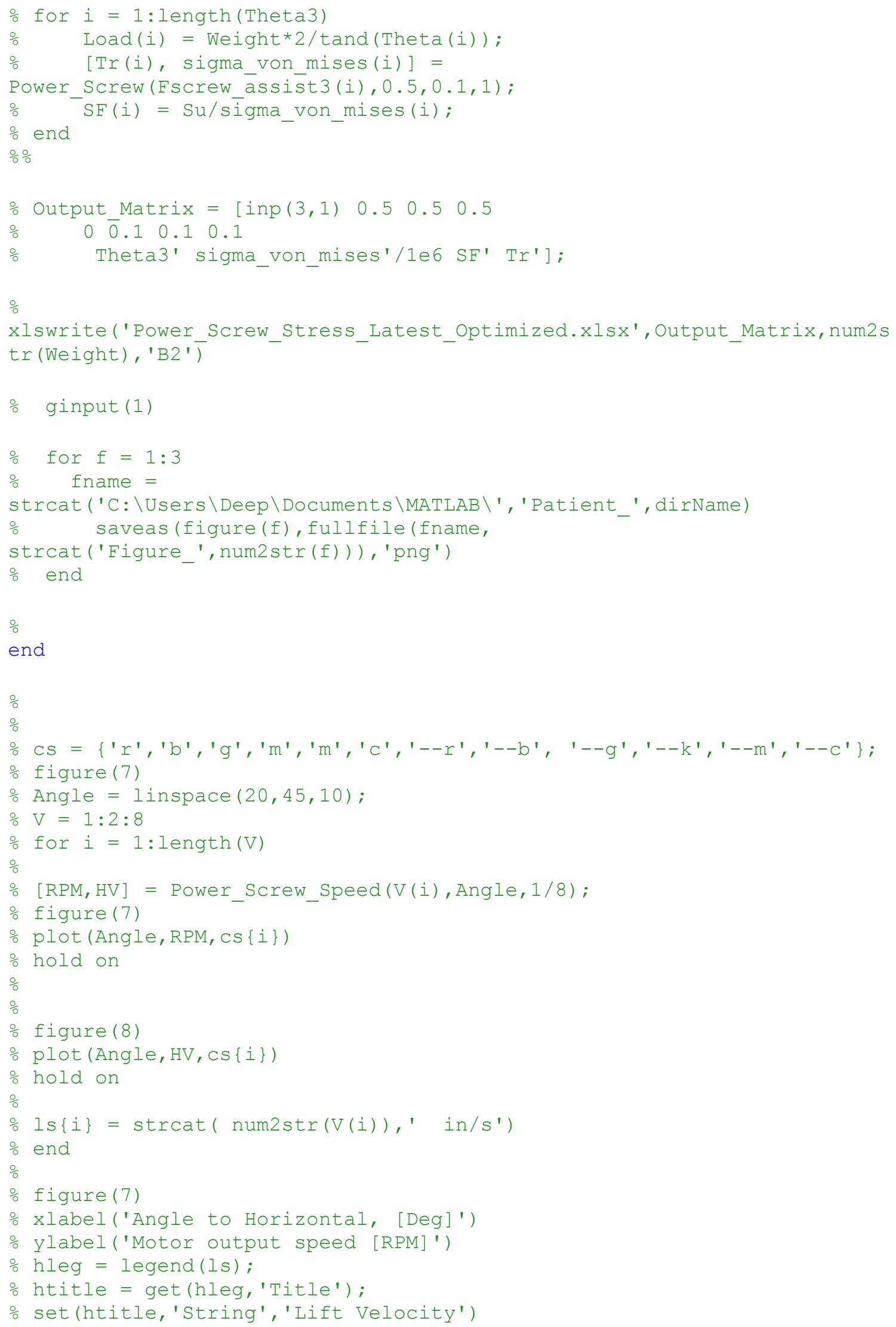




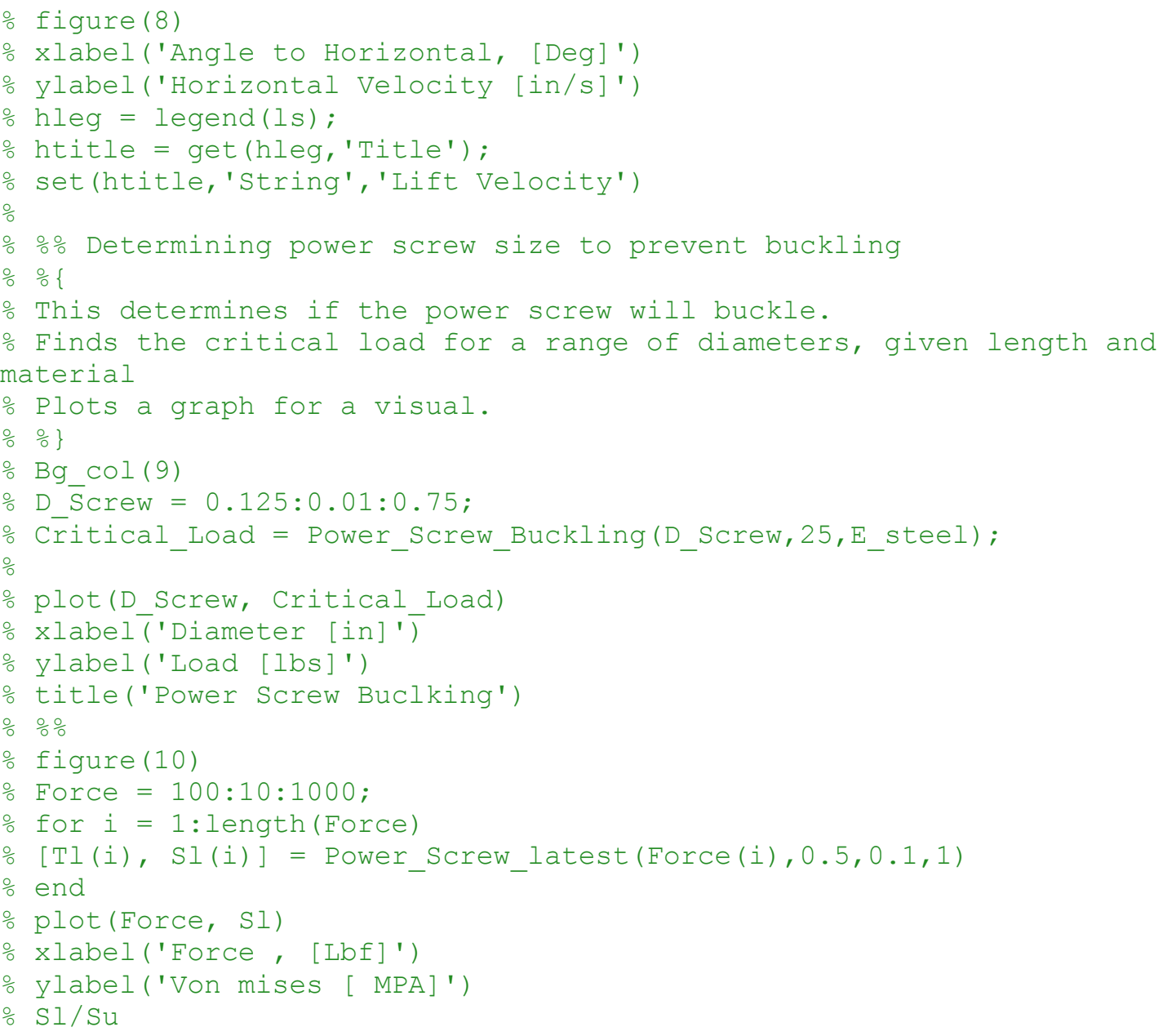

\section{A4.4 Background Color}

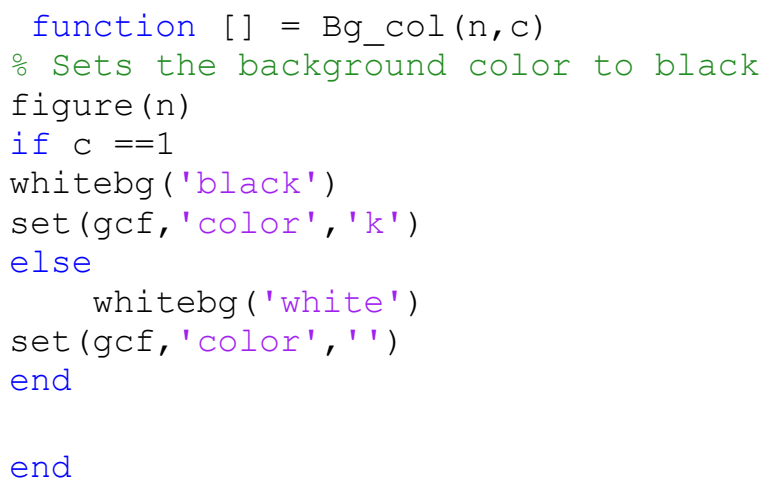




\section{A4.5 Plotting Adams Joint Forces}

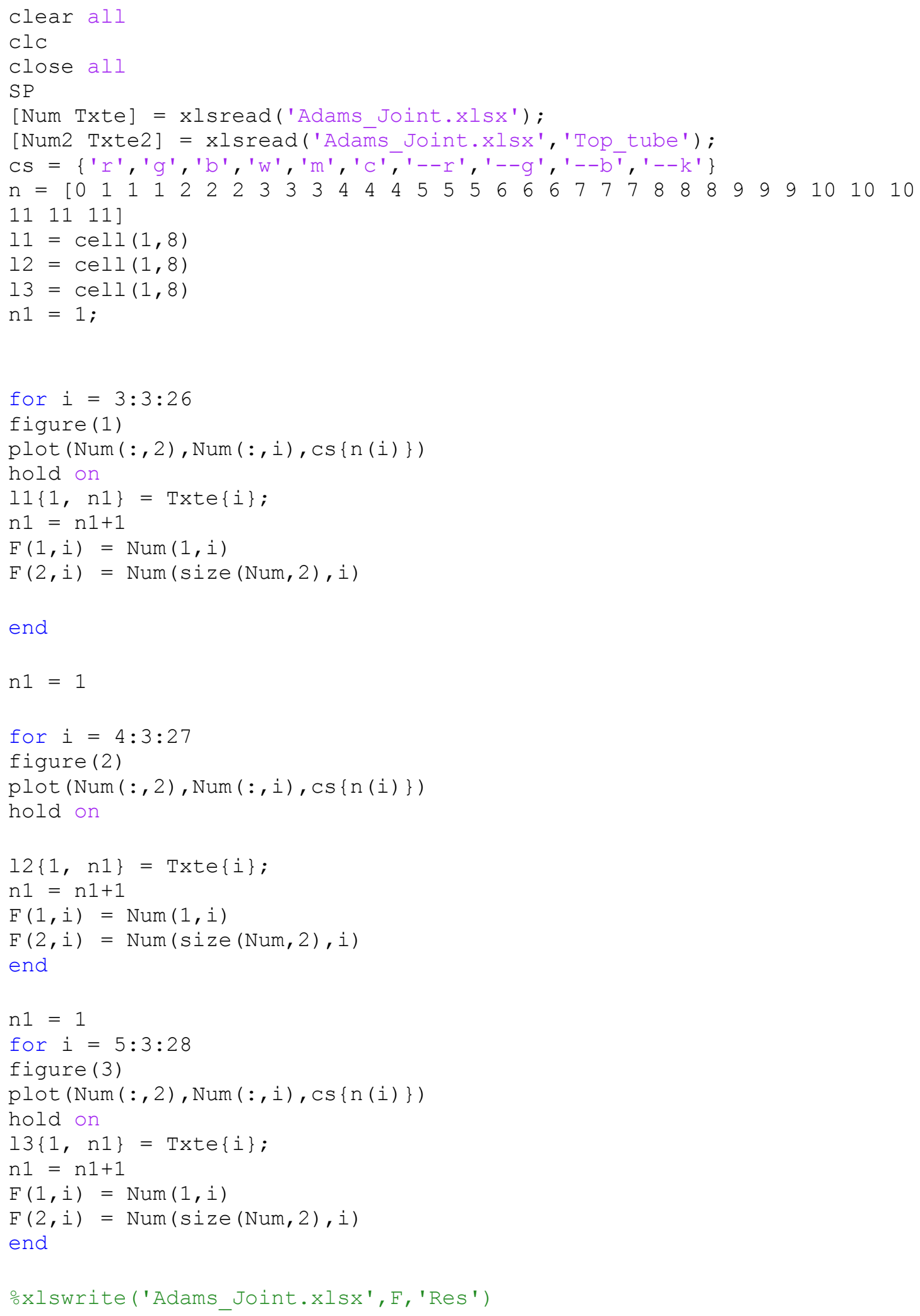




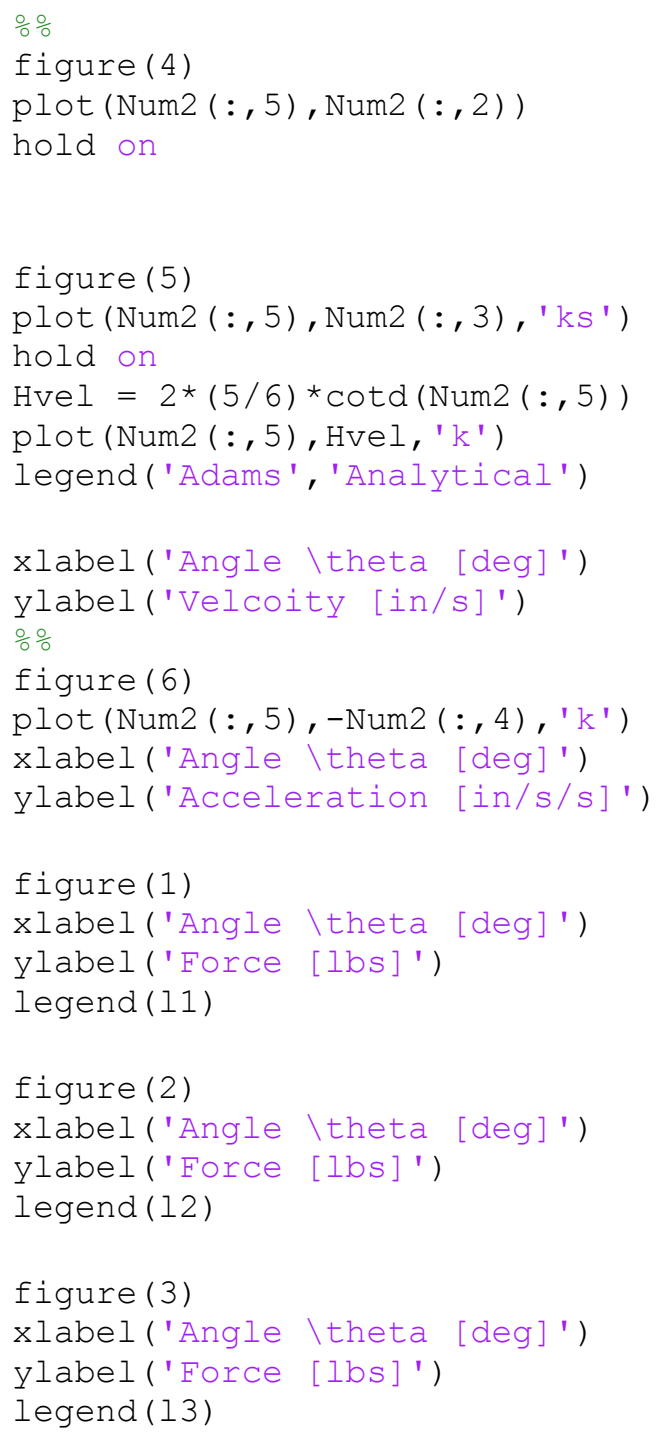

\section{A4.6 Gas Spring Force Function}

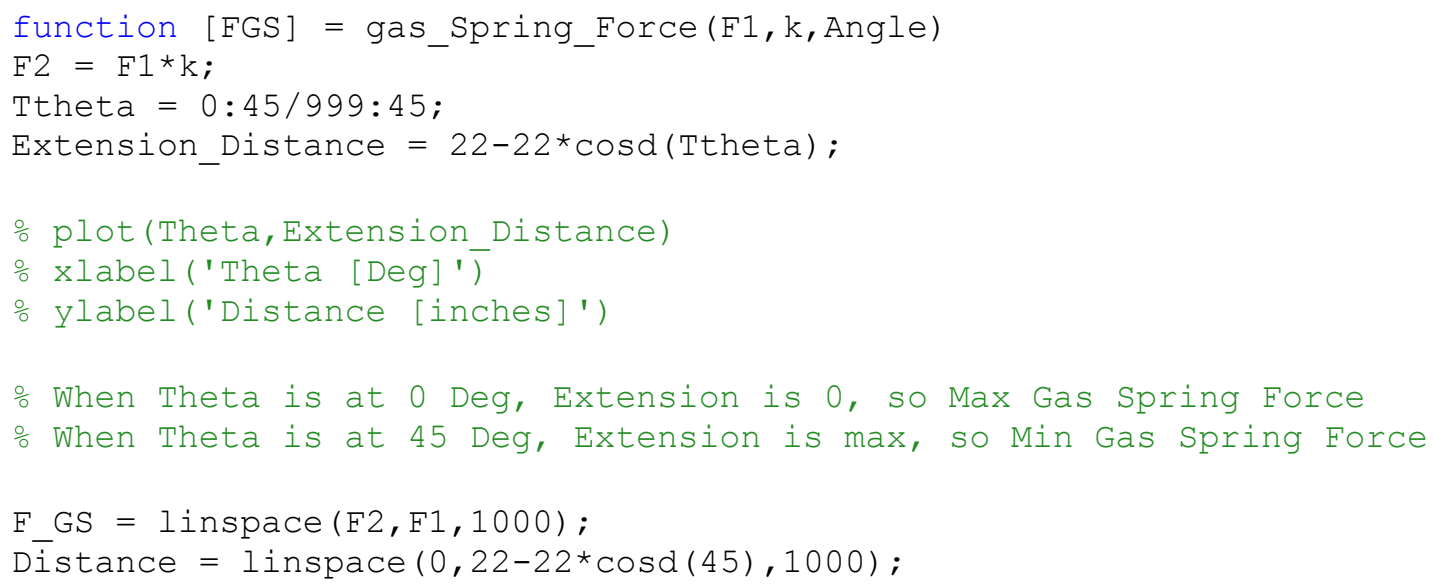




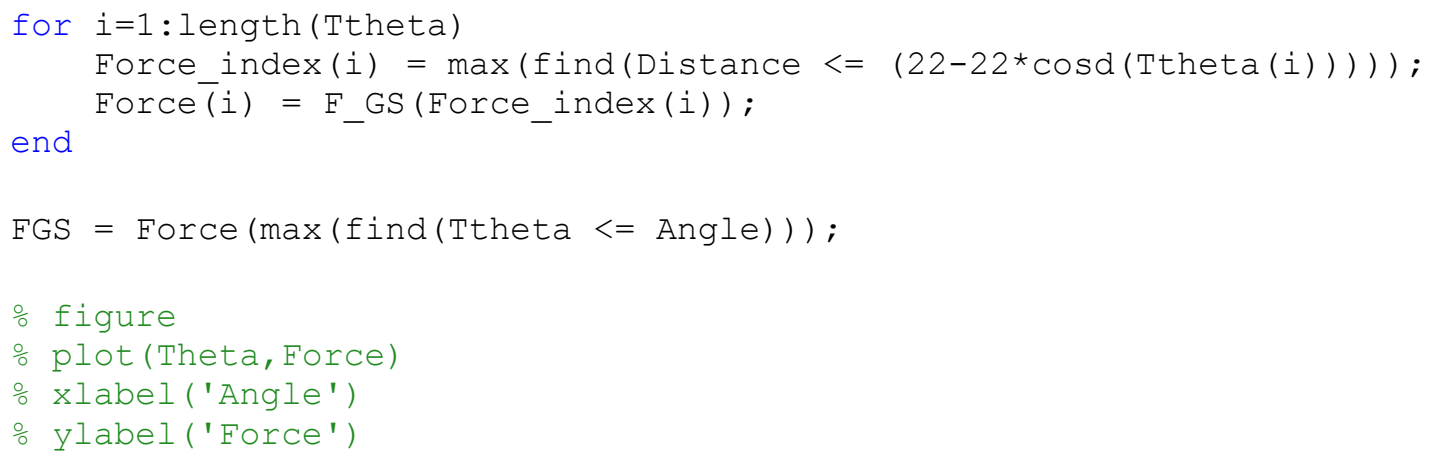

end

\section{A4.7 Bolt Stress}

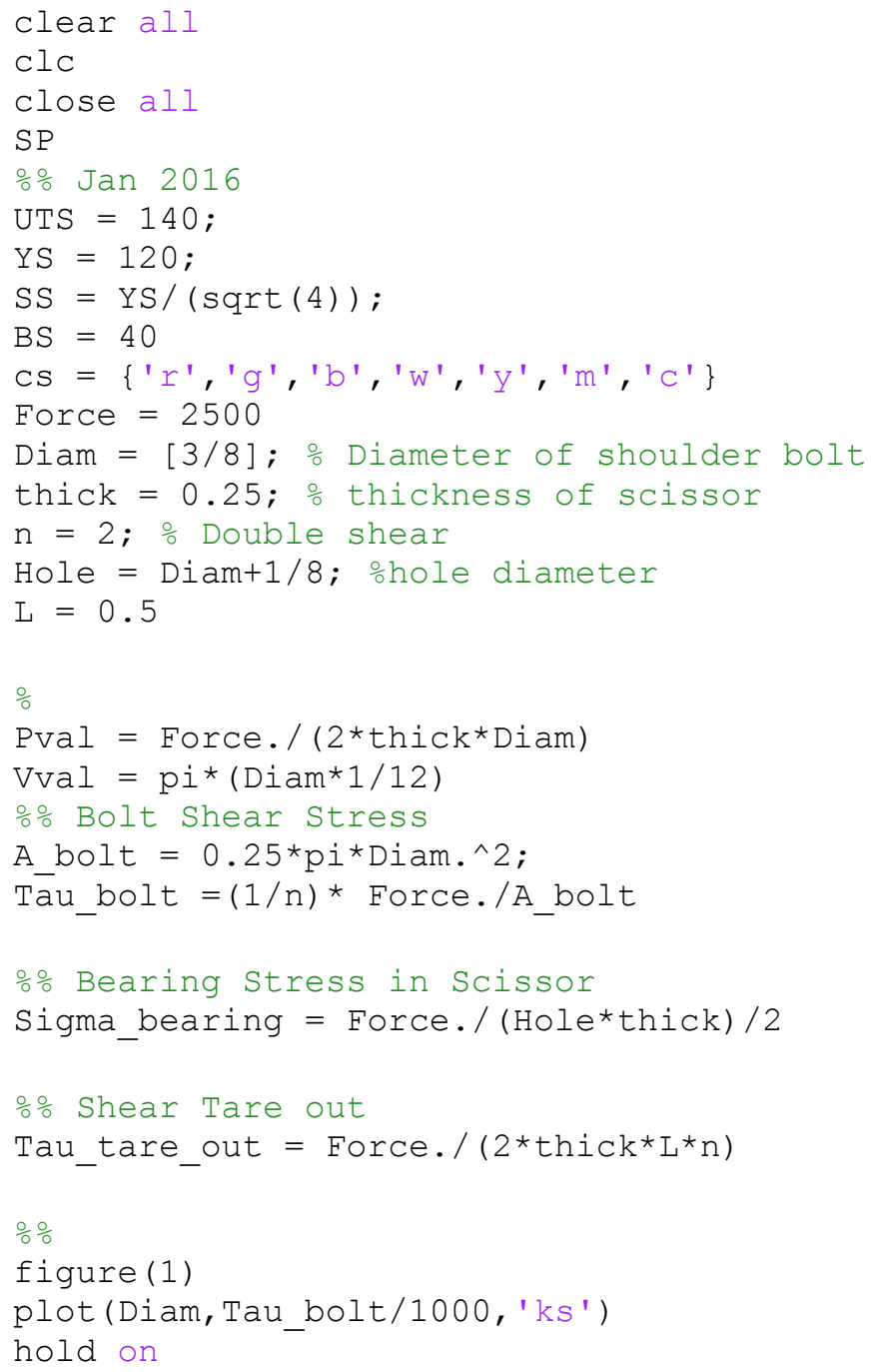




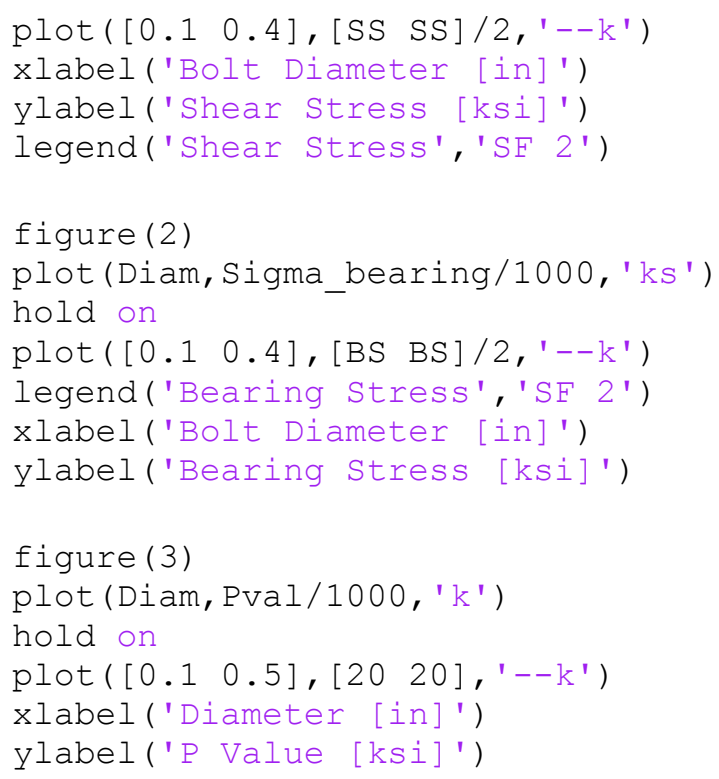

\section{A4.8 Scissor Height}

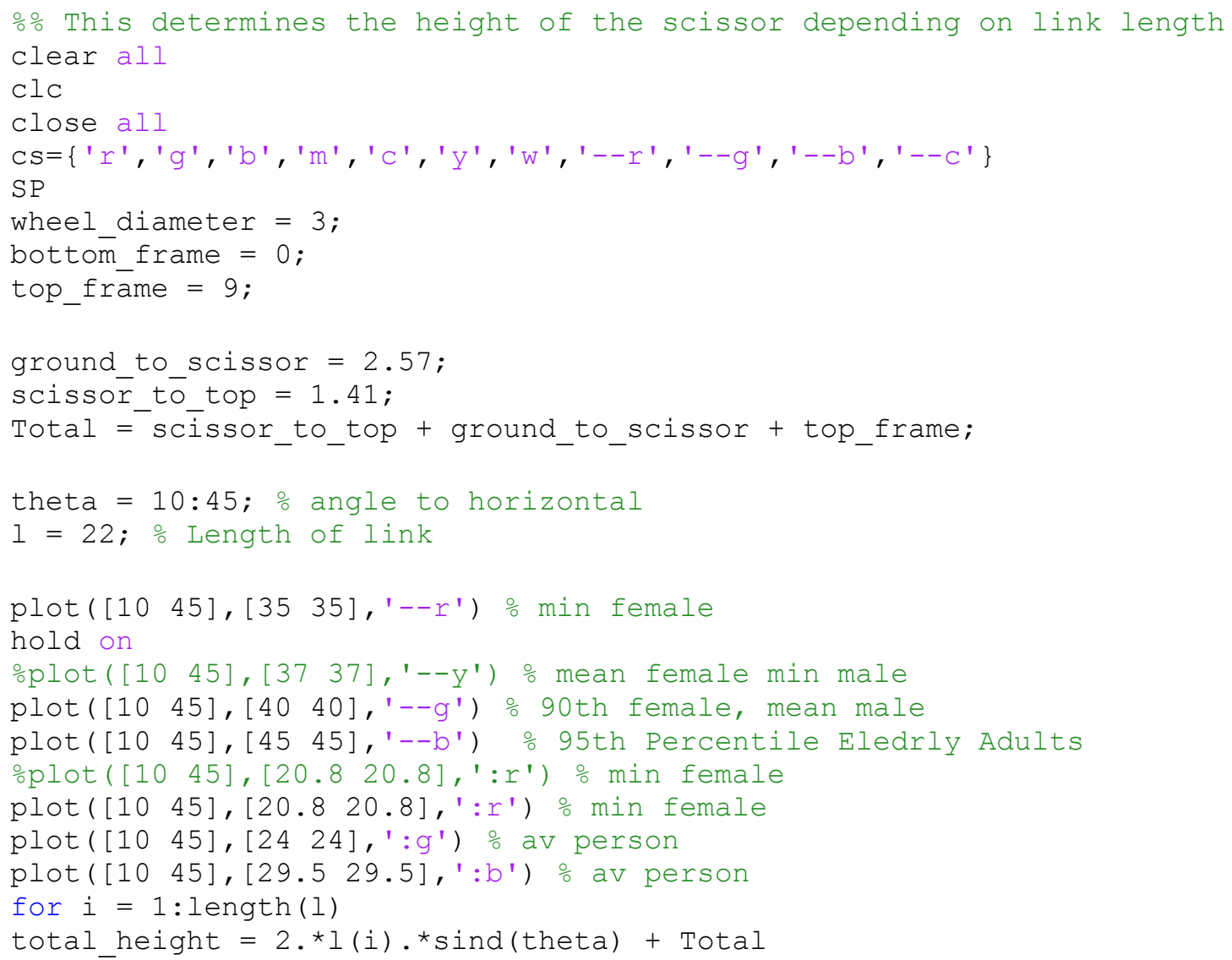




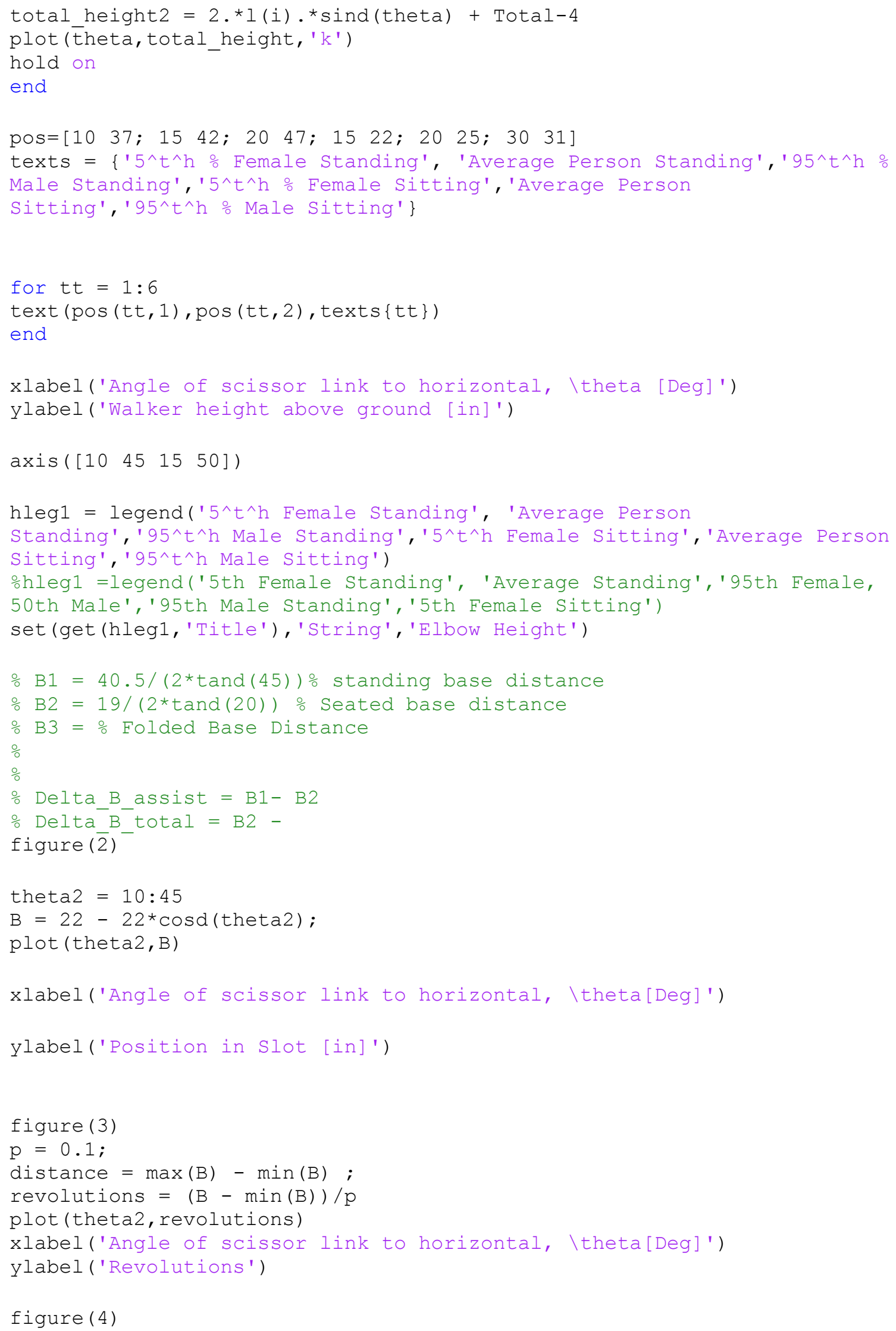




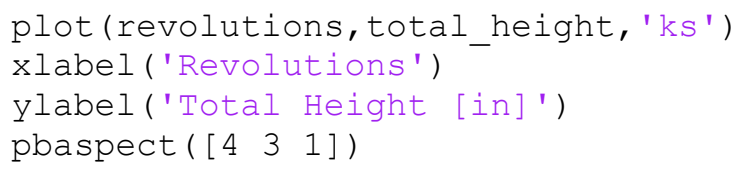

$\operatorname{Bg} \operatorname{col}(1,0)$ 


\section{Appendix 5: Material Properties used for Simulations and Finite Element Analysis}

Table 29 lists the material properties used in both ADAMS and Abaqus for Rigid Body Dynamics and Finite Element Analysis

Table 29: Material properties used in FEA and Adams simulations.

\begin{tabular}{|c|c|c|}
\hline & Aluminum 6061-T6 & Stainless Steel 304 \\
\hline Density, [lb/in ${ }^{3}$ ] & 0.0975 & 0.289 \\
\hline Young's Modulus [ksi] & 10,000 & 26,000 \\
\hline Poisson Ratio & 0.33 & 0.29 \\
\hline Tensile Yield Strength, [ksi] & 40 & 31.2 \\
\hline
\end{tabular}




\section{Appendix 6: Gas Spring Specifications}

Gas springs are used in a variety of mechanisms, most commonly found in automobile trunks. They can produce a large force within a smaller package compared to a mechanical spring of a similar size. The gas spring is typically characterized by its force ratio which can range from $1.1 \mathrm{x}-1.4 \mathrm{x}$, this is ratio of the force from contracted to extended position. In the case of a compression gas spring, this is the inverse of this ratio, i.e. extended to contract. The force of the gas spring is typically measured at $5 \mathrm{~mm}$ from the fully extended and fully contacted position and is an industry standard. The typical force ratio for a contraction gas spring is $1.25 \mathrm{x}$.

A gas spring is specified using the force at its extended position, P1 in the case of an extension gas spring and at a contracted positon for a contraction gas spring. Other parameters that are typically specified include Extended Length, Stroke Length, and End fittings.

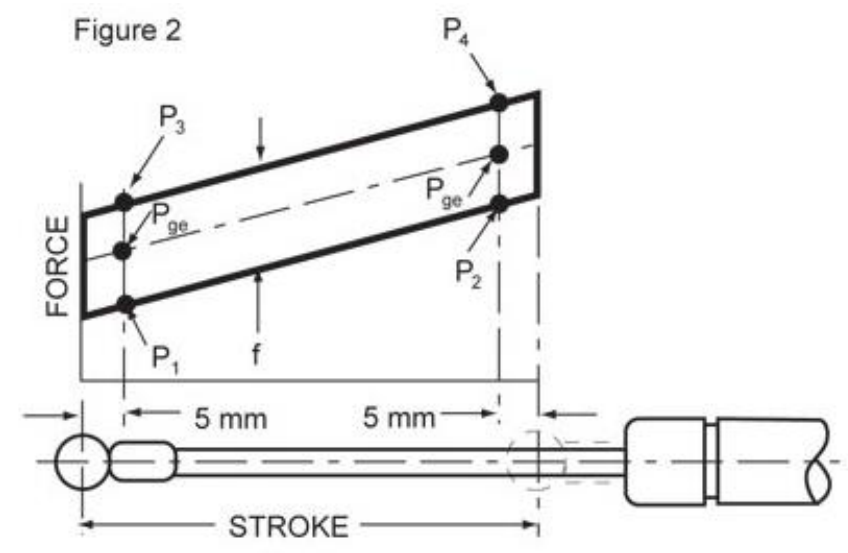

Figure 68: The force ratio is the slope of the gas spring is $\mathrm{P} 2 / \mathrm{P} 1$ for the case of an extension gas spring. This typically ranges from 1.1 to 1.4 for standard gas springs [19]. 
Table 30: Gas spring specifications.

\begin{tabular}{|c|c|}
\hline Property & Value \\
\hline Type & Contraction \\
\hline Force at P1 (Nominal Force) & $350 \mathrm{lbs}$ \\
\hline Extended Length (eyelet to eyelet) & 22 inches \\
\hline Contracted Length (eyelet to eyelet) & 15 inches \\
\hline Stroke Length & 7 inches \\
\hline End Fittings & M8 Eyelets, \\
\hline Eyelet Hole Diameter & 0.375 inches \\
\hline Thread lock Adhesive & LOCTITE® THREADLOCKER \\
& RED 271 \\
\hline
\end{tabular}

Typical end fittings include gas spring eyelet fittings which are typically found in Metric M6, M8 or M10 threads. 


\section{Appendix 7: Motor Key Way Information}

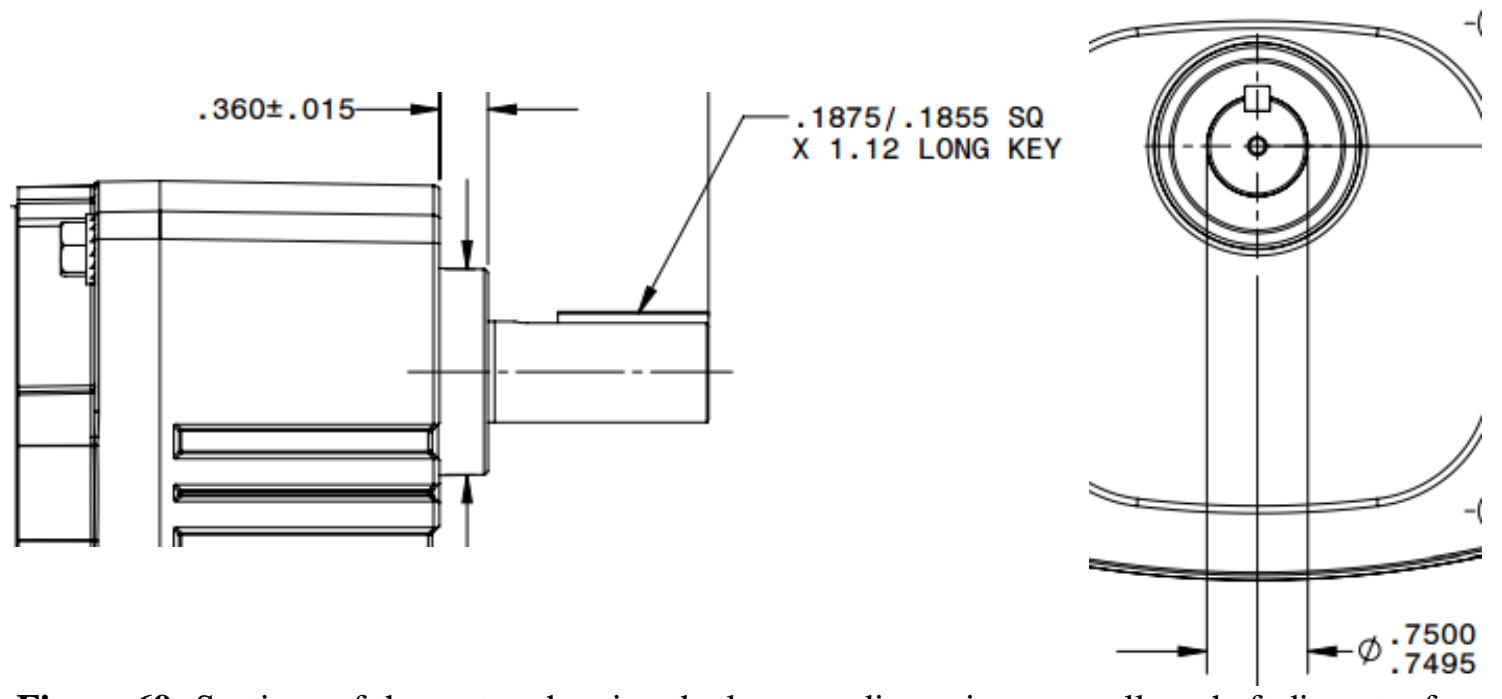

Figure 69: Sections of the motor showing the keyway dimensions as well as shaft diameter for the selected DC gear motor model no 5060 from Bodine electric. 


\section{Appendix 8: Final Design Dimensions}
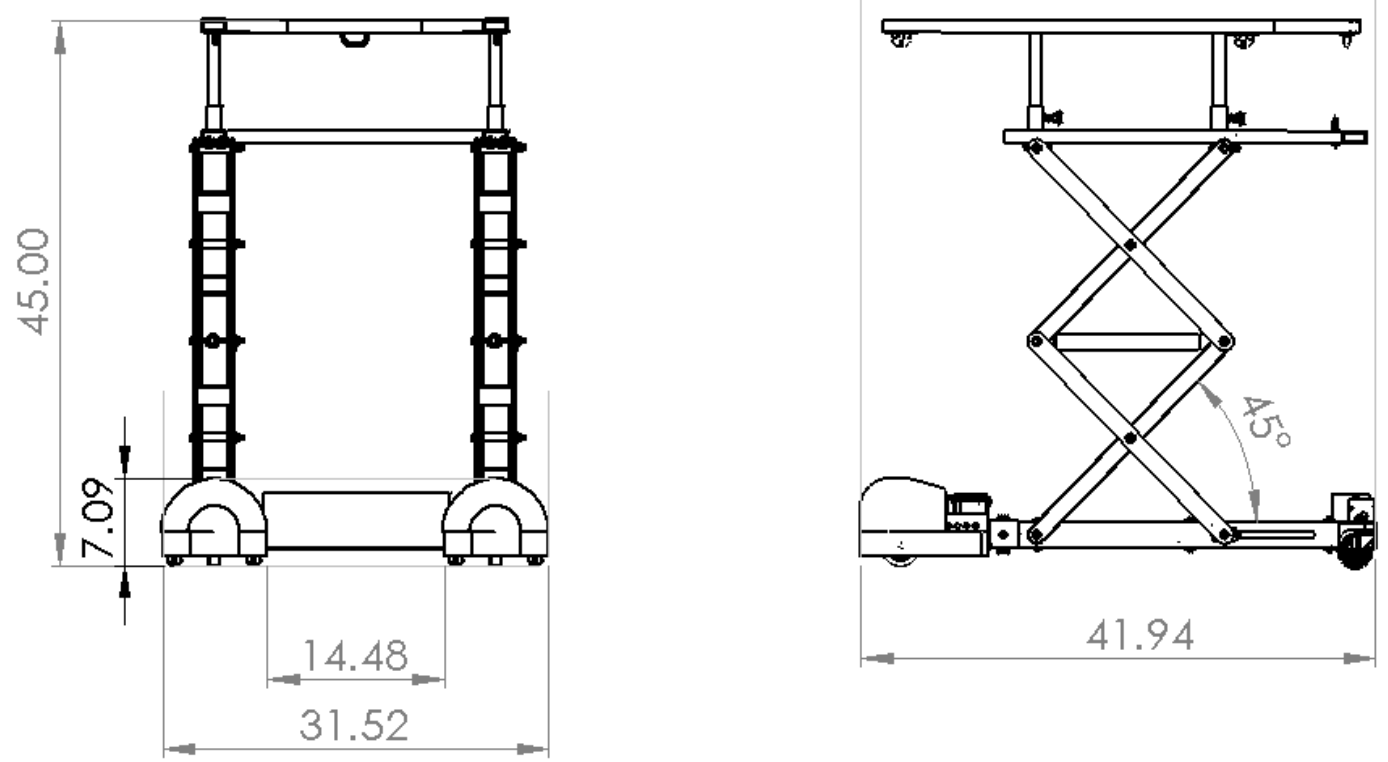

Figure 70: The overall dimensions of the final design are within the maximum specified requirements as listed in Table 3.

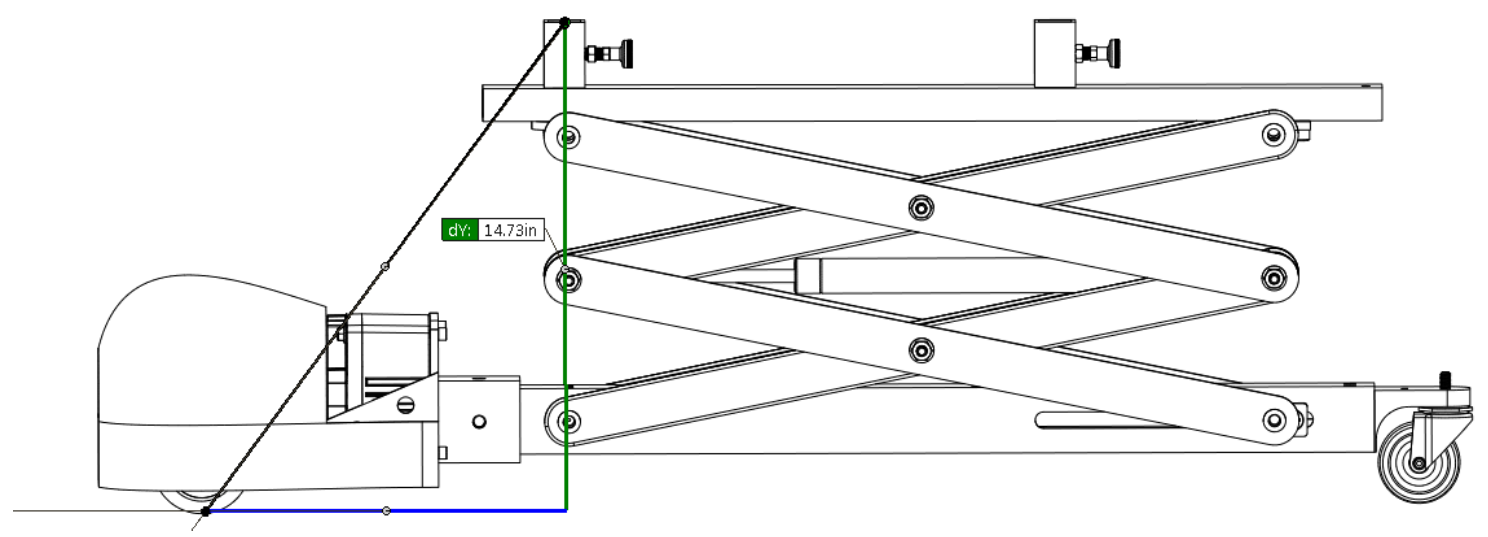

Figure 71: The collapsed height is 14.73 inches. 


\section{Appendix 9: Joint Loads for Typical Conditions (Functioning Gas Spring)}

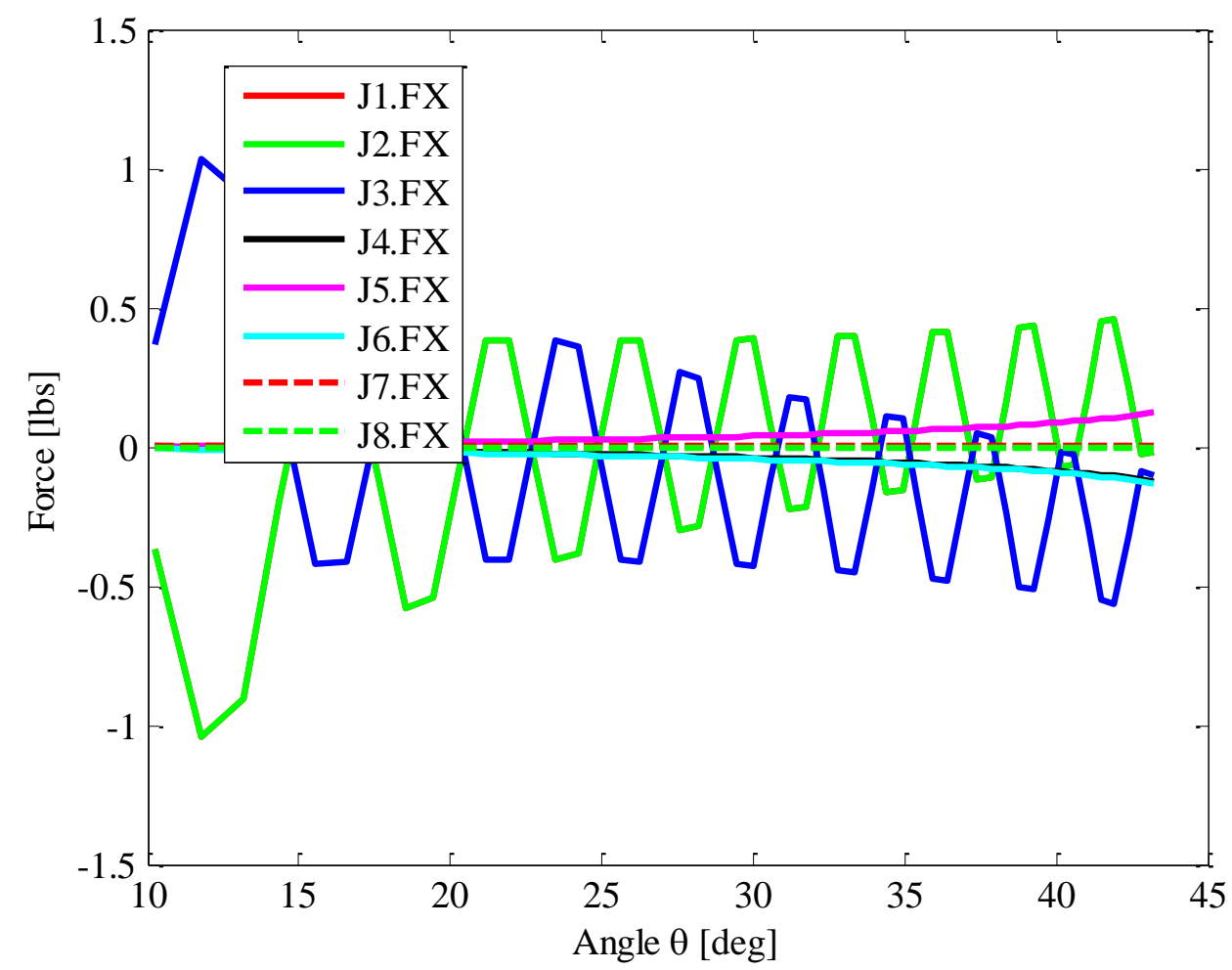

Figure 72: The force in the $\mathrm{x}$ is close to zero for Joints 1-8 indicates that simulation was successful, and that there is no lateral force. Case with failed gas spring. 


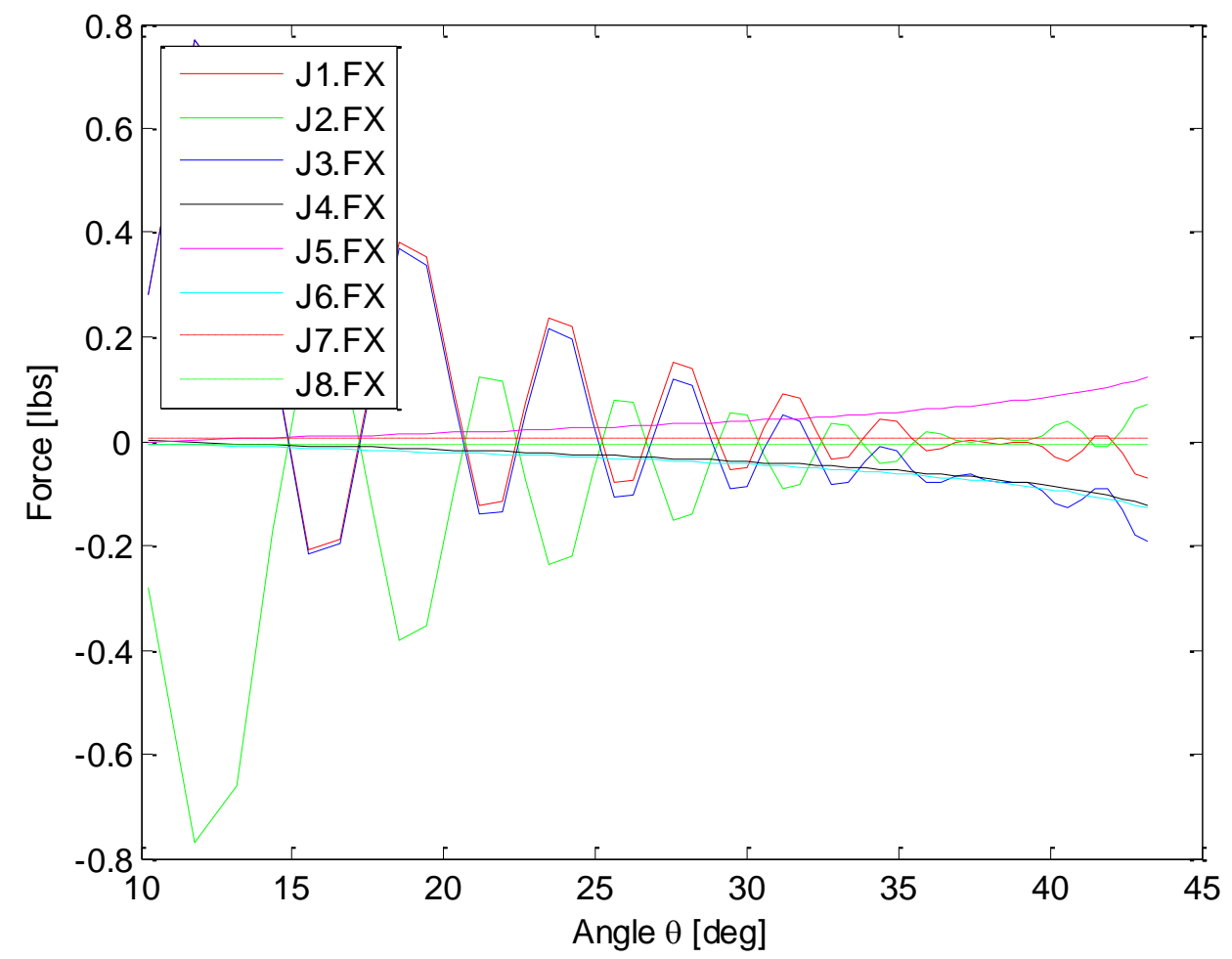

Figure 73: Joint force Fx with functioning gas spring. 


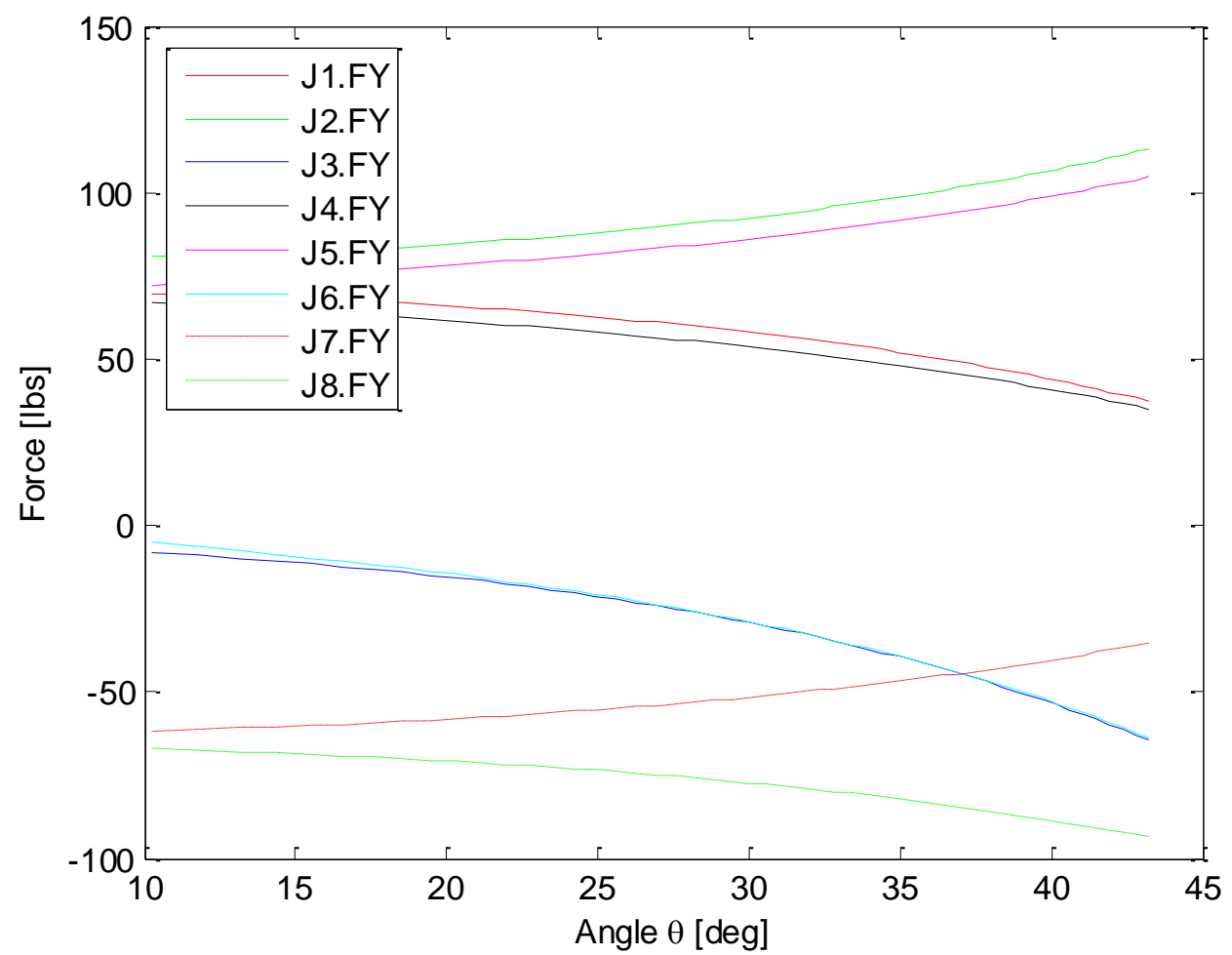

Figure 74: Joint Force Fy with functioning gas spring. 


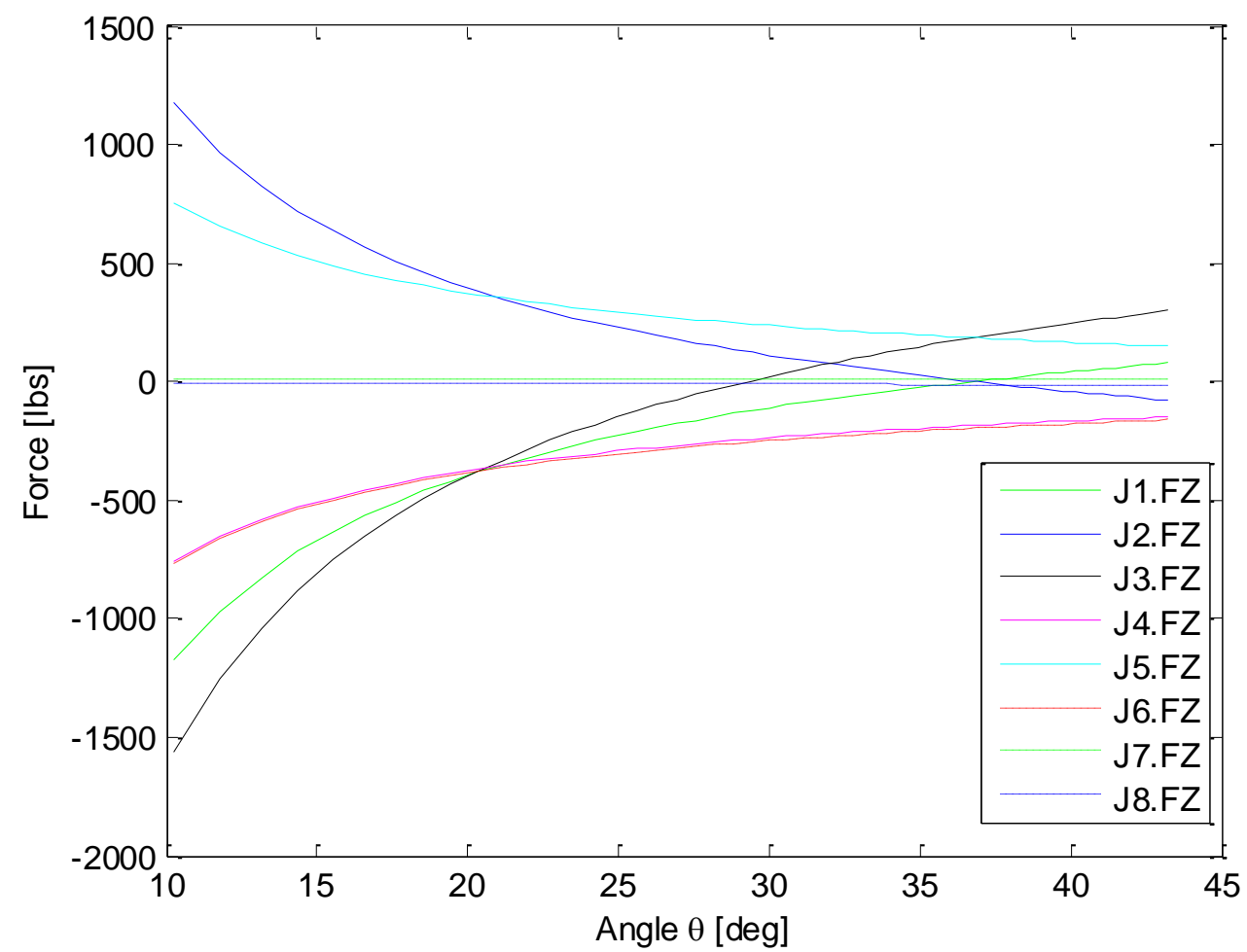

Figure 75: Joint force $\mathrm{Fz}$ with functioning gas spring. 


\section{Appendix 10: FDA Requirements}

Class I device, 510(K) Exempt.

[Code of Federal Regulations]

[Title 21, Volume 8]

[Revised as of April 1, 2015]

[CITE: 21CFR890.3825]

\section{TITLE 21--FOOD AND DRUGS}

\section{CHAPTER I--FOOD AND DRUG ADMINISTRATION DEPARTMENT OF HEALTH AND HUMAN SERVICES}

SUBCHAPTER H--MEDICAL DEVICES

\section{PART 890 -- PHYSICAL MEDICINE DEVICES}

Subpart D--Physical Medicine Prosthetic Devices

Sec. 890.3825 Mechanical walker.

(a) Identification. A mechanical walker is a four-legged device with a metal frame intended for medical purposes to provide moderate weight support while walking. It is used by disabled persons who lack strength, good balance, or endurance.

(b) Classification. Class I (general controls). The device is exempt from the premarket notification procedures in subpart $\mathrm{E}$ of part 807 of this chapter, subject to the limitations in 890.9. The device is also exempt from the current good manufacturing practice requirements of the quality system regulation in part 820 of this chapter, with the exception of 820.180 , regarding general requirements concerning records and 820.198, regarding complaint files.

[48 FR 53047, Nov. 23, 1983, as amended at 66 FR 38817, July 25, 2001]

https://www.accessdata.fda.gov/scripts/cdrh/cfdocs/cfcfr/CFRSearch.cfm?fr=890.3825 


\section{Appendix 11: Analytical Calculations}

Below are some of the equations used in various analytic calculations

$$
\begin{gathered}
\tau=\frac{T r}{J} \\
\sigma_{\text {axial }}=\frac{F}{A} \\
\sigma_{\text {bend }}=\frac{M c}{I} \\
M=R_{1} x \text { for } 0 \leq x<L_{1} \\
M=R_{1} x-W_{1}\left(x-L_{1}\right) \text { for } L_{1} \leq x<L_{2} \\
M=R_{1} x-W_{1}\left(x-L_{1}\right)-W_{2}\left(x-L_{1}-L_{2}\right) \text { for } L_{2} \leq x \leq L
\end{gathered}
$$




\section{Appendix 12: Acceleration of Scissor Lift}

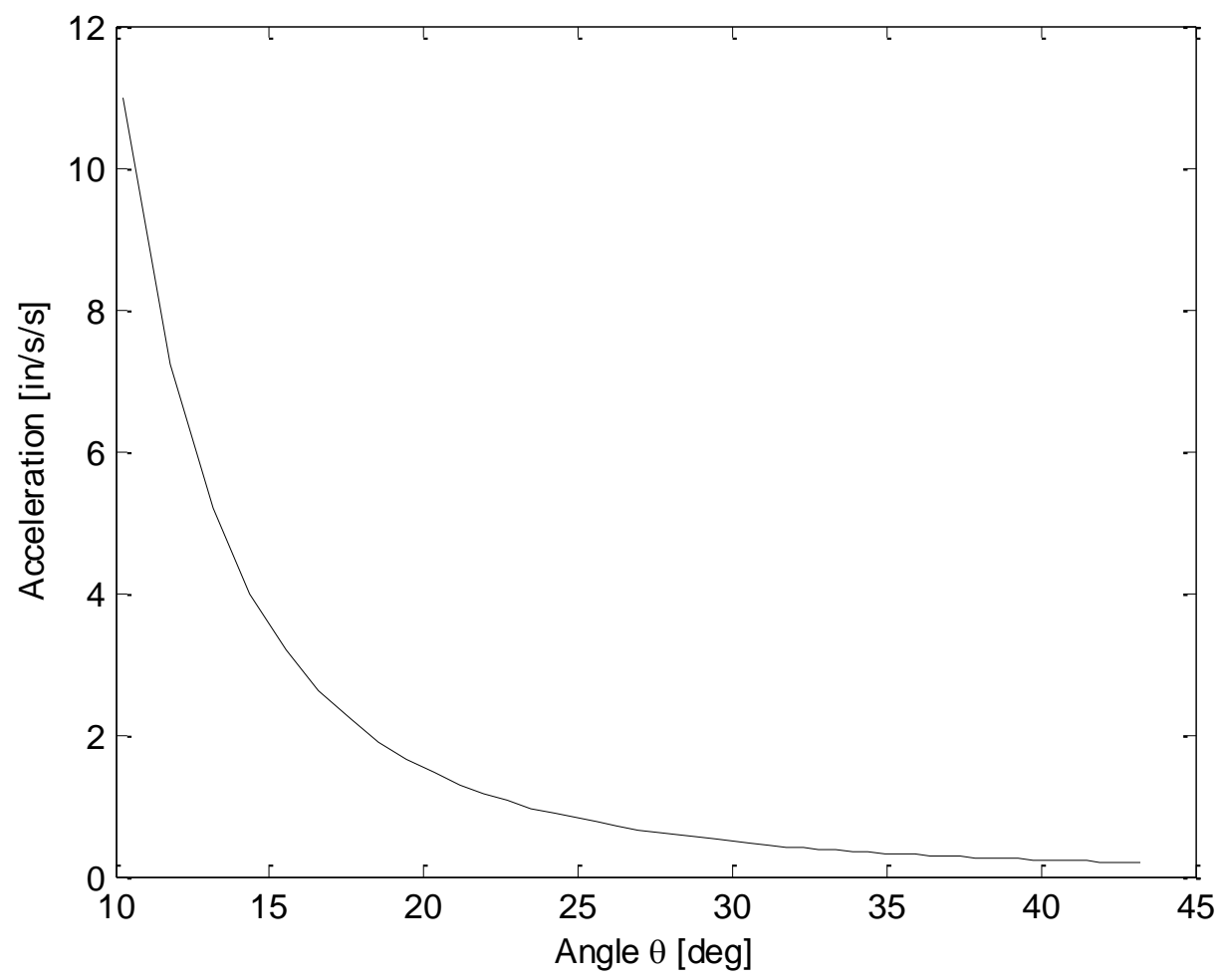

Figure 76: The acceleration vs angle during lifting. The acceleration well below $1 \mathrm{~g}(386 \mathrm{in} / \mathrm{s} / \mathrm{s})$. 


\section{Appendix 13: Scissor Link Bolt Strength Selection}

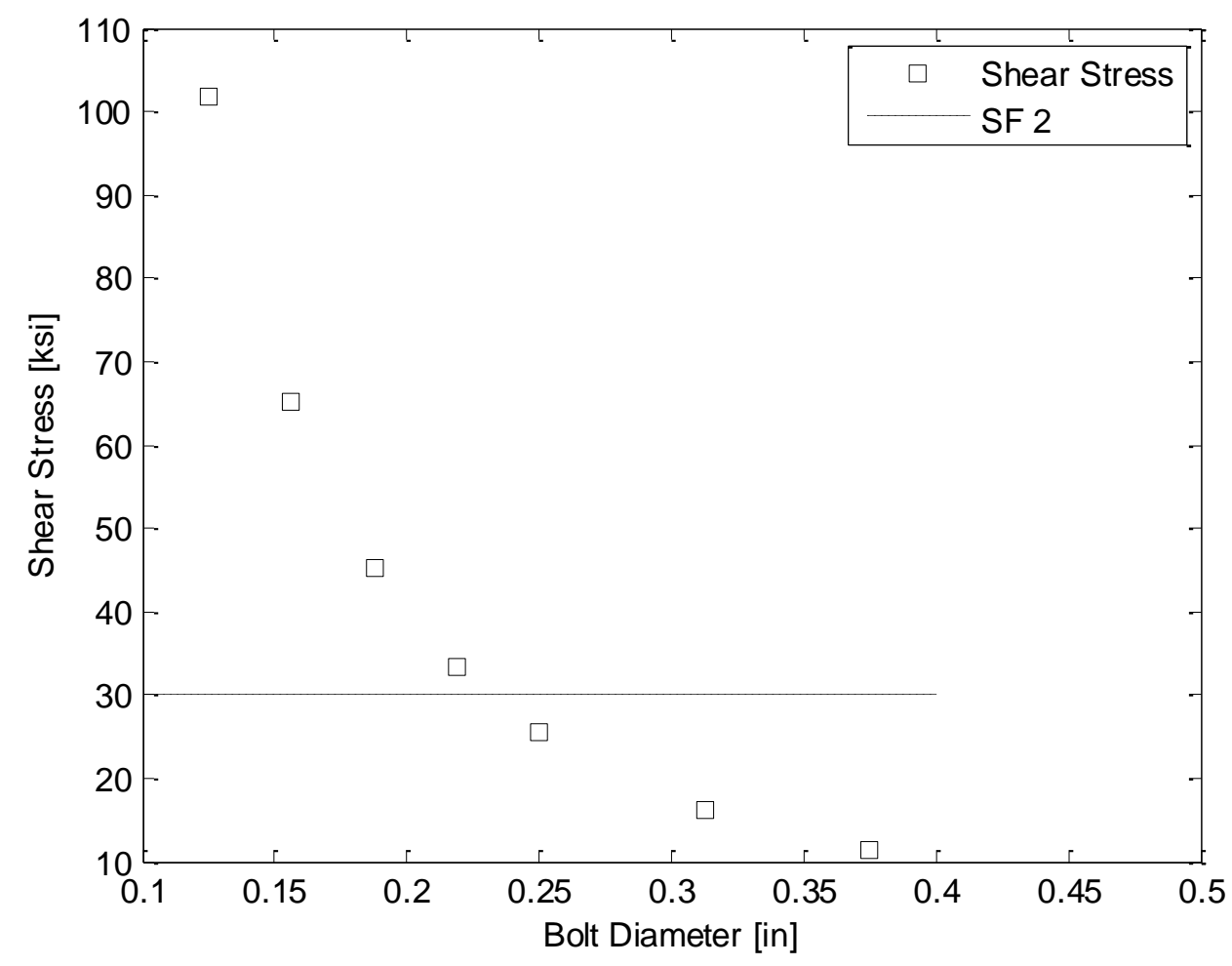

Figure 77: Bolt shear stress for various diameter bolts. A bolt over 0.25 inches will be strong enough. 


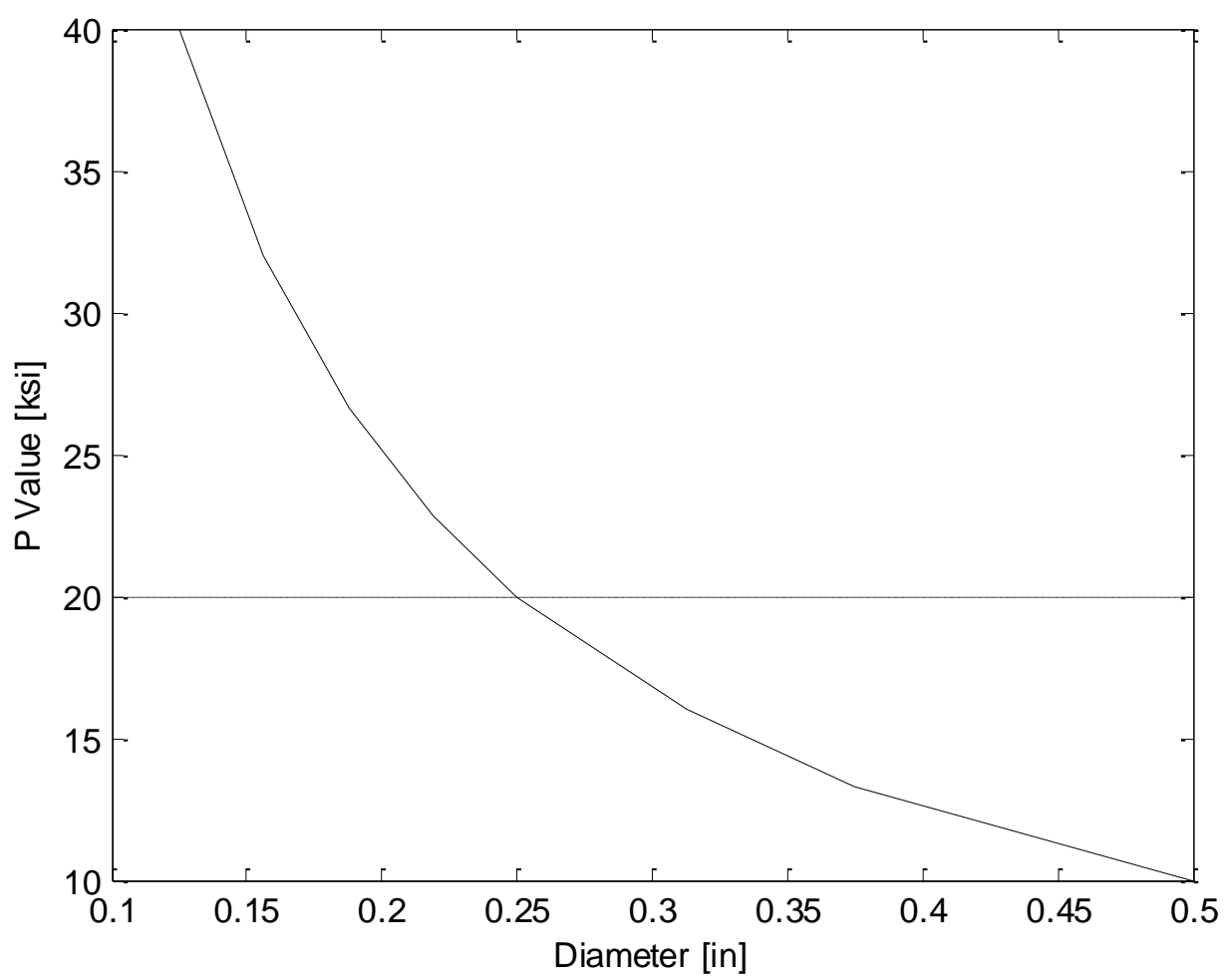

Figure 78: P-value calculator for a bushing, the dotted line shows a super oilite bronze bushing max pressure rating. 


\section{Appendix 14: FEA on Motor Mount}
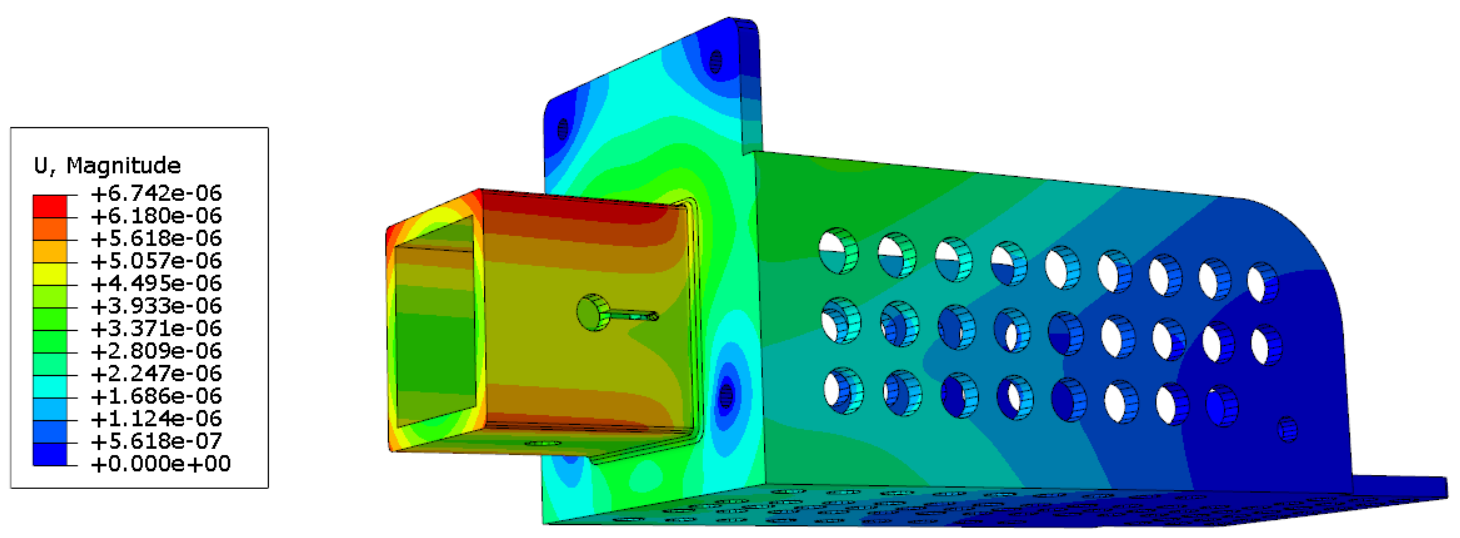

Figure 79: Displacement contour plot of the motor mount.

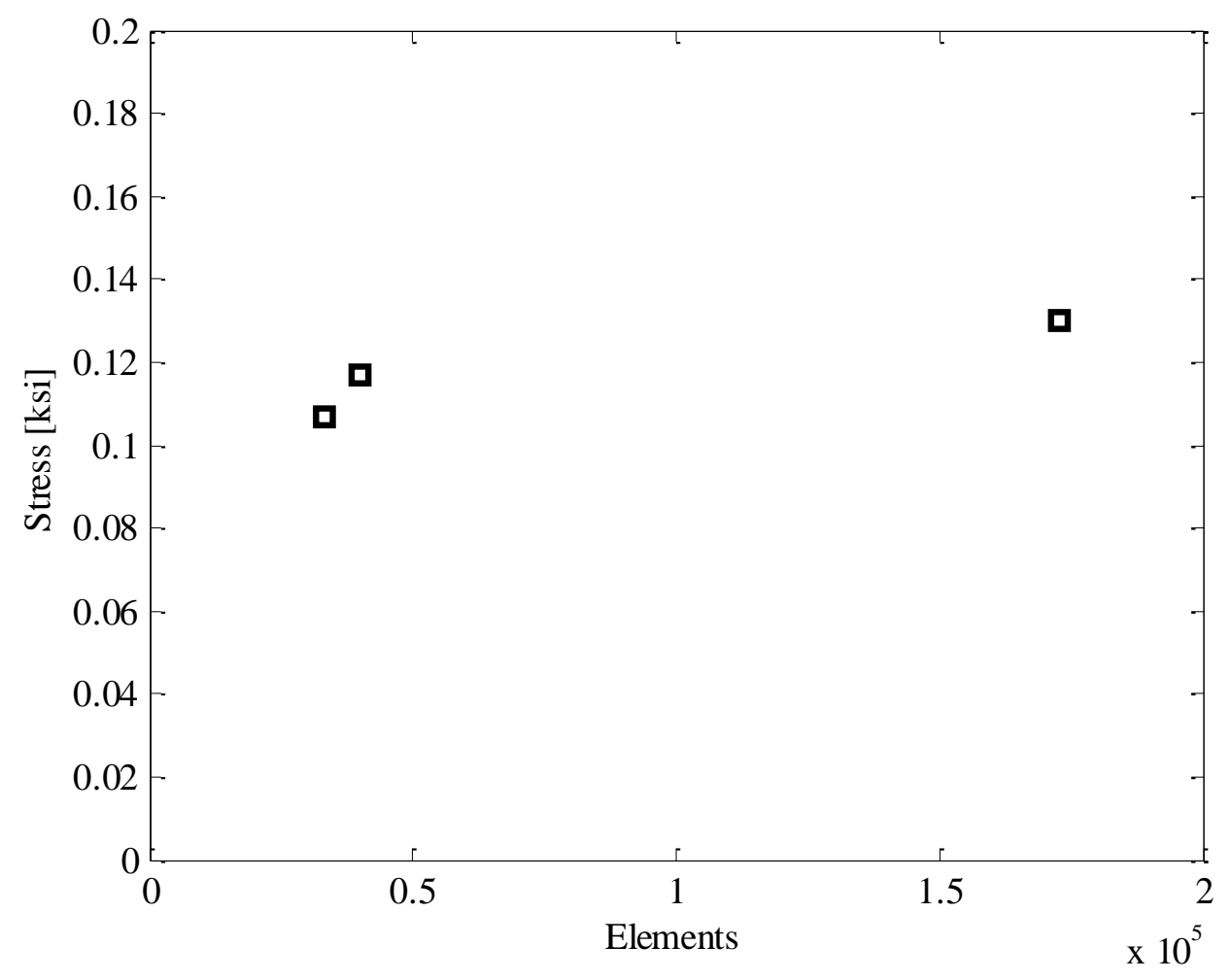

Figure 80: The stress at the attachment holes converges with increasing elements. 


\section{Appendix 15: FEA on Front Bearing Block}
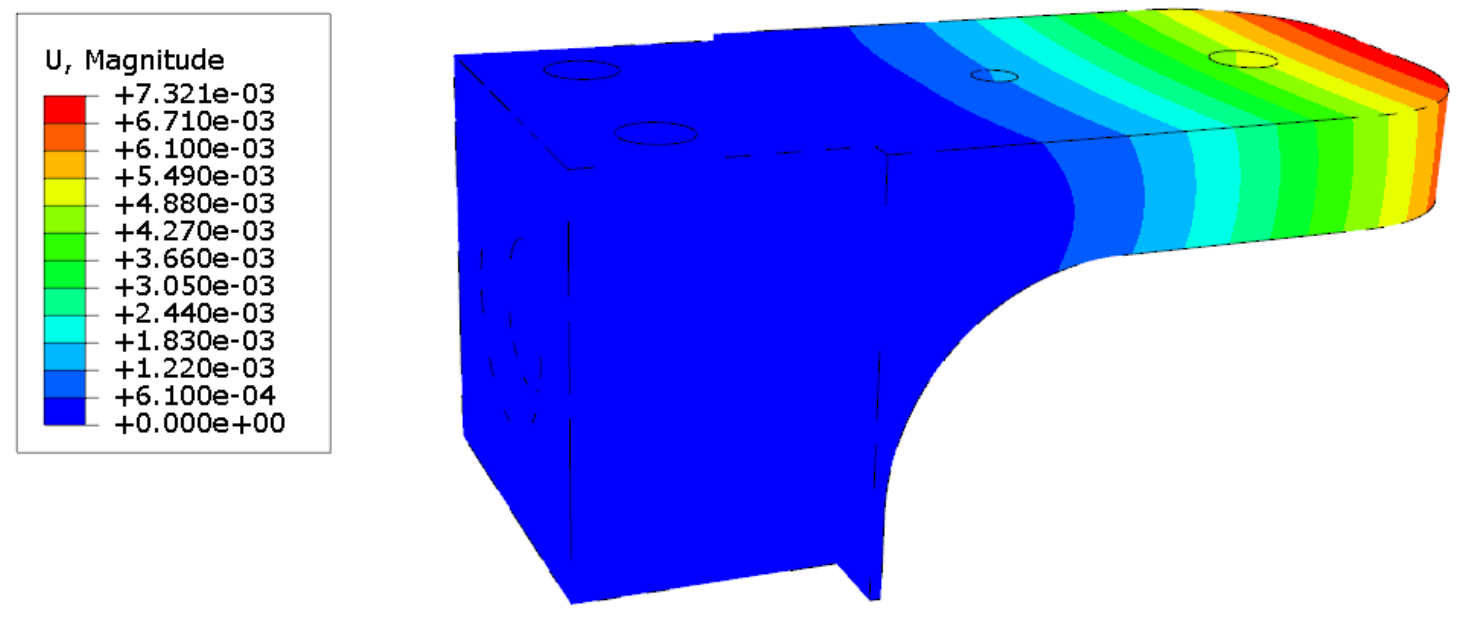

Figure 81: Displacement contour plot of front bearing block. The displacement is negligible as expected.

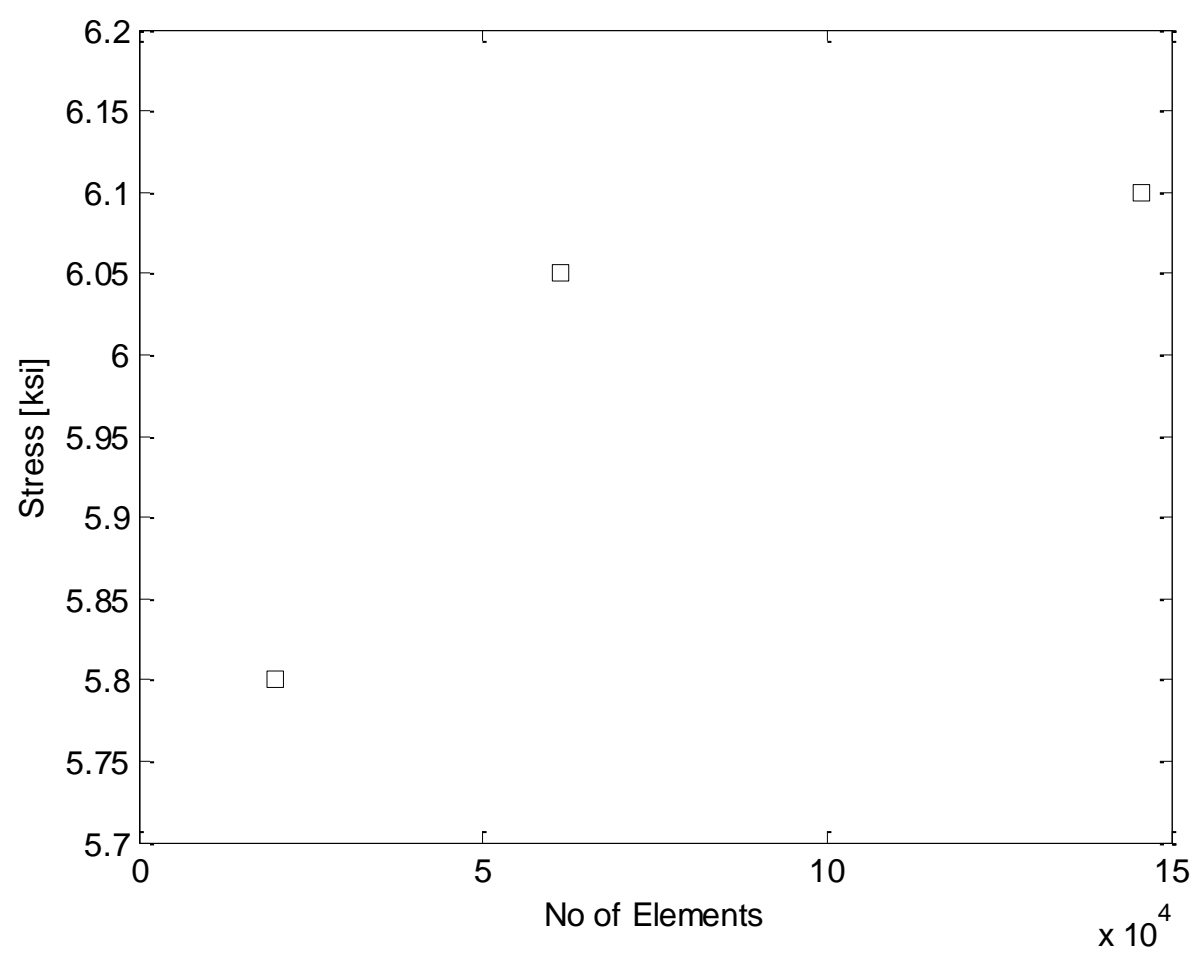

Figure 82: The stress at a in the middle of the bearing block converges with increasing elements. 


\section{Appendix 16: FEA on Lower Tube}

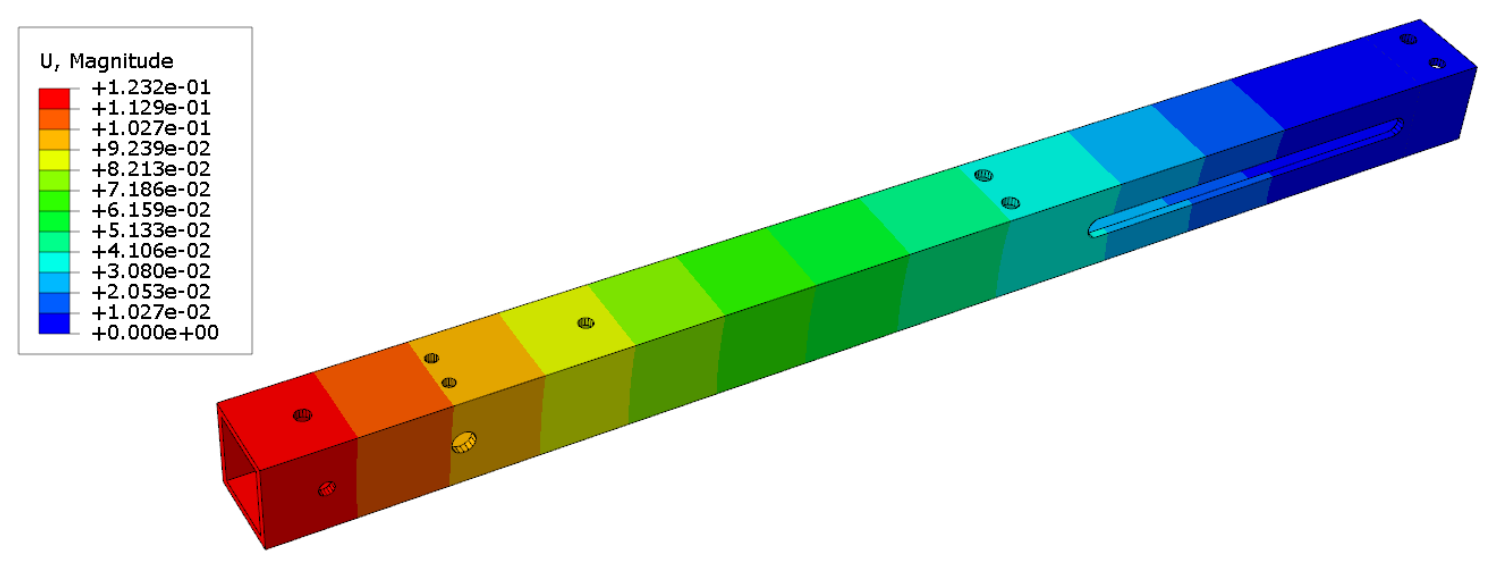

Figure 83: Displacement of Lower Tube, the maximum displacement is 0.12 inches.

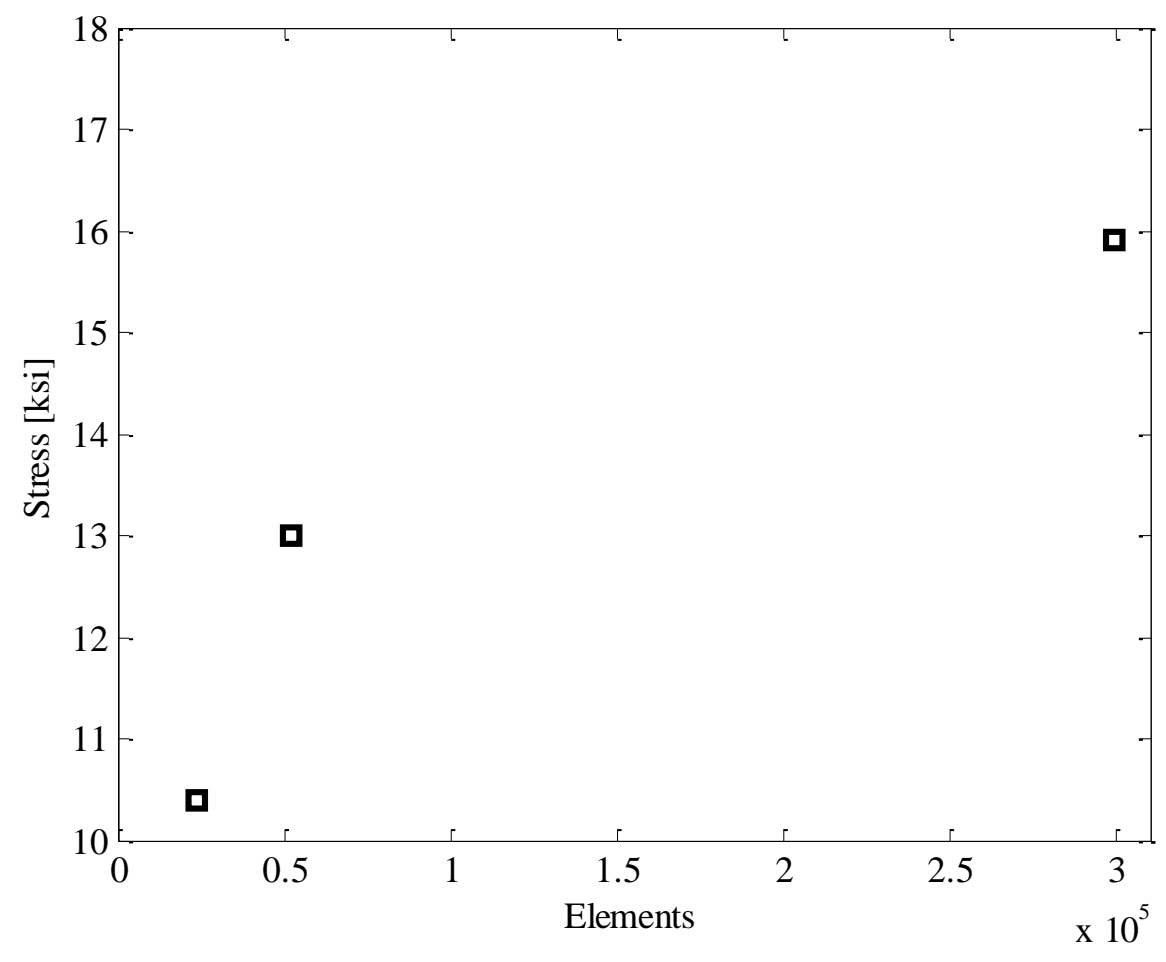

Figure 84: The stress at the attachment holes where the middle bearing block attaches is converging with a fine mesh. 


\section{Appendix 17: FEA on Top Frame}
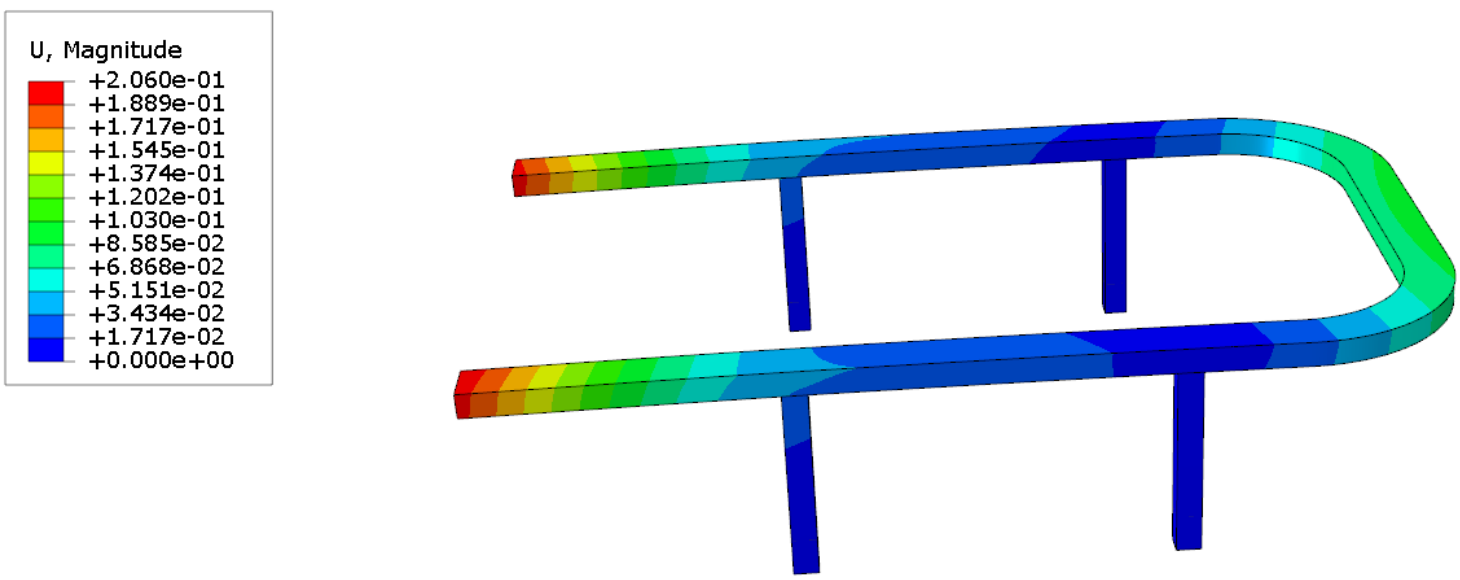

Figure 85: Displacement contour plot for the top frame, the maximum displacement is 0.2 inches.

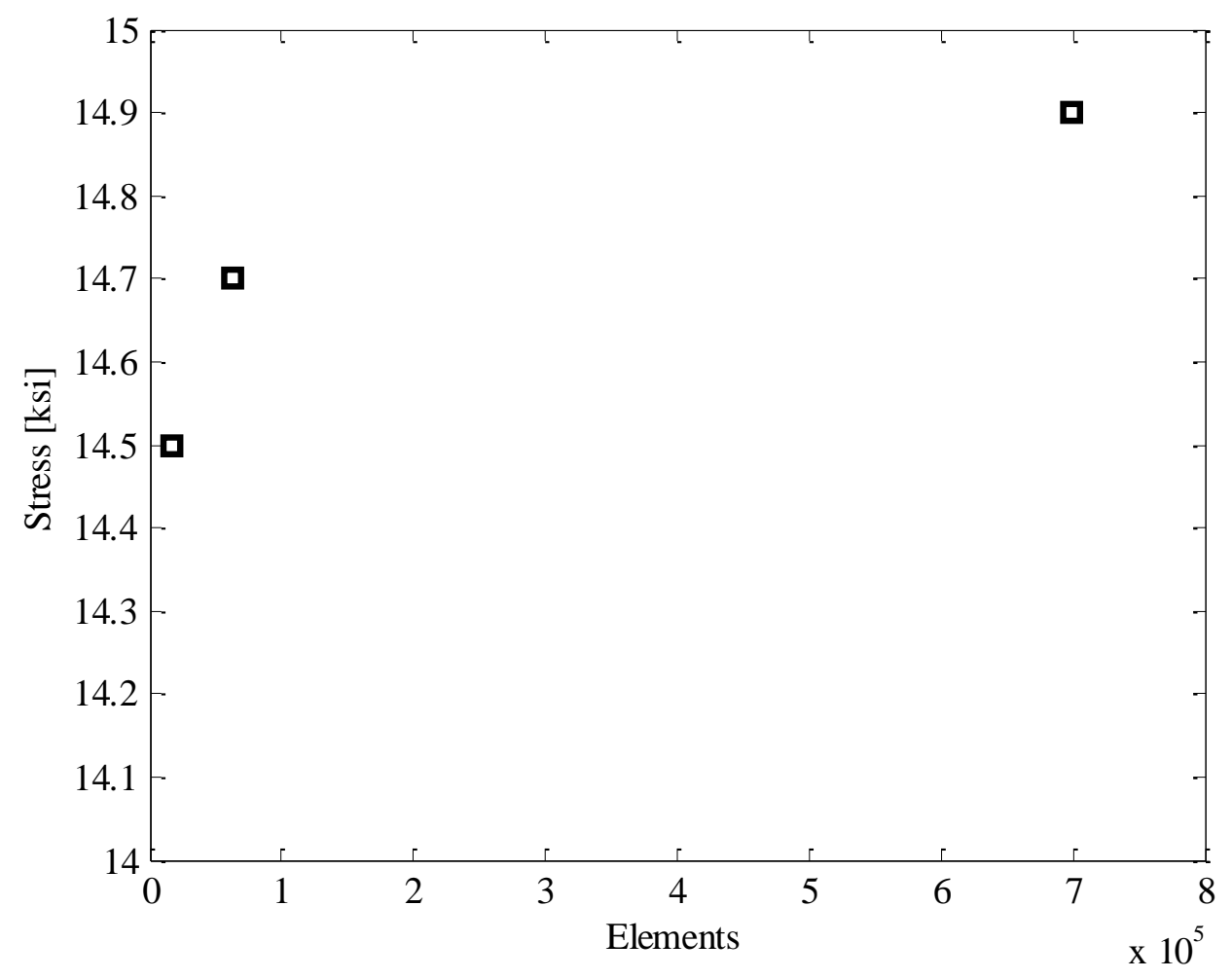

Figure 86: The stress converges with increasing elements. 


\section{Appendix 18: Scissor Link FEA}

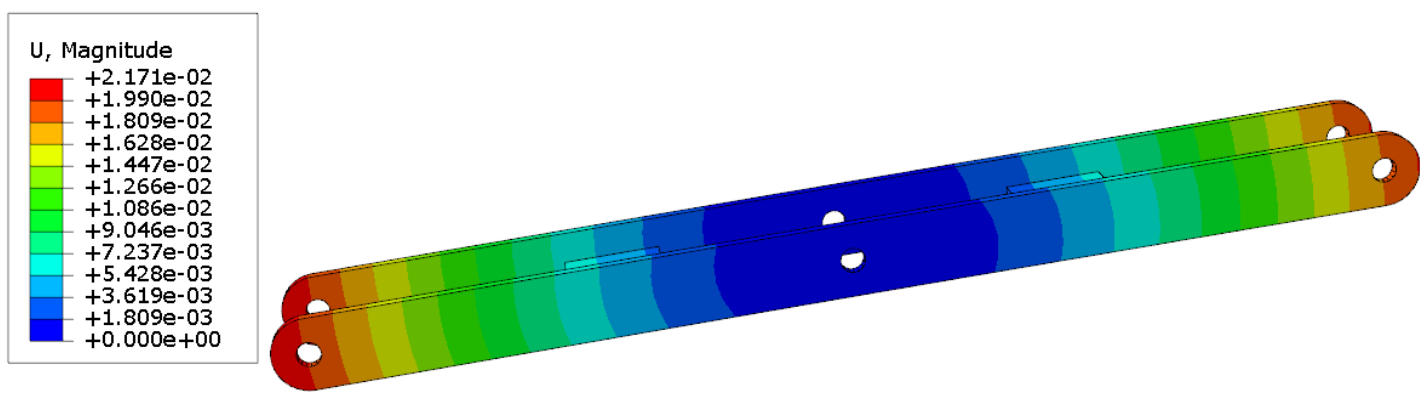

Figure 87: Displacement contour plot for a steel scissor, the displacement at the end is 0.022 inches.
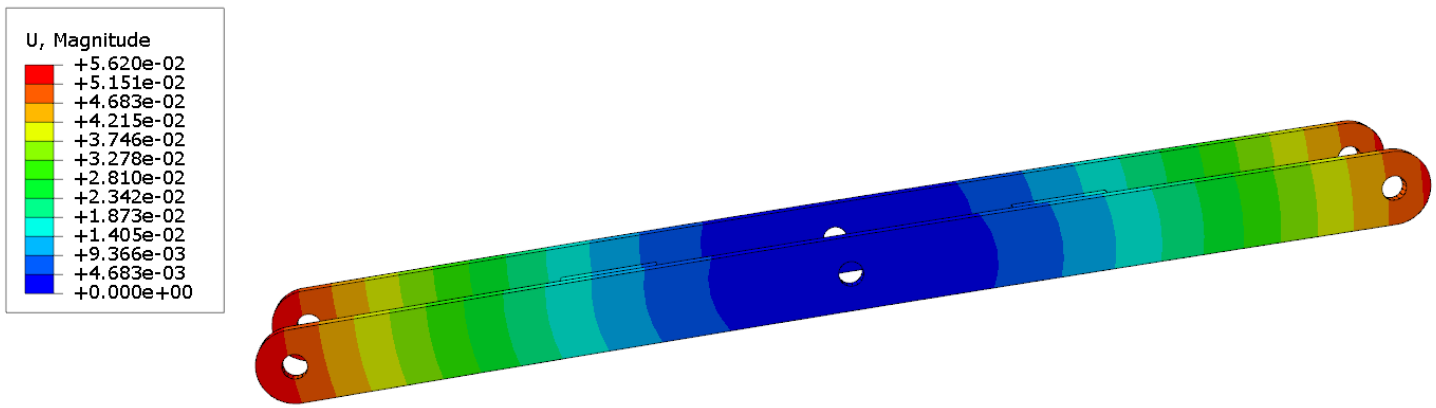

Figure 88: Displacement contour plot for an aluminum scissor, the displacement at the end is 0.056 inches. 


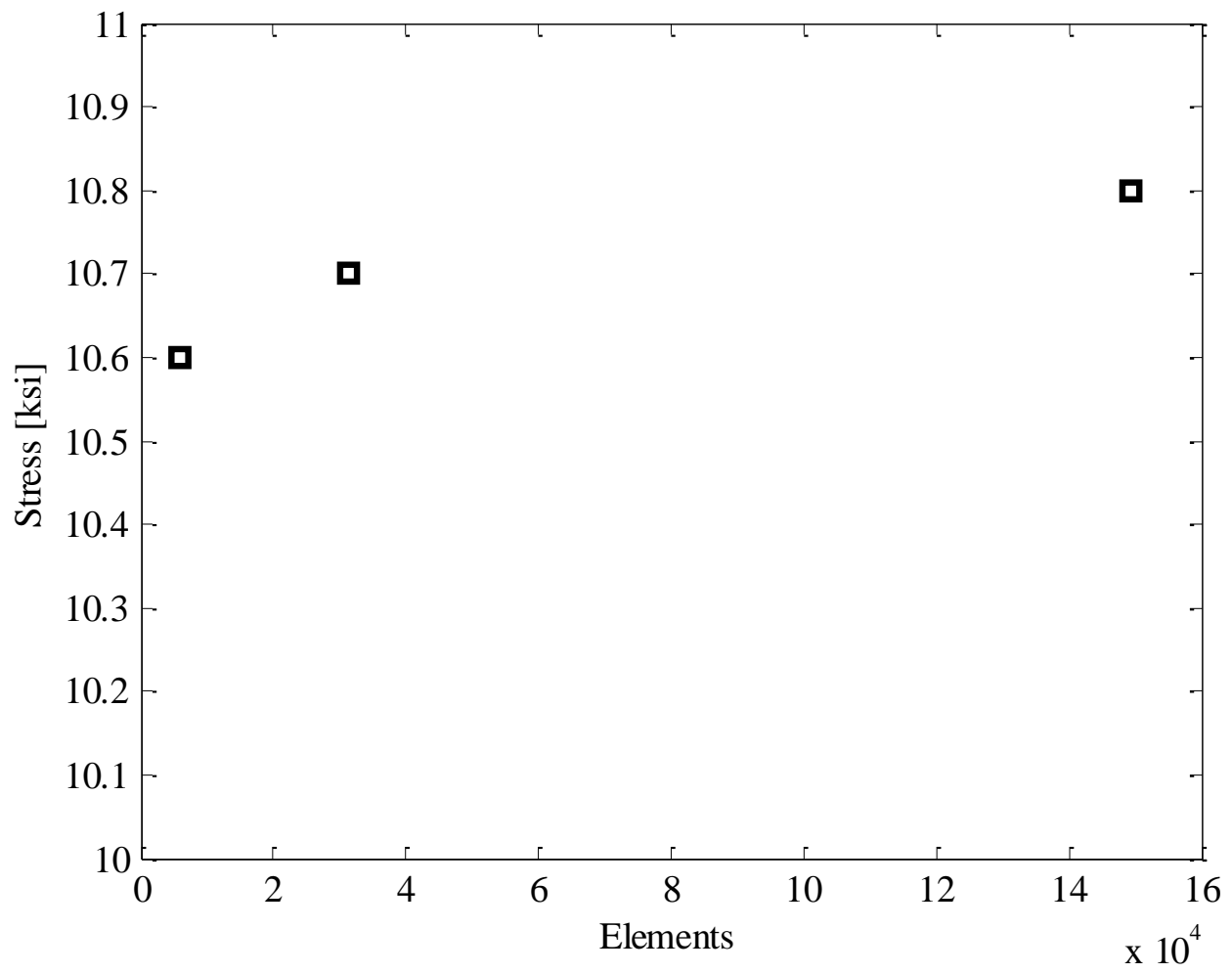

Figure 89: The stress around the center hole converges to $10.8 \mathrm{ksi}$ with increasing elements. 


\section{Appendix 19: Weigh Distribution of Components}

Table 31: System mass distribution with a total mass of $104 \mathrm{lbs}$.

\begin{tabular}{|c|c|c|c|}
\hline Part & Qty & Mass [lbs] & Sub Total[lbs] \\
\hline Front Caster & 2 & 1 & 2 \\
\hline Front Bearing Block & 2 & 0.63 & 1.26 \\
\hline Acme Threaded Rod & 2 & 0.5 & 1 \\
\hline Coupler Assembly & 2 & 2.4 & 4.8 \\
\hline Motor Mount & 2 & 3.54 & 7.08 \\
\hline Lower Tube & 2 & 3.62 & 7.24 \\
\hline Motor & 2 & 15 & 30 \\
\hline Scissor Links & 8 & 1.46 & 11.68 \\
\hline Mid Tube & 2 & 2.17 & 4.34 \\
\hline Battery & 1 & 15 & 15 \\
\hline Battery Mount & 1 & 1.43 & 1.43 \\
\hline Top U frame & 1 & 7.52 & 7.52 \\
\hline Mid front bar & 1 & 1.74 & 1.74 \\
\hline Sliding Clevis & 2 & 0.2 & 0.4 \\
\hline Sliding block & 2 & 0.5 & 1 \\
\hline Fixed Clevis & 2 & 0.2 & 0.4 \\
\hline Fasteners & 20 & 0.1 & 2 \\
\hline Rear Wheels & 4 & 0.25 & 1 \\
\hline Gas Spring & 2 & 2 & 4 \\
\hline Estimated Total Mass & & & $\mathbf{1 0 3 . 8 9}$ \\
\hline
\end{tabular}




\section{Appendix 20: Bill of Materials}

\begin{tabular}{|c|c|c|c|c|c|c|}
\hline $\begin{array}{c}\text { Sub } \\
\text { assembly }\end{array}$ & Part Name & Part No & Qty. & $\begin{array}{c}\text { Price } \\
\$\end{array}$ & $\begin{array}{c}\text { Sub } \\
\text { Total \$ }\end{array}$ & Notes \\
\hline \multirow{5}{*}{$\begin{array}{c}\text { Sliding } \\
\text { Block } \\
\text { Assembly }\end{array}$} & Teflon shell & $8735 \mathrm{~K} 61$ & 4 & 116.67 & 116.6 & bar stock \\
\hline & Sliding block & 9008K57 & 2 & 39.23 & 39.23 & bar stock \\
\hline & Acme threaded nut & 95270A144 & 2 & 6.89 & 13.78 & \\
\hline & Yoke & $9008 \mathrm{~K} 57$ & 4 & 39.23 & 39.23 & bar stock \\
\hline & Flat screw & 91500A583 & 8 & 7.37 & 7.37 & pack of 10 \\
\hline \multirow{6}{*}{$\begin{array}{c}\text { Mid } \\
\text { Bearing } \\
\text { Block } \\
\text { Assembly }\end{array}$} & $\begin{array}{c}\text { Clamp on Acme threaded } \\
\text { collar }\end{array}$ & $6698 \mathrm{~K} 130$ & 2 & 18.35 & 36.7 & \\
\hline & Thrust washer & $5909 \mathrm{k} 440$ & 4 & 1.02 & 4.08 & \\
\hline & Thrust bearing roller cage & $5909 \mathrm{~K} 310$ & 2 & 3.11 & 6.22 & \\
\hline & Sleeve bearing & $1688 \mathrm{~K} 140$ & 2 & 1.12 & 2.24 & \\
\hline & Mid bearing block & $9008 \mathrm{~K} 57$ & 2 & 39.23 & 39.23 & bar stock \\
\hline & Bolts & 91251A263 & 8 & & & \\
\hline \multirow{8}{*}{$\begin{array}{c}\text { Front } \\
\text { Bearing } \\
\text { Block } \\
\text { Assembly }\end{array}$} & $\begin{array}{c}\text { Clamp on Acme threaded } \\
\text { collar }\end{array}$ & $6698 \mathrm{~K} 130$ & 2 & 18.35 & 36.7 & \\
\hline & Thrust washer & $5909 \mathrm{k} 440$ & 4 & 1.02 & 4.08 & \\
\hline & Thrust bearing roller cage & $5909 \mathrm{~K} 310$ & 2 & 3.11 & 6.22 & \\
\hline & Sleeve bearing & $1688 \mathrm{~K} 140$ & 2 & 1.12 & 2.24 & \\
\hline & Front bearing block & $9008 \mathrm{~K} 57$ & 2 & 39.23 & 39.23 & bar stock \\
\hline & Caster & $2834 \mathrm{~T} 650$ & 2 & 7.35 & 14.7 & \\
\hline & Caster Nuts & 94758A029 & 2 & 5.1 & 10.2 & \\
\hline & Bolts & $91251 \mathrm{~A} 623$ & 8 & 8.3 & 8.3 & pack of 25 \\
\hline \multirow{3}{*}{$\begin{array}{c}\text { Rear } \\
\text { bearing } \\
\text { block }\end{array}$} & Sleeve bearing & $1688 \mathrm{~K} 140$ & 2 & 1.12 & 2.24 & \\
\hline & Attachment Bolts & 91274A160 & 8 & 8.93 & 8.93 & pack of 50 \\
\hline & Rear bearing block & $9008 \mathrm{~K} 57$ & 2 & 39.23 & 39.23 & bar stock \\
\hline \multirow{3}{*}{$\begin{array}{l}\text { Coupler } \\
\text { Assembly }\end{array}$} & $3 / 4$ inch & $6408 \mathrm{~K} 129$ & 2 & 5.89 & 11.78 & \\
\hline & $1 / 2$ inch & $6408 \mathrm{~K} 712$ & 2 & 5.89 & 11.78 & \\
\hline & Spider & 6408 K930 & 2 & 11.64 & 23.28 & \\
\hline \multirow{5}{*}{$\begin{array}{c}\text { Motor } \\
\text { Mount } \\
\text { Assembly }\end{array}$} & Wheels & & 4 & 20 & 80 & \\
\hline & Mount attachment bolts & 91251A623 & 8 & 8.3 & 8.3 & pack of 25 \\
\hline & Wheel bolts & $92981 \mathrm{~A} 205$ & 4 & 1.68 & 6.72 & \\
\hline & Motor attachment bolts & 91205A563 & 8 & 10.26 & 10.26 & pack of 25 \\
\hline & Motor Mount & & 2 & 30.39 & 60.78 & sheet stock \\
\hline \multirow{3}{*}{$\begin{array}{l}\text { Lower } \\
\text { Tube }\end{array}$} & Lower Tube & & 2 & 31.01 & 62.02 & tube stock \\
\hline & Gear tooth sensor & & & & & \\
\hline & Acme threaded rod & $95061 \mathrm{~A} 212$ & 2 & 69.27 & 69.27 & $6^{\prime}$ \\
\hline \multirow{3}{*}{$\begin{array}{c}\text { Scissor } \\
\text { Assembly }\end{array}$} & Inner scissor link & $8975 K 518$ & 4 & 15.13 & 60.52 & bar stock \\
\hline & Outer scissor link & $8975 \mathrm{~K} 518$ & 4 & 15.13 & 60.52 & bar stock \\
\hline & Gas spring & & 2 & 50 & 100 & \\
\hline
\end{tabular}




\begin{tabular}{|c|c|c|c|c|c|c|}
\hline & 2.75 shoulder bolts & 91259A635 & 2 & 1.74 & 3.48 & \\
\hline & 3.75 shoulder bolts & 91259A638 & 10 & 2.71 & 27.1 & \\
\hline & Sleeve bearing & SOF-317-1 & 50 & 1.44 & 72 & \\
\hline & Nuts & 91030A445 & 12 & 3.51 & 7 & pack of 10 \\
\hline & Lower attachment bolts & $91273 \mathrm{~A} 309$ & 8 & 6.66 & 53.28 & \\
\hline \multirow{8}{*}{$\begin{array}{l}\text { Mid } \\
\text { Frame }\end{array}$} & Mid tube & $6546 \mathrm{~K} 39$ & 2 & 24.59 & 49.18 & tube stock \\
\hline & Ball spring plungers & $8507 \mathrm{~A} 110$ & 4 & 14.17 & 56.68 & \\
\hline & Fixed clevis & & 2 & 30 & 30 & bar stock \\
\hline & Sliding clevis & & 2 & 30 & 30 & bar stock \\
\hline & Sliding block & & 2 & 30 & 30 & bar stock \\
\hline & Square nut & $94785 \mathrm{~A} 442$ & 4 & 8.48 & 8.48 & pack of 10 \\
\hline & Sliding block bolts & $91251 \mathrm{~A} 336$ & 4 & 2.81 & 11.24 & \\
\hline & Teflon gasket & $8545 \mathrm{~K} 11$ & 2 & 7.31 & 14.62 & \\
\hline \multirow{3}{*}{$\begin{array}{l}\text { Mid cross } \\
\text { bar }\end{array}$} & Quick release pin & $95255 \mathrm{~A} 263$ & 2 & 3.91 & 7.82 & \\
\hline & proximity sensors & & 4 & & & \\
\hline & mid cross bar & $6546 \mathrm{~K} 39$ & 1 & 24.59 & 24.59 & tube stock \\
\hline \multirow{4}{*}{$\begin{array}{l}\text { Top } \\
\text { frame }\end{array}$} & top frame & $6546 \mathrm{~K} 39$ & 1 & 200 & 200 & tube stock \\
\hline & magnets & $5862 \mathrm{~K} 11$ & 4 & 0.59 & 2.36 & \\
\hline & harness hooks & & 5 & & & \\
\hline & operating buttons & 7100005 & 8 & 2.22 & 17.76 & \\
\hline \multirow{11}{*}{$\begin{array}{l}\text { Lower } \\
\text { cross bar } \\
\text { assembly }\end{array}$} & lower cross bar & & 1 & 200 & 200 & sheet stock \\
\hline & Battery & & 1 & 400 & 400 & \\
\hline & Arduino & Mega 2560 & 1 & 45 & 45 & \\
\hline & Motor controller & $\begin{array}{c}\text { TE- } \\
0910255 \\
\end{array}$ & 1 & 125 & 125 & \\
\hline & Bellowing & & 2 & 150 & 300 & \\
\hline & DC Gear Motor & 5060 & 2 & 500 & 1000 & \\
\hline & Machining Labor Costs & & 40 & 25 & 1000 & $\begin{array}{c}\text { price per } \\
\text { hour }\end{array}$ \\
\hline & SD Card shield & & 1 & 40 & 40 & \\
\hline & Electrical Wiring & & & 200 & 200 & \\
\hline & Electrical Connectors & & & 150 & 150 & \\
\hline & Miscellaneous expenses & & & 500 & 500 & \\
\hline \multicolumn{5}{|c|}{ Estimated Total } & 5647.6 & \\
\hline
\end{tabular}

